\title{
Evaluation of evidence-based clinical guidelines in physical therapy : ankle sprain as case example
}

Citation for published version (APA):

van der Wees, P. J. (2009). Evaluation of evidence-based clinical guidelines in physical therapy : ankle sprain as case example. [Doctoral Thesis, Maastricht University]. Datawyse / Universitaire Pers Maastricht. https://doi.org/10.26481/dis.20090910pw

Document status and date:

Published: 01/01/2009

DOI:

10.26481/dis.20090910pw

Document Version:

Publisher's PDF, also known as Version of record

\section{Please check the document version of this publication:}

- A submitted manuscript is the version of the article upon submission and before peer-review. There can be important differences between the submitted version and the official published version of record.

People interested in the research are advised to contact the author for the final version of the publication, or visit the DOI to the publisher's website.

- The final author version and the galley proof are versions of the publication after peer review.

- The final published version features the final layout of the paper including the volume, issue and page numbers.

Link to publication

\footnotetext{
General rights rights.

- You may freely distribute the URL identifying the publication in the public portal. please follow below link for the End User Agreement:

www.umlib.nl/taverne-license

Take down policy

If you believe that this document breaches copyright please contact us at:

repository@maastrichtuniversity.nl

providing details and we will investigate your claim.
}

Copyright and moral rights for the publications made accessible in the public portal are retained by the authors and/or other copyright owners and it is a condition of accessing publications that users recognise and abide by the legal requirements associated with these

- Users may download and print one copy of any publication from the public portal for the purpose of private study or research.

- You may not further distribute the material or use it for any profit-making activity or commercial gain

If the publication is distributed under the terms of Article $25 \mathrm{fa}$ of the Dutch Copyright Act, indicated by the "Taverne" license above, 
Evaluation of evidence-based clinical guidelines in physical therapy

Ankle sprain as case example 
De druk van dit proefschrift is mogelijk gemaakt dankzij financiële steun van het Koninklijk Nederlands Genootschap voor Fysiotherapie (KNGF).

(c) Ph.J. van der Wees, Amsterdam 2009

ISBN: 9789052788401

Universitaire Pers Maastricht

Layout en druk : Datawyse BV, Maastricht

Cover

: Marjon Katerberg en Frank Eerland et al 


\title{
Evaluation of evidence-based clinical guidelines in physical therapy
}

Ankle sprain as case example

\author{
PROEFSCHRIFT \\ ter verkrijging van de graad van doctor \\ aan de Universiteit Maastricht, \\ op gezag van de Rector Magnificus, \\ Prof. mr. G.P.M.F. Mols \\ volgens het besluit van het College van Decanen, \\ in het openbaar te verdedigen \\ op donderdag 10 september 2009 om 16.00 uur \\ door
}

Philippus Jan van der Wees

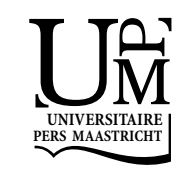




\section{Promotores}

Prof. dr. R.A. de Bie

Prof. dr. J. Dekker, VUmc

\section{Copromotor}

Dr. H.J.M. Hendriks

\section{Beoordelingscommissie}

Prof. dr. G.H.I.M. Walenkamp (voorzitter)

Prof. dr. H. Kuipers

Prof. dr. M.W.G. Nijhuis-van der Sanden, UMC St Radboud

Prof. dr. M.H. Prins

Dr. T. van der Weijden 


\section{CONTENTS}

Chapter 1 Introduction

$\begin{array}{lll}\text { Chapter } 2 & \text { Adherence to physiotherapy clinical guideline acute ankle } & 17\end{array}$ injury and determinants of adherence: a cohort study

Chapter 3 Effectiveness of exercise therapy and manual mobilization in acute ankle sprain and functional instability: a systematic review

Chapter 4 Comparison of international guideline programs to evaluate and update the Dutch program for clinical guideline development in physical therapy

Chapter 5 Multifaceted strategies may increase implementation of physiotherapy clinical guidelines: a systematic review

Chapter 6 Validity and responsiveness of the Ankle Function Score after 89 acute ankle injury

Chapter 7 Applicability of the Ottawa ankle rules in primary care: results from a pilot study

Chapter 8 General discussion

Summary

Samenvatting

Dankwoord

About the author 



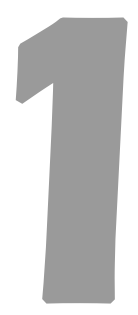

Introduction 


\section{INTRODUCTION}

The purpose of this thesis is to evaluate the quality and applicability of clinical guidelines ${ }^{1}$ in physical therapy ${ }^{2}$. It focuses on the cyclic process of developing, implementing, evaluating, and updating clinical guidelines. The cycle is described using ankle sprain as a case example.

This chapter offers an overview of the purpose of clinical guidelines in healthcare in general, and specifically in physical therapy. It also introduces the epidemiological factors related to ankle sprain. Finally it presents the rationale and outline of this thesis.

\section{CLINICAL GUIDELINES}

Development and implementation of evidence-based clinical guidelines is a major focus of healthcare policy in many countries. Clinical guidelines are 'systematically developed statements designed to help practitioners and patients to make decisions about appropriate healthcare for specific circumstances' ${ }^{1}$. Development of clinical guidelines in health services is generally considered an important instrument to improve and manage the care process ${ }^{2-5}$.

Important goals in guideline development are higher quality and improved costeffectiveness, ideally resulting in improved health outcomes ${ }^{6}$. Moreover, the process of guideline development addresses the need to decrease variability in clinical practice, and practitioners' desire to legitimize their profession in the eyes of external stakeholders ${ }^{2-5,7,8}$. The concept of evidence-based practice, supported by clinical guidelines, is a common aspect of healthcare today.

The key characteristics of Clinical Guidelines are that they:

- Present a clear picture of the 'best available evidence of effectiveness' for a particular condition or set of clinical circumstances.

- Provide recommendations on the most effective interventions in particular circumstances, derived by considering the 'best available evidence of effectiveness' in the context of clinical practice.

- Provide a resource for collaboration and decision-making for healthcare professionals and for patients about the most effective and efficient care for specific patient populations in particular clinical circumstances.

\footnotetext{
1 The words guidelines, clinical guidelines and clinical practice guidelines are used synonymously throughout this thesis.

2 The words physical therapy and physiotherapy are used synonymously throughout this thesis.
} 
- Are developed in a rigorous and systematic way so as to minimize bias and maximize the validity of the recommendations.

Clinical guidelines are not recipes for practice that must be followed in all circumstances, nor do they remove the need for healthcare practitioners to use their clinical insight or discuss choices with patients. However, where a guideline recommendation is based on strong evidence of effectiveness, a practitioner would need to have an explicit reason for not implementing it for a particular patient, such as other complicating conditions or patient preferences, and this reason should be documented.

\section{Recent developments in clinical guidelines}

Guideline development has shown a dramatic increase during the last decade. Numerous multidisciplinary programs for guideline developments exist around the world. One of the effects of the growing international body of knowledge about guideline development is the opportunity it offers for collaboration to improve the quality of guidelines. This has resulted in the founding of the AGREE collaboration (Appraisal of Guidelines, Research and Evaluation), which has published an instrument to appraise the quality of clinical practice guidelines ${ }^{9}$. The AGREE Instrument provides a framework, including 23 criteria, to assess the quality of clinical practice guidelines. The instrument is based on international consensus about methods to develop evidence-based clinical guidelines ${ }^{10,11}$, and also helps guideline developers to structure and improve the process of guideline development. The Dutch network of guideline organizations has adopted the AGREE Instrument, and has reached consensus about methods to assess and synthesize the evidence ${ }^{12,13}$. An international survey of 18 clinical guideline programs also showed a growing international consensus on the structure and working methods of such programs ${ }^{10}$. In 2002, the Guidelines International Network (G-I-N) was founded to promote systematic development of clinical guidelines ${ }^{14}$. Further refinement of the guideline development process is currently the subject of international debate. The Advisory Committee on Health Research of the World Health Organization (WHO) has conducted a series of reviews to advise on ways of improving the use of research evidence in guidelines $^{15}$.

\section{Clinical guidelines in physical therapy}

In physical therapy too, clinical guidelines are considered important instruments to improve the quality of care. Guidelines contribute to the development of the profession of physical therapy, in that they help reduce variations in physical therapy treatment and enhance consistency among professionals, show the tasks and responsibilities of the profession, and stimulate collaboration with other professions. 
In the last two decades, the physical therapy profession has increased its body of knowledge rapidly ${ }^{16}$, and the introduction of evidence-based clinical guidelines was a logical step in this respect. The Royal Dutch Society for Physical Therapy (KNGF) set up a national Quality Assurance Program, including the development and implementation of clinical guidelines ${ }^{17,18}$, resulting in the publication of 17 evidencebased guidelines by the end of 2008. KNGF guidelines were developed using a standardized procedure ${ }^{17,19}$. The British Chartered Society of Physiotherapy (CSP) has also developed and endorsed evidence-based clinical guidelines, while the Australian Physiotherapy Association (APA) has produced a series of evidencebased clinical statements outlining the efficacy of physiotherapy for the management of conditions such as low back pain ${ }^{20}$ and neck pain ${ }^{21}$. The Nordic countries are collaborating in a program for the development of clinical guidelines.

\section{International perspective}

International collaboration is essential to build a body of knowledge that can assist in developing and implementing clinical guidelines, but also to enhance efficiency by avoiding work being unnecessarily duplicated. The ADAPTE Collaboration is an international group of researchers, guideline developers, and guideline implementers who aim to promote the development and use of clinical practice guidelines by adapting existing guidelines. The group has developed a framework for the adaptation of clinical practice guidelines as an alternative to de novo guideline development ${ }^{22}$.

There is also increasing international collaboration for the development and implementation of clinical guidelines in physical therapy. The World Confederation for Physical Therapy (WCPT) has prioritized the development and implementation of clinical guidelines in its policy, in order to facilitate evidence-based practice ${ }^{23,24}$. The European Region of WCPT has developed a framework for the development of clinical guidelines ${ }^{25}$, and became a member of the Guidelines International Network (G-I-N) in 2007.

\section{ANKLE SPRAIN}

In the Netherlands around 600,000 people a year suffer a traumatic injury of the ankle $^{26}$. It is estimated that 200,000 to 300,000 of these injuries occur during sports activities $^{27-29}$. It is especially contact sports, indoor sports, and 'jumping' sports which are known for their high incidence of ankle sprain ${ }^{30}$.

Traumatic inversion injury of the ankle may lead to distortion, single rupture or multiple rupture of the lateral ligaments ${ }^{31-33}$. A single rupture affects only one of 
the three lateral ligaments, almost always the anterior talo-fibular ligament. A multiple rupture also affects the calcaneo-fibular ligament and/or the posterior talo-fibular ligament. Another common classification is Grade I (stretch), Grade II (partial rupture), Grade III (complete rupture). Percentages of incidence of ruptures identified at emergency departments in the Netherlands vary from 8 to $18 \%{ }^{32,34,35}$. The average duration of sick leave among patients with a functionally treated rupture (i.e. no plaster or surgery) is two and a half weeks; after six weeks $90 \%$ are back at work. Twelve weeks after the injury, $60-90 \%$ of all patients have returned to their previous level of sports activities ${ }^{31,35}$.

Residual complaints after acute ankle sprain have been reported in 3-63\% of patients $^{32}$. After six months, $10-40 \%$ of acute ankle sprains result in functional instability of the ankle $34,36,37$. Symptoms of functional instability are a sense of instability, recurrent sprains or a feeling of apprehension ${ }^{38}$.

\section{RATIONALE AND OUTLINE OF THIS THESIS}

Since 1998, KNGF has developed 17 evidence-based clinical guidelines, forming the core of its Quality Assurance Program for physical therapy in the Netherlands ${ }^{17,18,39}$. The Quality Assurance Program was developed in 1995 by KNGF to address developments from three relevant perspectives: legal requirements, professional developments, and patient empowerment. The overall aim of the Quality Assurance Program was to create a continuous cycle of improvement and implementation, in order to ensure the quality and transparency of physical therapy in the Netherlands and to foster continuous professionalization. Within the Quality Assurance Program, clinical guidelines represent one of the key elements of the drive to increase the quality and evidence base of routine practice among physical therapists. Two other key elements in the Quality Assurance program are continuing education and audit \& feedback. Physical therapists who adhere to all elements of the Quality Assurance Program are eligible for registration in the Quality Register for Dutch physical therapists. An overview of the Quality Assurance Program is presented in Box 1.

Audit \& feedback activities are organized in so-called Audit \& Feedback Groups. An Audit \& Feedback Group consists of 8-15 physical therapists who meet around five times a year. One of their activities is to discuss clinical guidelines, using supportive tools that are developed by KNGF. 
Box 1: KNGF's Quality Assurance Program

1. Continuing education

2. Clinical guidelines

3. Audit \& Feedback

4. Quality Register

Developments in the field of guideline research, and the importance of high quality clinical guidelines in the Quality Assurance Program, resulted in the need to evaluate and update the current procedure for guideline development in physical therapy. Also, the international field of physical therapy lacked a body of knowledge about guideline development and implementation: it was unclear whether clinical guidelines can be used in physical therapy and what implementation strategies would be effective. Knowledge about applicability is essential for the process of updating the guidelines, and implementation strategies should be based on current knowledge. These objectives and questions are reflected by the chapters of this thesis, and fit the cyclic process of developing, implementing, evaluating, and updating clinical guidelines. Ankle sprain was the first guideline in the KNGF program, and was used as a specific case example in the research underlying this thesis and in describing the development cycle. The ankle sprain guideline, published in 1998, was also the first guideline that was updated as a project within this research project, based on the new procedure for clinical guideline development.

The overall research question for this thesis was:

What is the quality and applicability of clinical guidelines in physical therapy, from an international perspective?

Chapter 2 discusses adherence to the first published ankle sprain guideline, to evaluate the applicability of the guideline in routine practice. The process of updating the sprain guideline started with a systematic review of the literature, the results of which are presented in Chapter 3, focusing on the effectiveness of exercise therapy and manual mobilization in acute ankle injury. Chapter 4 reflects the new development process for clinical guidelines, by comparing international guideline programs in order to evaluate and update the KNGF procedure for clinical guideline development. Another systematic review, presented in Chapter $\mathbf{5}$ studied the effectiveness of strategies to increase the implementation of clinical guidelines on physical therapy. Chapter 6 evaluates the validity and responsiveness of the Ankle Function Score (AFS), this being one of the recommended measurement instru- 
ments in the clinical guideline on ankle sprain. Chapter $\mathbf{7}$ evaluates the applicability of the Ottawa ankle rules in a primary care setting, as the ankle sprain guideline recommends the use of this instrument in the first week after acute injury to identify possible fractures. Chapter $\mathbf{8}$ is a general discussion, in which the main results are presented, and implementation strategies are described and discussed. It also offers recommendations for strategies for further development and implementation of clinical guidelines. 


\section{REFERENCES}

1. Field MJ, Lohr K. Guidelines for clinical practice, from development to use. Washington DC: Institute of medicine. National Academic Press; 1992.

2. Grimshaw J, Eccles M, Russell I. Developing clinically valid practice guidelines. J Eval Clin Pract. 1995;1:37-48.

3. Grimshaw J, Freemantle N, Wallace $S$ et al. Developing and implementing clinical practice guidelines. Qual Health Care. 1995;4:55-64.

4. Grol R, Grimshaw J. From best evidence to best practice: effective implementation of change in patients' care. Lancet. 2003;362:1225-1230.

5. Grol R, Wensing M, Eccles M. Improving patient care; the implementation of change in clinical practice. London: Elsevier; 2005.

6. Woolf SH, Grol R, Hutchinson A, Eccles M, Grimshaw J. Potential benefits, limitations and harms of clinical guidelines. BMJ. 1999;527-530.

7. Eddy DM. Clinical decision making: from theory to practice. Guidelines for policy statements: the explicit approach. JAMA. 1990;263:2239-40, 2243.

8. Grimshaw JM, Hutchinson A. Clinical practice guidelines--do they enhance value for money in health care? Br Med Bull. 1995;51:927-940.

9. The AGREE Collaboration. Appraisal of Guidelines for Research \& Evaluation (AGREE) Instrument. London: St George's Hospital Medical School; 2001.

10. Burgers JS, Grol R, Klazinga NS, Makela M, Zaat JOM. Towards evidence-based clinical practice: an international survey of 18 clinical guideline programs. Int J Qual Health Care. 2003;15:31-45.

11. Shekelle PG, Woolf SH, Eccles M, Grimshaw J. Developing guidelines. BMJ. 1999;593-596.

12. Evidence-based richtlijnontwikkeling. Een leidraad voor de praktijk. Houten: Bohn Stafleu Van Lochum; 2004.

13. Burgers JS, van Everdingen JJ. [Evidence-based guideline development in the Netherlands: the EBRO platform]. Ned Tijdschr Geneeskd. 2004;148:2057-2059.

14. Ollenschlager G, Marshall C, Qureshi S et al. Improving the quality of health care: using international collaboration to inform guideline programmes by founding the Guidelines International Network (G-I-N). Qual Saf Health Care. 2004;13:455-460.

15. Oxman AD, Fretheim A, Schunemann HJ. Improving the use of research evidence in guideline development: introduction. Health Res Policy Syst. 2006;4:12.

16. Moseley AM, Herbert RD, Sherrington C, Maher CG. Evidence for physiotherapy practice: a survey of the Physiotherapy Evidence Database (PEDro). Aust J Physiother. 2002;48:43-49.

17. Hendriks HJM, Bekkering GE, van Ettekoven H, Brandsma JW, Van der Wees PJ, de Bie RA. Development and implementation of national practice guidelines: a prospect for continuous quality improvement in physiotherapy. Physiotherapy. 2000;86:535-547.

18. Van der Wees PJ, Hendriks HJM, Veldhuizen HJ. Quality assurance in the Netherlands: from development to implementation and evaluation. Dutch J Physiother. 2003;113:3-6.

19. Hendriks HJM, van Ettekoven H, Reitsma ER, Verhoeven AL, Van der Wees PJ. Methode voor centrale richtlijnontwikkeling en implementatie in de fysiotherapie. Amersfoort: Koninklijk Nederlands Genootschap voor Fysiotherapie (KNGF); 1998.

20. Rebbeck, T. Low back pain position statement. Melbourne, Australia: Australian Physiotherapy Association; 2002

21. Costello, J and Jull, G. Neck pain position statement. Melbourne, Australia: Australian Physiotherapy Association (APA); 2000

22. Fervers B, Burgers JS, Haugh MC et al. Adaptation of clinical guidelines: literature review and proposition for a framework and procedure. Int J Qual Health Care. 2006;18:167-176. 
23. Mead J, Van der Wees PJ. Clinical guidelines: An introduction. WCPT Keynotes. EBP ed. London: World Confederation for Physical Therapy (WCPT); 2006.

24. van der Wees PJ, Mead J. Clinical guidelines 2: Developing the guidelines. WCPT Keynotes. EBP ed. London: World Confederation for Physical Therapy (WCPT); 2006.

25. van der Wees, P. J. and Mead J. Framework for clinical guideline development. Brussels: European Region of World Confederation for Physical Therapy; 2004

26. Mulder S, Bloemhoff A, and Harris S. Ongevallen in Nederland, opnieuw gemeten. Amsterdam: Stichting Consument en Veligheid; 1995

27. Schmikli S, Wit MJP, and Backx FJG. Sportblessures driemaal geteld: kerncijfers en trends uit landelijk onderzoek naar sportblessures in Nederland. Arnhem: NOC*NSF Breedtesport; 2001

28. Vriend I, van Kampen B, Schmikli S, Eckhardt J, Schoots W, and den Hertog P. Ongevallen en bewegen in Nederland 2000-2003. Ongevalsletsels en sportblessures in kaart gebracht. Amsterdam: Stichting Consument en Veiligheid; 2005

29. Vriend I, Schoots W, Toet H, and Mulder S. Kosten en baten van enkelbraces bij voetbal. Amsterdam: Stichting Consument en Veiligheid; 2005

30. Verhagen EALM. Ankle sprains in Volleybal: players off balance? Vrije Universiteit Amsterdam; 2004.

31. Goudswaard AN, Thomas S, Van den Bosch WJHM, Van Weert HCPM, Geijer RMM. NHG-Standaard Enkeldistorsie. Huisarts Wet. 2000;43:32-37.

32. Van Dijk CN. On diagnostic strategies in patients with severe ankle sprain (thesis) University of Amsterdam; 1994.

33. Van Dijk CN, De Bie RA, Benink RJ, Bots RAA, Bossuyt PMM, Goudswaard AN, Hammacher ER, Helders PJM, Hendriks HJM, Huisman AB, Langenhorst AMWW, Pijnenburg ACM, and Thomas S. Consensus diagnostiek en behandeling van het acute enkelletsel. Utrecht: CBO; 1999

34. Van Moppes FI, Van den Hoogenband CR. Diagnostic and therapeutic aspects of inversion trauma of the ankle joint. Maastricht University; 1982.

35. Zeegers AVCM. Het supinatieletsel van de enkel. Resultaten (proefschrift). Universiteit Utrecht; 1995.

36. Freeman MA. Treatment of ruptures of the lateral ligament of the ankle. J Bone Joint Surg Br. 1965;47:661-668.

37. Moller-Larsen F, Wethelund JO, Jurik AG, De Carvalho A, Lucht U. Comparison of three different treatments for ruptured lateral ankle ligaments. Acta Orthop Scand. 1988;59:564-566.

38. Karlsson J, Eriksson BI, Sward L. Early functional treatment for acute ligament injuries of the ankle joint. Scand J Med Sci Sports. 1996;6:341-345.

39. Hendriks HJM. Implementeren van richtlijnen: een brug tussen kennis en praktijk? In: Hullegie W, Lettinga A, Verhagen A, eds. Fysiotherapie en wetenschap: over de gespannen verhouding tussen theorie, onderzoek en praktijk. Maarsen: Elsevier Gezondheidszorg; 2003. 



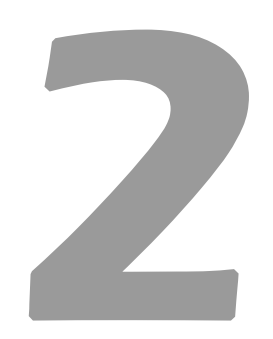

\title{
Adherence to physiotherapy clinical guideline acute ankle injury and determinants of adherence: a cohort study
}

\author{
Philip J van der Wees ${ }^{1,2}$ \\ Erik JM Hendriks ${ }^{1,3}$ \\ Mariette J Jansen ${ }^{3}$ \\ Hans van Beers ${ }^{1}$ \\ Rob A de Bie ${ }^{1}$ \\ Joost Dekker ${ }^{4}$
}

\footnotetext{
${ }^{1}$ Department of Epidemiology, Center for Evidence Based Physiotherapy and Caphri Research Institute, Maastricht University, Netherlands

${ }^{2}$ Royal Dutch Society for Physical Therapy (KNGF), Amersfoort, Netherlands ${ }^{3}$ Dutch Institute for Allied Health Care (NPi), Amersfoort, Netherlands

${ }^{4}$ Department of Rehabilitation Medicine, EMGO Institute, VU University Medical Center, Amsterdam, Netherlands
}

BMC Musculoskeletal Disorders 2007; 8:45 


\begin{abstract}
Background

Clinical guidelines are considered important instruments to improve quality in health care. In physiotherapy, insight in adherence to guidelines is limited. Knowledge of adherence is important to identify barriers and to enhance implementation. Purpose of this study is to investigate the ability to adherence to recommendations of the guideline Acute ankle injury, and to identify patient characteristics that determine adherence to the guideline.
\end{abstract}

\title{
Method
}

Twenty-two physiotherapists collected data of 174 patients in a prospective cohort study, in which the course of treatment was systematically registered. Indicators were used to investigate adherence to recommendations. Patient characteristics were used to identify prognostic factors that may determine adherence to the guideline. Correlation between patient characteristics and adherence to outcomeindicators (treatment sessions, functioning of patient, accomplished goals) was calculated using univariate logistic regression. To calculate explained variance of combined patient characteristics, multivariate analysis was performed.

\section{Results}

Adherence to individual recommendations varied from $71 \%$ to $100 \%$. In 99 patients (57\%) the physiotherapists showed adherence to all indicators. Adherence to preset maximum of six treatment sessions for patients with severe ankle injury was $81 \%$ (132 patients).

The odds to receive more than six sessions were statistically significant for three patient characteristics: females (OR:3.89; $95 \% \mathrm{Cl}: 1.41-10.72$ ), recurrent sprain (OR: $6.90 ; 95 \% \mathrm{Cl}: 2.34-20.37$ ), co-morbidity (OR: $25.92 ; 95 \% \mathrm{Cl}: 6.79-98.93$ ). All factors together explained $40 \%$ of the variance. Inclusion of physiotherapist characteristics in the regression model showed that work-experience reduced the odds to receive more than six sessions (OR: $0.2 ; 95 \% \mathrm{Cl}: 0.06-0.77$ ), and increased explained variance to $45 \%$.

\section{Conclusion}

Adherence to the clinical guideline Acute ankle sprain showed that the guideline is applicable in daily practice. Adherence to the guideline, even in a group of physiotherapists familiar with the guideline, showed possibilities for improvement. The necessity to exceed the expected number of treatment sessions may be explained by co-morbidity and recurrent sprains. It is not clear why female patients were treated with more sessions. Experience of the physiotherapist reduced the number of treatment sessions. Quality indicators may be used for audit and feedback as part of the implementation strategy. 


\section{BACKGROUND}

Evidence-based clinical guidelines are considered important tools to improve quality in health care $^{1-3}$. Clinical guidelines are systematically developed statements designed to help practitioners and patients to make decisions about appropriate health care for specific circumstances ${ }^{4}$. The clinical guideline Acute ankle injury was the first physiotherapy specific evidence-based guideline in the Netherlands, published in 1998 by the Royal Dutch Society for Physical Therapy ${ }^{5}$. Acute lateral inversion sprains of the ankle are common in sports and activities of daily living ( $A D L$ ), and concern usually young, physically active individuals ${ }^{6-8}$. In the guideline Acute ankle injury a Function score was introduced to assist physiotherapists to determine severity of the injury and set a prognostic profile for recovery. Research by De Bie et al. showed that the Function Score can be used to distinguish light injury from severe injury ${ }^{9}$. When using the Function Score, separate scores for pain, dynamic stability, loading, swelling and gait are added to a maximum of 100 points. A summary of recommendations of the clinical guideline are presented in table 1.

Implementation of clinical guidelines is influenced by several factors, like the performance gap between theory and practice ${ }^{10}$. The process of implementation starts with dissemination of guidelines ${ }^{11}$. For the implementation and evaluation of clinical guidelines it is important to know whether physiotherapists are able to adhere to the recommendations of guidelines. The actual use of and adherence to clinical guidelines, can be measured by using quality indicators ${ }^{3}$. Quality indicators are elements of health care for which evidence or consensus exists that they are indicative for the quality of health care, and they are usually categorized in structure, process and outcome indicators ${ }^{12,13}$. Structure- and process-indicators are based on recommendations for practice and intervention, while outcome-indicators represent the results of care.

Insight in adherence to clinical guidelines using indicators is important to identify barriers and provide information for further implementation of the guideline ${ }^{14}$.

Adherence to guidelines should be put in perspective to specific patient characteristics, because recommendations in guidelines are based on the 'average' patient. For clinical decision making it is important to tailor treatment to specific individual needs of the patient. It is therefore interesting to identify possible patient characteristics that influence adherence to the guideline as prognostic factors.

Objective of this study is to investigate the ability for adherence to recommendations of the clinical guideline Acute ankle injury by measuring process and outcome of the intervention with the use of indicators, and to identify patient characteristics that determine adherence to the clinical guideline. 
Table 1. Summary of recommendations in clinical guideline Acute ankle injury

\section{Function Score}

If a patient scores more than $\mathbf{4 0}$ points within the first five days after injury, it is considered a light injury, which requires no specific physiotherapy treatment. For these patients full recovery to normal ADL activities (except sport) can be expected in 14 days, which equals a Function score of at least 75 points.

\section{Light injury}

For patients with light injuries and without necessity for sport-specific rehabilitation the guideline recommends a maximum of three treatment sessions.

\section{Severe injury}

Severe injuries may require up to six treatment sessions within six weeks. Choice of interventions is based on normal recovery after ligament sprains, going from acute inflammation to proliferation and remodelling of the injured tissue. Furthermore, the guideline recommends that exercise therapy should be the main focus of the intervention, while physical modalities like Ultrasound or Electrotherapy are not recommended to be part of the intervention.

Sports rehabilitation

Sport specific rehabilitation requires specific treatment, which may last for about 12 weeks. Progressive increase of loading. Exercise therapy: from static to dynamic; from single-task to multi-task; from cyclic to non-cyclic exercises

\section{METHODS}

\section{Study design}

A prospective cohort study was performed to measure physiotherapy care for patients with acute ankle injury. After publication of the guideline Acute ankle injury in 1998, a group of 59 physiotherapists, who commented on the draft guideline during its development, were requested to participate in the study. This resulted in the inclusion of 22 physiotherapists. Major reason for not participating was the expected lack of patients with acute ankle injury $(n=17)$. Ethical approval for this study was granted by Deventer Hospitals.

Average age of the physiotherapists was 38 years, including two females. The majority $(n=17 ; 77 \%)$ worked in primary health care in private practice, while the remainder worked in a hospital setting. More than half $(n=12 ; 55 \%)$ were to some extent specialized in sports physiotherapy.

The physiotherapists collected data of consecutive patients with acute ankle sprain using a specific registration form. Criterion for inclusion was an acute inversion trauma of the ankle. Criteria for exclusion were injuries older than six weeks and severe trauma (fracture). 
Patients were informed by the physiotherapists about the objective of the study, and were asked to give their informed consent to use their data for the study. The participating physiotherapists were prepared for the study in two meetings, during which the guideline Acute ankle injury was discussed, and instructions were given for registration of patient data.

\section{Data collection}

Using the registration form, data were collected about patient characteristics. Specific details about diagnosis and treatment were collected: recurrent injury, comorbidity, duration of complaint, normal or abnormal recovery, phase of recovery, cause of abnormal recovery, indication for physiotherapy treatment, treatment goals, interventions, accomplished treatment goals, number of treatment sessions, duration of treatment (in weeks). At the beginning and at the end of treatment the Function Score was assessed. Extraction of data was done by two researchers (PW and MJ).

\section{Quality indicators}

To measure adherence to the guideline an initial set of 15 possible indicators were identified by two researchers ( $\mathrm{EH}$ and $\mathrm{MJ}$ ). Based on consensus they selected four process-indicators for final inclusion in this study. These process-indicators reflect the most important recommendations in the guideline: Use of Function score at intake and end of treatment (yes/no), Measurement of the phase of recovery at intake (yes/no); Measurement of normal or abnormal recovery at intake (yes/no); Interventions used according to guideline (yes/no). Also three outcome measures were identified as outcome-indicators: Accomplished treatment goals (completely vs. partly, stabilized, worsened) at the end of treatment for each phase of recovery at intake (\%); Number of treatment sessions (maximum of six sessions if Function score $\leq 40$ points at 0-5 days after injury; maximum of three sessions if Function score $>40$ points at 0-5 days after injury); Function score of minimal 75 points at end of treatment.

\section{Prognostic factors for adherence}

Patient characteristics at the beginning of treatment were used to investigate correlation with adherence to the guideline. Using the International Classification of Functioning (ICF), patient characteristics can be classified in Functioning (body function, activities, participation) and Contextual factors (personal factors and environmental factors) ${ }^{15}$. Based on the ICF we collected 16 patient characteristics at intake: age (years), gender (female vs. male), education (high vs. low or medium), absence of work (yes vs. no), sport (yes vs. no), load in ADL (high vs. low), 
duration of complaint (days), recurrent injury (yes vs. no), co-morbidity (yes vs. no), delayed recovery (yes vs. no), Function score at intake (0-100), Pain at intake (0$35)$, Swelling at intake (0-10), Dynamic stability at intake (0-25), Loading at intake (0-20), Gait at intake (0-10).

\section{Data analysis}

Patient characteristics were described using descriptive statistics. To determine process and outcome indicators relative frequencies, percentages and averages of the relevant components of diagnosis and treatment process were calculated.

To investigate correlations between prognostic factors (patient characteristics) and adherence to the guideline, univariate logistic regression was carried out between each prognostic (independent) variable and the three separate outcome-indicators (dependent variables) for not adhering to the guideline: $>6$ treatment sessions, < 75 points on Function score, not accomplished treatment goals.

Regression coefficient (B), Standard Error of Mean (SE) and statistical significance ( $p$-value) were calculated. Prognostic factors with $p$-values of $<0.10$ were included in a multivariate logistic regression analysis. Patients with $>40$ points on the Function score within 0-5 days after injury were excluded from analysis, because their injury was considered light and required no specific treatment.

Multivariate logistic regression was carried out using the enter model. Stepwise forward selection (LR-test; $p$-inclusion $<0.05$; p-exclusion $>0.10$ ), and stepwise backward elimination (LR-test; $p$-inclusion <0.05; $p$-exclusion $>0.10$ ) were used as alternate models. Odds Ratio using $\mathrm{e}^{B}, 95 \%$ Confidence Interval, and $p$-value were calculated for each prognostic variable. For each outcome indicator the percentage of explained variance $\left(R^{2}\right)$ was calculated. The three models were compared to investigate consistency in statistical significance and prediction of determinants.

To correct for potential bias, relevant physiotherapist characteristics were added in the regression model: years of experience in treating ankle injuries ( $\geq 3$ years), specialization (sports physiotherapy, manual therapy).

\section{RESULTS}

\section{Patient characteristics}

During a period of 14 months the 22 participating physiotherapists collected data of 174 patients (mean:7.6; range:1-26). In table 2 an overview of patient characteristics is given. 
Table 2. Characteristics of patients $(\mathrm{N}=174)$

\begin{tabular}{|c|c|c|c|c|c|}
\hline & & $\mathrm{N}$ & (\%) & & sd \\
\hline \multirow[t]{2}{*}{ Gender } & Male & 100 & (57) & & \\
\hline & Female & 74 & (43) & & \\
\hline Age & Years & & & 29.8 & $(12.7)$ \\
\hline \multirow[t]{3}{*}{ Education } & Low/Medium & 112 & $(65)$ & & \\
\hline & High & 61 & (35) & & \\
\hline & Missing & 1 & & & \\
\hline \multirow[t]{6}{*}{ Participation } & Employed* & 91 & $(52)$ & & \\
\hline & Student & 49 & $(28)$ & & \\
\hline & Housewife/-man & 16 & (9) & & \\
\hline & Disabled & 3 & (2) & & \\
\hline & Unemployed & 2 & (1) & & \\
\hline & Missing & 13 & (8) & & \\
\hline \multirow[t]{2}{*}{ Load ADL } & Low/normal & 71 & $(41)$ & & \\
\hline & High & 103 & (59) & & \\
\hline \multirow[t]{2}{*}{ Sports } & No & 66 & (38) & & \\
\hline & Yes & 108 & $(62)$ & & \\
\hline
\end{tabular}

* 34 patients (20\%) suffered during treatment from temporary absence of work

\section{Diagnosis, treatment and evaluation}

In table 3 relevant variables of physiotherapy assessment, treatment and evaluation are summarized. Twenty percent of the patients had a history of recurrent ankle injury. The average Function score was 28.4 (sd:17.5) at intake, and 87.7 (sd:13.4) at the end of treatment. The average number of treatment sessions was 5.2 (sd:2.9).

\section{Adherence to recommendations}

Table 4 shows the adherence to recommendations based on the quality indicators. Eleven patients had a light injury with a score of more than 40 points on the Function score while duration of complaints was not more than 5 days. For 8 of these patients $(73 \%)$ the maximum number of treatment sessions adhered to the outcome-indicator of maximal 3 sessions. The injury of 163 patients was classified as severe ( $<40$ points on the Function score). For 132 of these patients (81\%) the maximum number of treatment sessions adhered to the outcome-indicator (max. 6 sessions).

In 99 patients (57\%) the physiotherapists showed full adherence to all indicators. Adherence to process-indicators is quite higher (155 patients; $89 \%$ ) than adherence to outcome-indicators (102 patients; 59\%). 
Table 3. Diagnosis, treatment and evaluation $(n=174)$

\begin{tabular}{llrrrr}
\hline & & $\mathrm{N}$ & $(\%)$ & $\mathrm{x}$ & (sd) \\
\hline Recurrent injury & No & 138 & $(80)$ & & \\
& Yes & 35 & $(20)$ & & \\
Co-morbidity & Mo & 1 & & & \\
& Yes & 158 & $(91)$ & & $(7.1)$ \\
Duration complaint & Days & 16 & $(9)$ & & \\
Normal recovery & No & 174 & & 7.1 & \\
& Yes & 30 & $(17)$ & & \\
& Unknown & 142 & $(82)$ & & \\
Phase of recovery & Missing & 1 & $(0.5)$ & & \\
& Phase 1 & 1 & $(0.5)$ & & \\
& Phase 2 & 74 & $(43)$ & & \\
Function Score & Phase 3 & 79 & $(45)$ & & \\
(max of 100 points) & Phase 4 & 14 & $(8)$ & & $(17.5)$ \\
Treatment sessions & Intake (assessment) & 174 & & 28.4 & $(13.4)$ \\
\hline
\end{tabular}

Table 4. Results of adherence to process and outcome indicators ( $N=174$ )

\begin{tabular}{|c|c|c|c|c|}
\hline \multirow[t]{2}{*}{ Indicator } & \multirow[t]{2}{*}{ Type } & \multirow[t]{2}{*}{ Criterion } & \multicolumn{2}{|c|}{ Adherence } \\
\hline & & & $\mathrm{N}$ & $(\%)$ \\
\hline Function score (intake and end) & Process & Assessed & 171 & (98) \\
\hline Recovery (phase at intake) & Process & Assessed & 174 & (100) \\
\hline Recovery (normal/abnormal) & Process & Assessed & 172 & (99) \\
\hline Interventions & Process & According guideline & 160 & (92) \\
\hline Accomplished treatment goals: & Outcome & Fully accomplished & & \\
\hline Phase $1\left(n=73^{a}\right)$ & & & 56 & (77) \\
\hline Phase $2\left(n=78^{a}\right)$ & & & 66 & (85) \\
\hline Phase $3(n=14)$ & & & 10 & (71) \\
\hline Phase $4(n=7)$ & & & 6 & (86) \\
\hline $\begin{array}{l}\text { \# treatment sessions with severe injury } \\
\text { Function score } \leq 40 \text { points }(N=163)\end{array}$ & Outcome & Maximal 6 sessions & 132 & (81) \\
\hline $\begin{array}{l}\text { \# treatment sessions with light injury } \\
\text { Function score }>40 \text { points }(\mathrm{N}=11)\end{array}$ & Outcome & Maximal 3 sessions & 8 & (73) \\
\hline Function score at end treatment & Outcome & $\geq 75$ points & 152 & (87) \\
\hline \multirow[t]{3}{*}{ Overall adherence } & Outcome & $\begin{array}{l}\text { Adherence to all indica- } \\
\text { tors }\end{array}$ & 99 & (57) \\
\hline & & $\begin{array}{l}\text { Adherence to process } \\
\text { indicators }\end{array}$ & 155 & (89) \\
\hline & & $\begin{array}{l}\text { Adherence to outcome } \\
\text { indicators }\end{array}$ & 102 & (59) \\
\hline
\end{tabular}

ane missing value 


\section{Determinants for adherence}

The multivariate logistic regression analysis for determinants to adherence using the enter method, is shown in table 5 . Based on univariate correlations, five prognostic factors were associated with more than six treatment sessions as outcomeindicator for not adhering to the guideline (females, active in sport, high load in $A D L$, recurrent sprain, co-morbidity). Based on multivariate analysis, the odds to receive more than six treatment sessions were statistically significant for three characteristics of patients: females (OR: $3.89 ; 95 \% \mathrm{Cl}: 1.41-10.72$ ), recurrent injury (OR: 6.90; 95\% Cl: $2.34-20.37$ ), co-morbidity (OR: 25.92; 95\% Cl: $6.79-98.93$ ). All five factors together explained $40 \%$ of the variance.

Two prognostic factors were individually associated with a Function score of less than 75 points at the end of treatment (lower function score at intake, more pain at intake). These factors together explained $12 \%$ of the variance, but were not statistically significant in multivariate analysis.

Using not accomplished treatment goals as outcome-indicator for adherence, only variables of patients that enrolled in treatment at phase 1 or phase 2 of recovery were associated with a $p$-value of $<0.10$ in univariate analysis. Multivariate analysis of patients in phase 1 and phase 2 of recovery showed explained variance of $23 \%$ and $18 \%$ respectively.

\section{Consistency of explained variance in different models}

Stepwise forward selection and stepwise backward elimination were used as alternate models to calculate explained variance. Both models showed an explained variance of $39 \%$ for the number of treatment sessions as outcome-indicator for not adhering to the guideline. The explained variance for all three models was consistent.

\section{Inclusion of physiotherapist characteristics in the regression model}

Based on univariate regression, experience of the physiotherapist and specialization in manual therapy were associated with less than six treatment sessions. Inclusion of these characteristics in multivariate logistic regression showed that physiotherapists with at least three years of experience in treating ankle injury, reduced the odds to receive more than six treatment sessions (OR: $0.2 ; 95 \% \mathrm{Cl}: 0.06-0.77$ ). It still showed statistically significant results for the odds to receive more than six treatment sessions for three patient characteristics: females, recurrent injury, comorbidity. By including the physiotherapist characteristics in the model, the explained variance increased to $45 \%$. 
Table 5. Regression analysis for prognostic factors that determine non-adherence.

\begin{tabular}{|c|c|c|c|c|c|}
\hline $\begin{array}{l}\text { Outcome-indicator } \\
\text { (non-adherence) }\end{array}$ & Prognostic factors & OR & $95 \% \mathrm{Cl}$ & $p$ & $\mathrm{R}^{2}(\%)$ \\
\hline Treatment sessions $(>6)$ & Gender (f/m) & 3.89 & $1.41-10.72$ & 0.009 & 40 \\
\hline \multirow[t]{4}{*}{$(n=163)$} & Sport $(y / n)$ & 2.66 & $0.73-9.68$ & 0.14 & \\
\hline & Load in ADL (high/low) & 1.75 & $0.51-6.02$ & 0.38 & \\
\hline & Recurrent sprain $(\mathrm{y} / \mathrm{n})$ & 6.90 & $2.34-20.37$ & $<0.001$ & \\
\hline & Other pathology $(\mathrm{y} / \mathrm{n})$ & 25.92 & $6.79-98.93$ & $<0.001$ & \\
\hline Function score $(<75)$ & Function score begin $(0-100)$ & 0.99 & $0.95-1.05$ & 0.95 & 12 \\
\hline$(n=163)$ & Pain (0-35) & 0.81 & $0.67-0.97$ & 0.89 & \\
\hline Treatment goals phase 1 not & Function score begin (0-100) & 1.01 & $0.86-1.18$ & 0.95 & 23 \\
\hline accomplished & Pain (0-35) & 0.76 & $0.53-1.10$ & 0.15 & \\
\hline$(n=68)$ & Dynamic stability (0-25) & 0.85 & $0.62-1.16$ & 0.30 & \\
\hline $\begin{array}{l}\text { Treatment goals phase } 2 \text { not } \\
\text { accomplished } \\
(n=74)\end{array}$ & Swelling (0-10) & 0.66 & $0.49-0.91$ & 0.01 & 18 \\
\hline
\end{tabular}

\section{DISCUSSION}

\section{Adherence to the guideline}

Adherence to process-indicators was very high, signifying that the group of physiotherapists was very well capable of working according to the recommendations and that the guideline is applicable in daily practice. Although all individual outcome indicators showed adherence of more than $70 \%$, the combined adherence was lower: $57 \%$. Still, these data show that it is possible to work according to the recommendations in the clinical guideline.

Bekkering et al studied adherence to the physiotherapy guideline Low back pain in a randomized clinical trial. She found adherence to recommendations varying from $20.1 \%$ (number of treatment sessions) to $91.3 \%$ (provide adequate information and advice). Overall adherence was $42 \%$ for physiotherapists who participated in an active implementation strategy ${ }^{16}$. A prospective cohort study by Jansen et al showed that adherence to the physiotherapy clinical guideline Osteoarthritis of hip and knee varied from $46 \%$ to $100 \%{ }^{17}$. Two different implementation strategies (active implementation vs. dissemination) for whiplash guidelines in physiotherapy was studied by Rebbeck et al. ${ }^{18}$ They found statistically significant increase of knowledge and identification of recommendations in the active intervention group compared to the passive dissemination group. Grol studied adherence to clinical guidelines by family doctors and found an average overall adherence in 30 clinical guidelines of $67 \%$, with a range from 34 to $100 \%^{3}$. Differences in study design, reg- 
istration, and performance-indicators makes it difficult to compare the outcomes of these studies.

\section{Determinants for adherence}

A limited number of patient characteristics (female, recurrent injury, co-morbidity) were identified as determinants for adherence to the guideline, also when corrected for physiotherapist characteristics. The number of treatment sessions showed a reasonable explained variance $(40 \%)$ in a combination of five patient characteristics that predict lack of adherence to the guideline. Recurrent injury and co-morbidity seem logical determinants, because recovery may take more time and requires specific intervention. However, why female patients have been treated with more sessions does not seem to be related to their condition. Adherence to the guideline is compromised when the physiotherapist has reasonable arguments to diverge from the recommendations. If we consider recurrent injury or comorbidity as reasonable arguments to use more treatment sessions, adherence to that outcome measure will increase.

Adherence to the guideline is also influenced by physiotherapist characteristics. Experience of the physiotherapist increased adherence to the number or treatment sessions, which also increased the explained variance. Unfortunately, due to lack of sufficient data, it was impossible to further investigate the interaction between patient and physiotherapist characteristics in multi-level analysis.

In multivariate analysis, decreased function of the patient at the end of treatment ( $<75$ points on the Function score) was significantly correlated with patient characteristics at the start of treatment. The explained variance was low (12\%). This may be a logical consequence of the fact that physiotherapists will usually continue treatment until the patient is recovered. It can therefore be expected that reasons for not reaching normal function at the end of treatment may vary and show no consistency in prognostic factors. Also the Function score was designed to be used at intake to distinguish between light and severe injury. The validity of the Function score as instrument to evaluate recovery is unknown, and more research is required to investigate the evaluative use of the Function score.

\section{Generalization of the outcome}

Characteristics of the patients in this study were similar to data from an earlier study concerning patients with acute ankle injury ${ }^{19}$, which showed that the group of patients in this study resembles the normal population of patients with acute ankle injury.

The physiotherapists that participated in this study, commented on the draft version of the guideline Acute ankle injury. Furthermore, the major reason for not 
participating was a lack of patients with acute ankle injury. That means a possible selection took place of physiotherapists who have more knowledge about the clinical guideline, who treat more patients with acute ankle injury, and who are more competent in treating ankle injuries. This may also explain that the majority of the physiotherapists were to some extend specialized in sports physiotherapy, because about half of all acute ankle injuries occur during sports activities. We should also notice that the physiotherapists were instructed to use a registration form, which may have guided them in adhering to the guideline.

Our conclusion is that adherence to recommendations in the guideline is possible, but possibly overestimates the adherence, which may reduce the external validity of this study.

\section{Development of indicators}

Although the use of indicators to measure quality of health care and performance in health care is common, methodology to develop quality indicators is still in development $^{20}$. Campbell et al described research methods to develop indicators ${ }^{13}$. They distinguished non-systematic from systematic methods to develop indicators. Systematic development can be based on evidence e.g. derived from recommendations in clinical guidelines, and on consensus procedures. Although our methodology for development of indicators was systematic by using recommendations from an evidence-based clinical guideline, the consensus procedure was basic and may require further refinement. Delphi procedures and panel meetings may enhance the production of valid, reliable and useful indicators ${ }^{12-14,21}$.

\section{Application of indicators}

Data generated using quality indicators can be used for a variety of purposes. Practitioners can use them as benchmark to compare their performance with others. Indicators are also useful to develop implementation strategies for clinical guidelines ${ }^{14}$. From the financiers perspective, indicators can be used to reward or penalize care provision ${ }^{13}$. The number of treatment sessions reflects both process and outcome of care. Insurance companies may be interested in adherence to the number of treatment sessions as outcome-indicator because it directly reflects the costs of treatment. This study indicates that it is not possible to use a maximum of six treatment sessions as a fixed indicator for all acute ankle injuries, because several patient characteristics influence adherence to that specific indicator.

\section{Implications for implementation}

Implementation of clinical guidelines requires a tailored and multi-facetted approach $^{1}$. The results of this study show that the guideline Acute ankle sprain is 
applicable in daily practice, which is promising for further implementation. Although the use of the registration form as guidance or reminder for the physiotherapist may have biased the outcome of this study, it may also be an effective means for further implementation. The development of a web based electronic registration form may be helpful for further implementation of the clinical guideline. Electronic registration also enables to create benchmarks by using quality indicators for feedback and monitoring.

\section{Conclusions}

Adherence to the clinical guideline Acute ankle sprain by a specific group of physiotherapists showed that the guideline is applicable in daily practice and the results are promising for further implementation. Adherence to the guideline, even in a specific group familiar with the guideline, showed possibilities for improvement. The necessity to exceed the expected number of treatment sessions may be explained by co-morbidity and recurrent sprains. It is not clear why female patients were treated with more sessions. Experience of the physiotherapist reduced the number of treatment sessions. Quality indicators may be used for audit and feedback as part of the implementation strategy.

\section{Competing interests}

The authors declare that they have no competing interests.

\section{Authors' contributions}

PW extracted data, carried out data analysis and drafted the manuscript. EH set up the design of the study, collected and extracted data, participated in data analysis, and selected quality indicators. MJ collected data and selected quality indicators. HB participated in data analysis. RB and JD contributed to design of the study, data analysis and critically revised the manuscript. All authors read and approved the final manuscript. 


\section{REFERENCES}

1. Grimshaw JM, Thomas RE, MacLennan G et al. Effectiveness and efficiency of guideline dissemination and implementation strategies. Health Technol Assess. 2004;8:iii-72.

2. Hayward RS, Wilson MC, Tunis SR, Bass EB, Guyatt G. Users' guides to the medical literature. VIII. How to use clinical practice guidelines. A. Are the recommendations valid? The Evidence-Based Medicine Working Group. JAMA. 1995;274:570-574.

3. Grol R. Successes and failures in the implementation of evidence-based guidelines for clinical practice. Med Care. 2001;39:||46-II54.

4. Field MJ, Lohr K. Guidelines for clinical practice, from development to use. Washington DC: Institute of medicine. National Academic Press; 1992.

5. De Bie RA, Hendriks H, Lenssen AF et al. KNGF-richtlijn Acuut enkelletsel. Ned Tijdschr Fysiother. 1998;108:1-23.

6. Eils $E$, Rosenbaum D. A multi-station proprioceptive exercise program in patients with ankle instability. Med Sci Sports Exerc. 2001;33:1991-1998.

7. Garrick JG. The frequency of injury, mechanism of injury, and epidemiology of ankle sprains. Am J Sports Med. 1977;5:241-242.

8. Kannus P, Renstrom P. Treatment for acute tears of the lateral ligaments of the ankle. J BoneJoint Surg. 1991;73-A:305-312.

9. de Bie RA, de Vet HC, van den Wildenberg FA, Lenssen T, Knipschild PG. The prognosis of ankle sprains. Int J Sports Med. 1997;18:285-289.

10. Grol R, Grimshaw J. From best evidence to best practice: effective implementation of change in patients' care. Lancet. 2003;362:1225-1230.

11. Eccles MP, Grimshaw JM. Selecting, presenting and delivering clinical guidelines: are there any "magic bullets"? Med J Aust. 2004;180:S52-S54.

12. Barnsley J, Berta W, Cockerill R, MacPhail J, Vayda E. Identifying performance indicators for family practice: assessing levels of consensus. Can Fam Physician. 2005;51:700-701.

13. Campbell SM, Braspenning J, Hutchinson A, Marshall M. Research methods used in developing and applying quality indicators in primary care. Qual Saf Health Care. 2002;11:358-364.

14. Hermens RP, Ouwens MM, Vonk-Okhuijsen SY et al. Development of quality indicators for diagnosis and treatment of patients with non-small cell lung cancer: A first step toward implementing a multidisciplinary, evidence-based guideline. Lung Cancer. 2006;54:117-124.

15. WHO. International classification of functioning, disability and health: ICF. Geneva: World Health Organization (WHO); 2001.

16. Bekkering GE, Hendriks HJ, van Tulder MW et al. Effect on the process of care of an active strategy to implement clinical guidelines on physiotherapy for low back pain: a cluster randomised controlled trial. Qual Saf Health Care. 2005;14:107-112.

17. Jansen MJ, Hendriks HJM, de Bie RA, Dekker J, Oostendorp RAB. Handelen volgens de KNGFrichtlijn 'Artrose heup-knie': een prospectieve cohortstudie. Ned Tijdschr Fysiother. 2005;115:6873.

18. Rebbeck T, Maher CG, Refshauge KM. Evaluating two implementation strategies for whiplash guidelines in physiotherapy: a cluster randomised trial. Aust J Physiother. 2006;52:165-174.

19. Roebroeck ME, Dekker J, Oostendorp RAB, Bosveld W. Physiotherapy for patients with lateral ankle sprains. A prospective survey of practice patterns in Dutch primary health care. Physiotherapy. 1998;84:421-431.

20. Arah OA, Westert GP, Hurst J, Klazinga NS. A conceptual framework for the OECD Health Care Quality Indicators Project. Int J Qual Health Care. 2006;18 Suppl 1:5-13.

21. Nicolucci A, Greenfield S, Mattke S. Selecting indicators for the quality of diabetes care at the health systems level in OECD countries. Int J Qual Health Care. 2006;18 Suppl 1:26-30. 


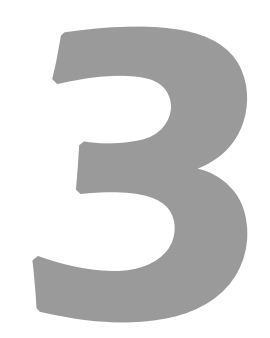

\section{Effectiveness of exercise therapy and manual mobilisation in acute ankle sprain and functional instability: a systematic review}

Philip J van der Wees ${ }^{1,2}$

Anton $\mathrm{F}$ Lenssen $^{3}$

Erik JM Hendriks ${ }^{1,4}$

Derrick J Stomp ${ }^{4}$ Joost Dekker ${ }^{5}$

Rob A de Bie ${ }^{1}$

\footnotetext{
${ }^{1}$ Department of Epidemiology, Maastricht University

${ }^{2}$ Royal Dutch Society for Physical Therapy (KNGF)

${ }^{3}$ University Medical Centre Maastricht

${ }^{4}$ Dutch Institute of Allied Health Care (NPi)

${ }^{5}$ VU Medical Centre, Amsterdam
}

Australian Journal of Physiotherapy 2006; 52:27-37 


\begin{abstract}
This study critically reviews the effectiveness of exercise therapy and manual mobilisation in acute ankle sprains and functional instability by conducting a systematic review of randomised controlled trials. Trials were searched electronically and manually from 1966 to March 2005. Randomised controlled trials that evaluated exercise therapy or manual mobilisation of the ankle joint with at least one clinically relevant outcome measure were included. Internal validity of the studies was independently assessed by two reviewers. When applicable relative risk (RR) or standardised mean differences (SMD) were calculated for individual and pooled data.

In total 17 studies were included. In thirteen studies the intervention included exercise therapy and in four studies the effects of manual mobilisation of the ankle joint was evaluated. Average internal validity score of the studies was 3.1 (range 1-7) on a 10-point scale. Exercise therapy was effective in reducing the risk of recurrent sprains after acute ankle sprain: RR $0.37(95 \% \mathrm{Cl}: 0,18-0,74)$, and with functional instability: RR 0.38 ( $95 \% \mathrm{Cl}$ : $0.23-0.62)$. No effects of exercise therapy in patients with functional instability were found on postural sway: SMD: $0.38(95 \% \mathrm{Cl}:-0.15-0.91)$. Four studies demonstrated an initial positive effect of different modes of manual mobilisation on dorsiflexion range of motion.

It is likely that exercise therapy, including the use of a wobble board, is effective in the prevention of recurrent ankle sprains. Manual mobilisation has an (initial) effect on dorsiflexion range of motion, but the clinical relevance of these findings for physiotherapy practice may be limited.
\end{abstract}

Key words: Ankle, Ligament, Injury, Review, Exercise Therapy, Manipulation Therapy. 


\section{INTRODUCTION}

In the Netherlands around 600,000 people suffer every year from traumatic injury of the ankle. Functional instability as a residual problem after acute injury has been reported in $10-60 \%$ of the patients ${ }^{1-6}$. Symptoms of functional instability are a feeling of instability, recurrent sprains or a feeling of apprehension ${ }^{7}$. Limitation of dorsiflexion range of motion is associated with pain and functional problems after ankle sprains ${ }^{8}$, and with an increased risk of ankle sprains in healthy subjects ${ }^{9}$.

Several reviews have been written about the effectiveness of different forms of interventions in acute ankle sprains ${ }^{10-15}$. The effects of interventions commonly used by physiotherapists are partly described in those reviews. Van der Windt et $\mathrm{al}^{14}$ found no effects of ultrasound in acute ankle sprains. A review done by the Dutch Health Council ${ }^{16}$ showed no effects for the use of ultrasound, electro-therapy and laser-therapy. Handoll et al $^{10}$ found limited evidence for the effects of ankle disc training in reducing recurrent ankle sprains.

The use of tape and brace has been reviewed by Kerkhoffs et $\mathrm{al}^{12,13}$, Verhagen et $\mathrm{al}^{15}$ and Handoll et $\mathrm{al}^{10}$. The review by Kerkhoffs et $\mathrm{al}^{13}$ shows that functional treatment, based on an early mobilisation programme using external ankle support (brace, tape or elastic bandage) and exercises, appears to be the favourable strategy for treating acute ankle sprains when compared with immobilisation in a plaster cast. External ankle support using tape or brace is effective in preventing ankle injuries, specifically in preventing recurrent sprains ${ }^{10,15}$. Verhagen et al ${ }^{15}$ conclude that braces seem to be more effective in preventing ankle sprains than tape. A narrative review by Zöch et al $^{17}$ describes the effects of rehabilitation of ligamentous ankle injuries. They conclude that improvement in proprioception is important in ankle rehabilitation, and could be associated with better postural control. Van Os et al $^{18}$ compared supervised rehabilitation for treatment of acute lateral ankle sprains to usual care. The authors found limited evidence that the addition of supervised exercises results in greater reduction of swelling and faster return to work. The effects of exercise therapy and manual mobilisation of the ankle joint as common physiotherapy interventions in acute ankle sprains and functional instability are not yet described in a meta-analysis. The objective of this study is to evaluate qualitatively and quantitatively the effectiveness of exercise therapy and manual mobilisation of the ankle joint in acute ankle sprains and in patients with functional instability. This systematic review was performed to collect evidence to update the Clinical Practice Guideline Ankle Injury of the Royal Dutch Society for Physical Therapy (KNGF). 


\section{METHOD}

\section{Literature Search}

Two reviewers (TL and PvdW) searched computerised databases independently. The following databases were searched: MEDLINE (1966 to March 2005) , EMBASE (1988 to March 2005), CINAHL (1982 to March 2005). In addition the Cochrane Central Register of Controlled Trials (2005, Issue 1), the PEDro database (to March 2005) and the DocOnline database (to March 2005) of the Dutch Institute of Allied Health Professions were searched. Subject specific search was based on combinations of 'ankle', 'sprains', 'injuries', 'prevention', 'ligamentous', 'lateral', 'functional instability', 'rehabilitation', 'physiotherapy', physical therapy'. Finally, references from retrieved articles were screened.

\section{Types of studies}

This review includes randomised controlled trials (RCTs). Full text articles until March 2005, published in English, German or Dutch, were considered for this study. To determine whether a study should be included, the abstracts of all identified articles were assessed by both reviewers. If there was any doubt, the full text article was retrieved and read independently by both reviewers. Disagreement was resolved by consensus.

\section{Types of participants}

Trials that include patients with acute ankle sprain, or with functional instability, or trials with a recognisable subgroup with a history of ankle injury were considered. In acute ankle sprain symptoms may be pain, swelling and functional disability. Functional instability includes residual problems after acute injury as recurrent sprains, feeling of giving way or feeling of apprehension.

\section{Types of interventions}

At least one of the interventions in the trial had to be an intervention aimed at exercise therapy (including proprioceptive training, co-ordination training, strength training or functional exercises), or at manual mobilisation of the ankle joint. The intervention had to be compared with placebo, no treatment or other interventions.

\section{Outcome measures}

At least one of the following outcome measures had to be used for inclusion in this study: recurrent sprains, functional disability, gait pattern, subjective instability, postural control, ankle joint range of motion, pain. 


\section{Quality assessment}

Two reviewers (PvdW and TL) assessed the methodological quality independently. A slightly modified version of the Amsterdam-Maastricht consensus list ${ }^{19}$ was used to assess the quality of the internal validity of the studies. The list of criteria for assessment of the methodological quality is shown in Table 1. The reviewers scored each item with a 'Yes' (sufficient information is available and bias is considered to be unlikely) , 'No' (bias was considered to be likely), or 'Don't know' (insufficient information is given, the criterion is rated as inconclusive). Positive scores (Yes) were added. A study was considered high quality when it had a minimum score of 4. Disagreement was followed by discussion, followed if necessary by scrutiny from another reviewer $(\mathrm{EH})$.

\section{Data collection}

Two reviewers (PvdW and TL) extracted the data independently from the studies using a standard data-extraction form and cross checked for accuracy. Disagreement was resolved by a consensus procedure, followed, if necessary by scrutiny from a third reviewer (EH). When appropriate and possible, additional data were obtained from authors of the studies.

\section{Data analysis}

For dichotomous outcomes we calculated Relative Risks (RR) and 95\% confidence intervals $(\mathrm{Cl})$. For continuous outcomes, Standardized Mean Differences (SMD) were calculated. RR and SMD were calculated for three most common outcome measures (recurrent sprains, postural sway, range of motion), when sufficient data were available. A random effects model was used if the studies or subgroups of studies were considered clinically heterogeneous; otherwise where appropriate a fixed effects model was used to pool the outcomes.

\section{Best evidence synthesis}

Further analysis to weigh the quality of the evidence from the selected studies was done using a rating system with a hierarchy of four levels. The strength of the evidence of combined studies is also expressed in four levels. The levels of evidence are derived from the methodology used in clinical practice guidelines and are shown in Table 2. 


\section{RESULTS}

Selection of studies is shown in figure 1. After extraction of doubles and inclusion of manually retrieved articles, 198 titles were considered for initial selection. Based on the abstracts 169 studies were excluded. Twenty-nine full text articles were retrieved for further analysis, resulting in exclusion of another twelve studies. Two studies did not meet the criteria for study design ${ }^{20,21}$; six studies did not meet the intervention criteria ${ }^{2,7,22-25}$, in three studies the patients did not meet the criteria $^{26-28}$ and in one study the outcome measure led to exclusion ${ }^{29}$. As a result 17 studies were included in this systematic review.

Table 3 shows the methodological quality of the studies. The average score of the studies was 3.1 (range 1-7). Six studies were considered high quality ${ }^{3,30-34}$ at the A2 level. Identical timing of outcome measures (V8) had a positive score in all studies, while eight studies had a positive score for loss to follow-up (V7). None of the studies scored positive on blinding of the therapist (V5).

An overview of the studies is shown in Table 4 which describes the population, intervention, outcome measures and results. Eight studies concerned patients with (sub)acute ankle sprain ${ }^{30-33,35-38}$. Patients with functional instability were included in six studies ${ }^{1,3,39-42}$. One study included patients with both (sub)acute and chronic ankle injuries $^{34}$. Two studies included cohorts of sports players with a recognizable subgroup with history of ankle injury ${ }^{43,44}$.

\section{Interventions}

In thirteen studies ${ }^{1,3,33,35-44}$ the intervention included exercise therapy. A wobble board, ankle disc or tilt board was used in nine studies ${ }^{1,33,35,36,38,39,42-44}$. In three studies $^{33,35,37}$ exercise therapy was embedded in a multi-facetted intervention under supervision of a physiotherapist. Four studies ${ }^{30-32,34}$ studied the specific effects of manual mobilisation.

Effect sizes of the different interventions for three most common outcome measures (recurrent sprains, postural sway, range of motion) are listed in table 5. Relative Risks (RR) are calculated for the incidence of recurrent injuries and Standardised Mean Differences (SMD) for postural sway and range of motion. 
Figure 1: Selection of studies

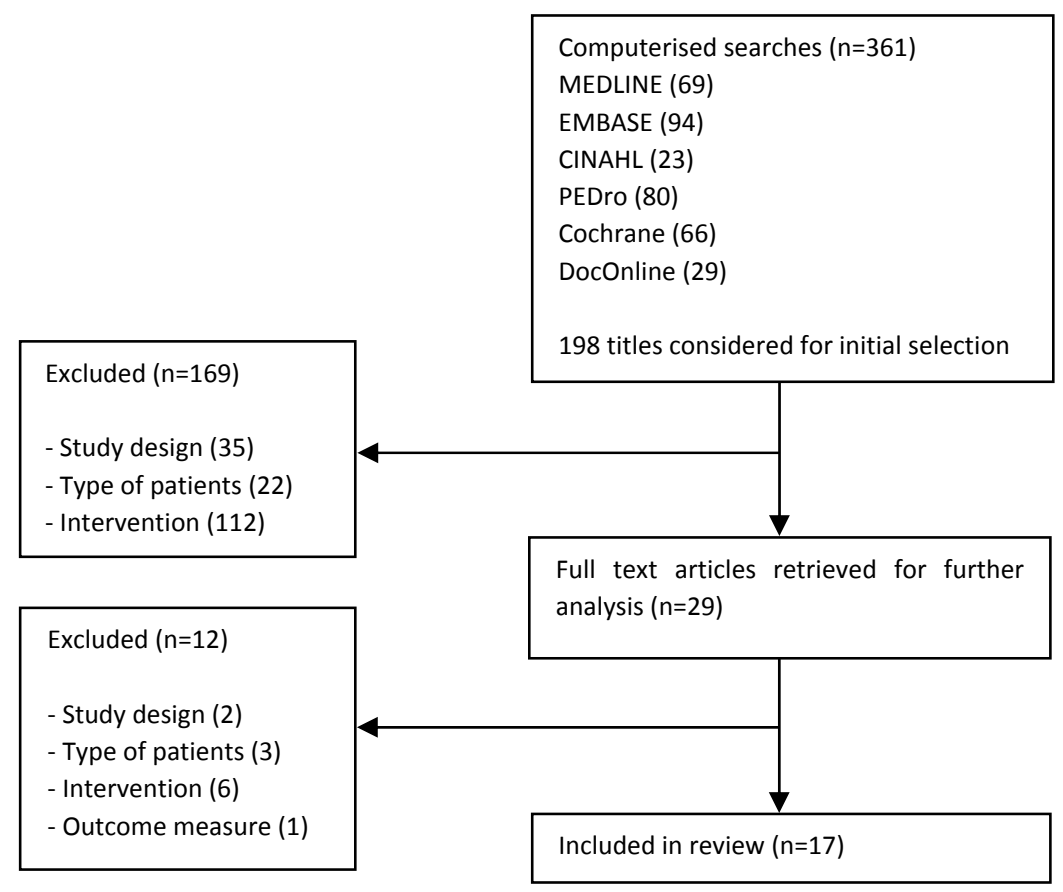

Table 3: Quality of studies

\begin{tabular}{|c|c|c|c|c|c|c|c|c|c|c|c|c|}
\hline Study & V1 & $\mathrm{V} 2$ & V3 & V4 & V5 & V6 & V7 & V8 & V9 & V10 & Score & Quality \\
\hline Bernier & - & - & - & - & - & + & + & + & - & - & 3 & $B$ \\
\hline Brooks & - & - & - & - & - & - & - & + & - & - & 1 & B \\
\hline Collins & - & - & - & + & - & + & + & + & - & + & 5 & $\mathrm{~A} 2$ \\
\hline Eils & - & + & - & - & - & - & - & + & - & - & 2 & B \\
\hline Eisenhart & - & + & + & + & - & - & - & + & - & - & 4 & $\mathrm{~A} 2$ \\
\hline Green & + & - & - & + & - & - & + & + & - & + & 5 & $\mathrm{~A} 2$ \\
\hline Hess & - & - & + & - & - & - & - & + & - & - & 2 & B \\
\hline Hoiness & + & + & + & + & - & - & + & + & + & - & 7 & $\mathrm{~A} 2$ \\
\hline Holme & + & - & - & - & - & - & - & + & - & - & 2 & B \\
\hline Nilsson & - & - & - & - & - & - & + & + & - & - & 2 & B \\
\hline Oostendorp & - & - & - & - & - & - & + & + & + & + & 4 & $\mathrm{~A} 2$ \\
\hline Pellow & + & - & - & - & - & + & + & + & - & - & 4 & $\mathrm{~A} 2$ \\
\hline Powers & - & - & - & - & - & - & - & + & - & + & 2 & B \\
\hline Stasinopoulos & + & - & - & - & - & - & - & + & - & - & 2 & B \\
\hline Tropp & - & - & - & - & - & - & $*$ & + & - & - & 1 & B \\
\hline Verhagen & - & + & - & - & - & - & - & + & - & + & 3 & B \\
\hline Wester & + & - & - & - & - & - & + & + & - & - & 3 & B \\
\hline
\end{tabular}

* study design allows 'voluntary' withdrawals in experimental group 


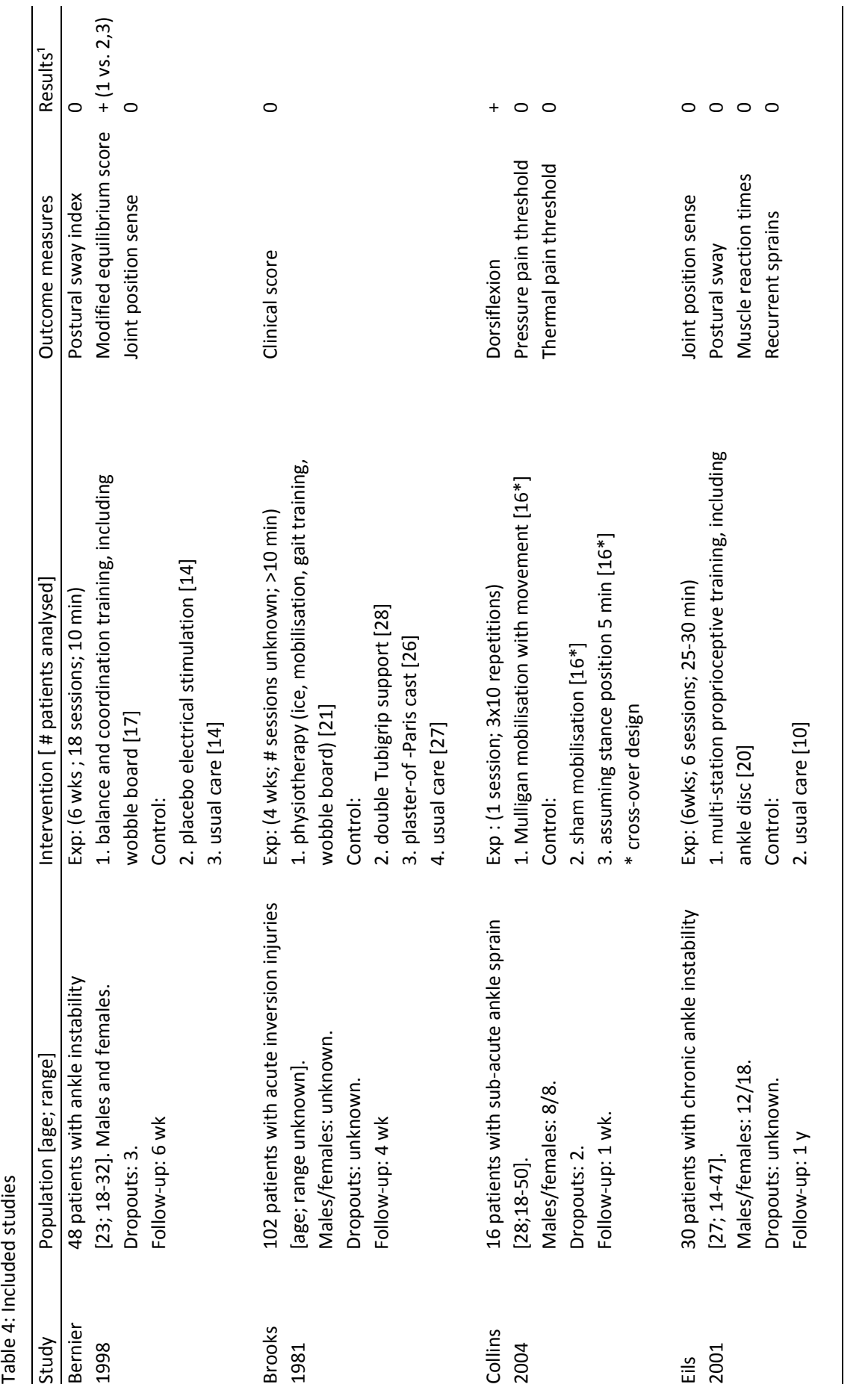




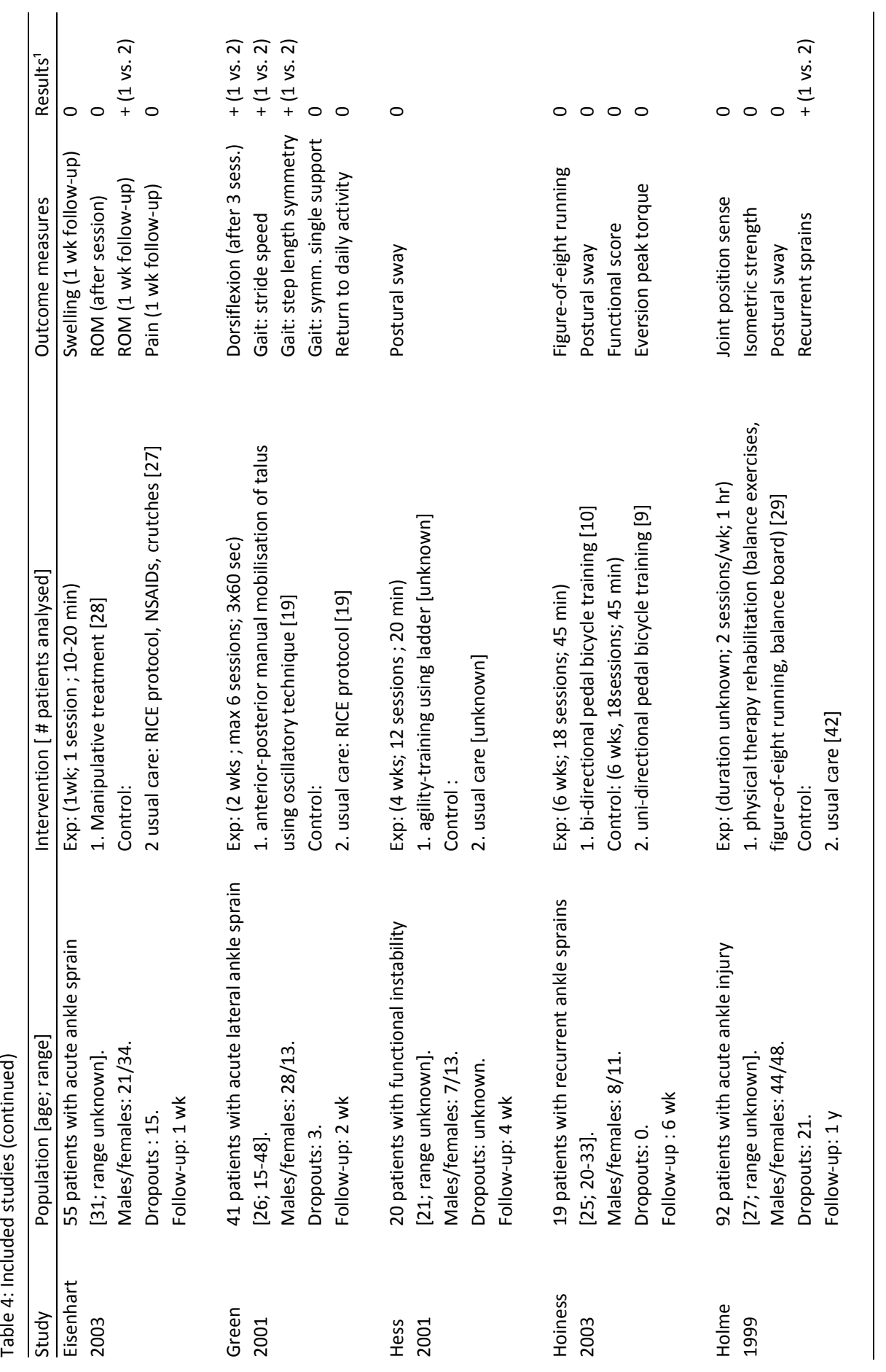




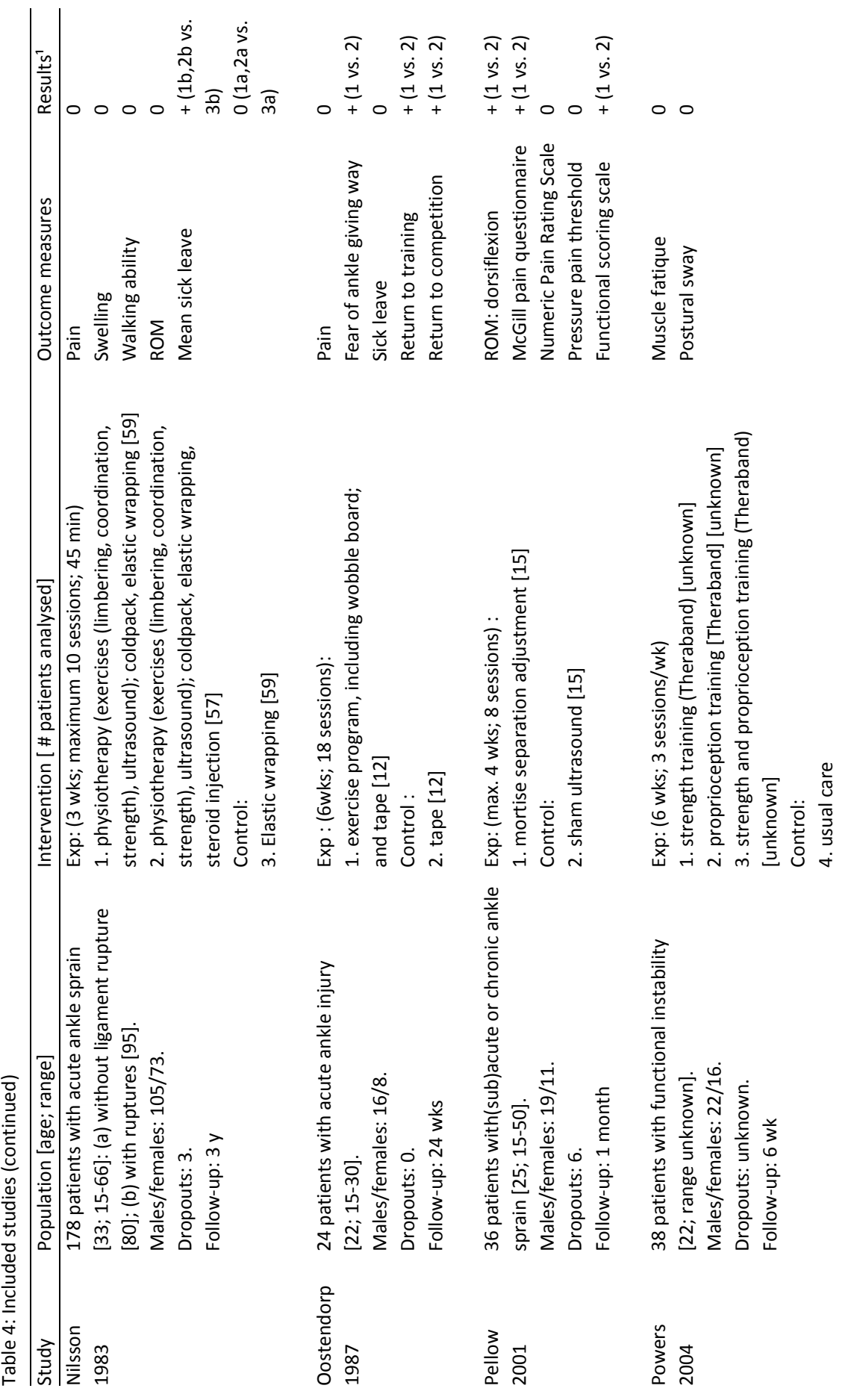




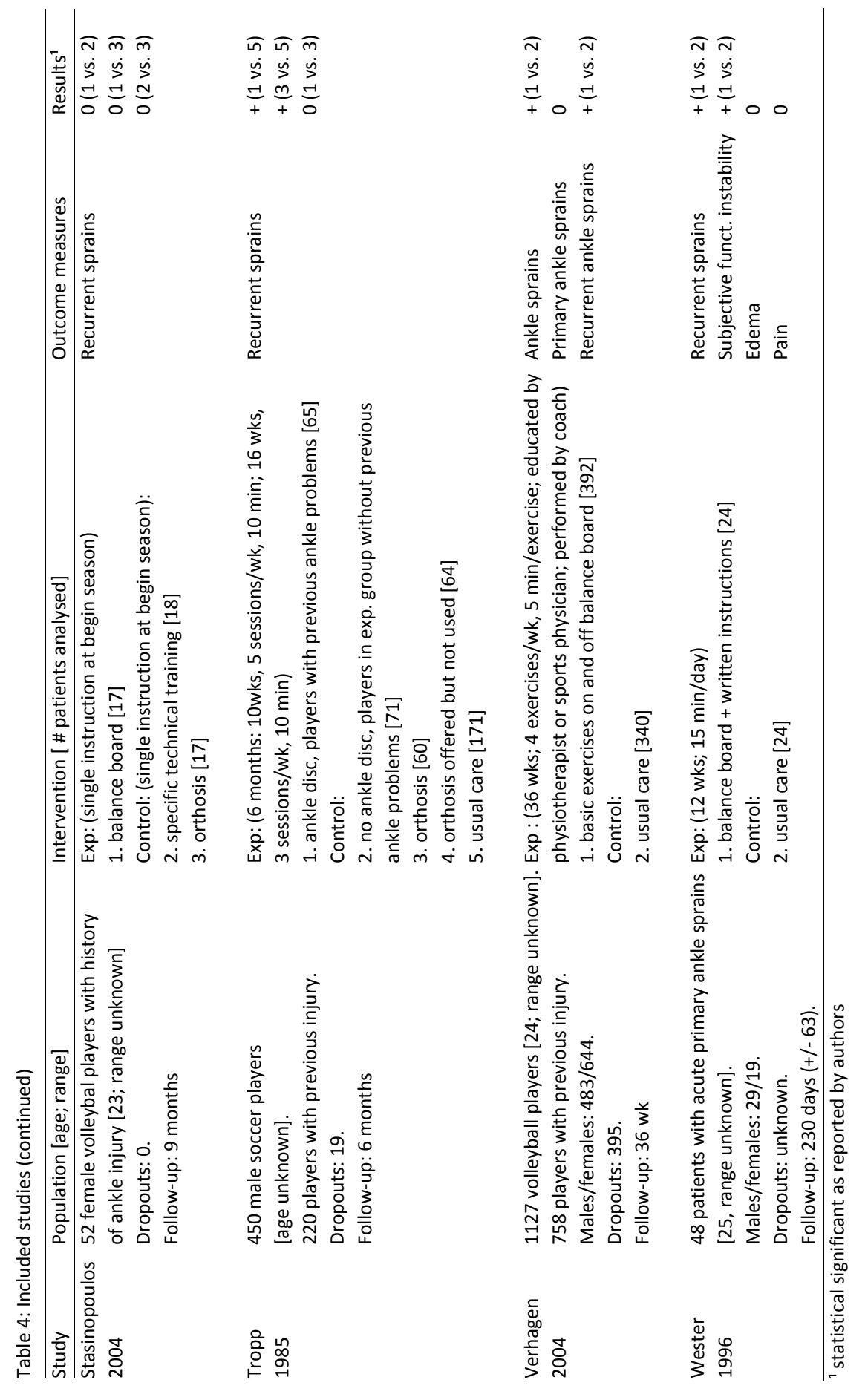




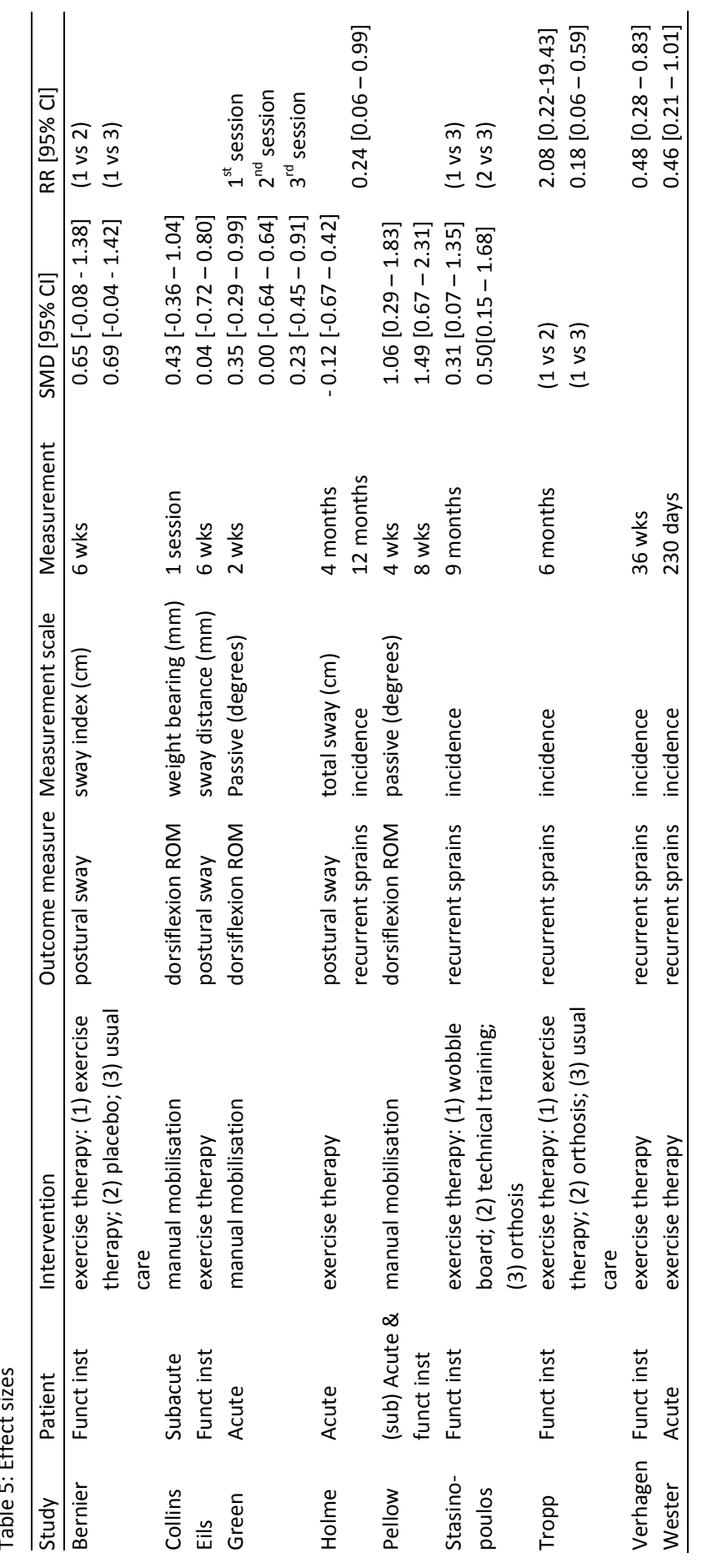




\section{Exercise therapy}

Exercise therapy versus usual care

Eight studies compared exercise therapy with usual care ${ }^{1,35,36,38,40,41,43,44}$. In five of these studies the effect of exercise therapy was related to the incidence of recurrent injuries: Holme et $\mathrm{al}^{36}$, Tropp et $\mathrm{al}^{43}$, Verhagen et $\mathrm{al}^{44}$ and Wester et $\mathrm{al}^{38}$ found less recurrent injuries in the experimental groups that received exercise therapy, while Eils and Rosenbaum ${ }^{1}$ described no differences between experimental and control groups.

Concerning patients with acute ankle sprains, pooling of the results was possible for two studies ${ }^{36,38}$. The pooled results show a statistical significant RR of 0.37 (95\%Cl: 0.18-0.74) in favour of exercise therapy (Table 6). Pooling was also possible in two studies for patients with functional instability ${ }^{43,44}$. These pooled results show a statistical significant RR of $0.38(95 \% \mathrm{Cl}: 0.23-0.62)$ in favour of exercise therapy (Table 6).

It is likely (level 2) that exercise therapy is effective in the prevention of recurrent ankle sprains, both for patients with acute ankle sprain and with functional instability

The effect of exercise therapy on postural sway was investigated in six stud-

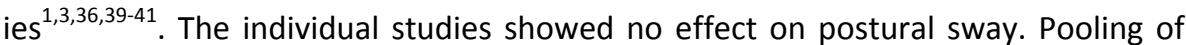
the results of two studies with patients with functional instability ${ }^{1,39}$ resulted in a non-significant Standardized Mean Difference (SMD) of 0.38 (95\% Cl: $-0.15-0.91$ ) (Table 6).

It is likely (level 2) that exercise therapy for patients with functional instability has no effect on postural sway

Brooks et $\mathrm{al}^{35}$ found no clinical effects of a physiotherapy program (including ice, mobilisation, gait training, wobble board), using a 'clinical score' (score of 0-3 points on pain, swelling and bruising) as outcome measure.

\section{Exercise therapy versus external support}

Five studies $33,35,37,42,43$ compared a physiotherapy program including exercise therapy versus external support only. Nilsson et $a^{37}$ found a difference in mean sick leave in patients with ligament ruptures in favour of two experimental physiotherapy groups compared to elastic wrapping. Oostendorp et al $^{33}$ found no differences in sick leave after 6, 12 and 24 weeks between physiotherapy including tape, versus tape alone. Brooks et $a^{35}$ found no difference between physiotherapy versus tubi- 
grip support using a clinical score. Oostendorp et $\mathrm{al}^{33}$ describe a positive effect in favour of physiotherapy intervention for fear of ankle giving way at 6 weeks and at 24 weeks follow-up, but not at 12 weeks. Oostendorp et al also found positive effects in favour of physiotherapy at 12 week follow-up on return to training and return to sports competition.

Table 6: Pooled effect sizes

\begin{tabular}{|c|c|c|c|c|}
\hline \multirow[t]{2}{*}{ Intervention } & \multirow[t]{2}{*}{ Patients } & \multirow[t]{2}{*}{ Studies } & \multirow[t]{2}{*}{$\operatorname{RR}[95 \% \mathrm{Cl}]$} & \multirow{2}{*}{$\begin{array}{l}\text { Pooled RR }[95 \% \mathrm{Cl}] \\
\text { Fixed effects model }\end{array}$} \\
\hline & & & & \\
\hline \multicolumn{5}{|l|}{ Recurrent sprains } \\
\hline Exercise therapy & Acute ankle sprain & Holme & 0.24 [0.06-0.99] & $0.37[0.18-0.74]^{*}$ \\
\hline vs. control & & Wester & $0.46[0.21-1.01]$ & \\
\hline Exercise therapy & Functional instability & Tropp & 0.18 [0.06-0.59] & $0.38[0.23-0.62]^{* *}$ \\
\hline vs. control & & Verhagen & $0.48[0.28-0.83]$ & \\
\hline Exercise therapy & Functional instability & Stasinopoulos & 0.50 [0.15-1.68] & $0.76[0.27-2.11]$ \\
\hline vs. orthosis & & Tropp & 2.08 [0.22-19.34] & \\
\hline \multicolumn{5}{|l|}{ Postural Sway } \\
\hline Exercise therapy & Acute ankle sprain & Bernier & $0.69[-0.04-1.42]$ & $0.38[-0.15-0.91]$ \\
\hline vs. control & & Eils & $0.04[-0.72-0.80]$ & \\
\hline
\end{tabular}

Tropp et al $^{43}$ and Stasinopoulos ${ }^{42}$ found no differences between wobble board exercises versus external support using an orthosis on recurrent sprains in sports players patient with a history of ankle sprains. Statistical pooling (table 6) of both studies resulted in a non-significant RR of 0.76 [95\% $\mathrm{Cl}: 0.27-2.11$.

\section{Exercise therapy versus Immobilisation}

Only Brooks et $\mathrm{al}^{35}$ examined the effect of physiotherapy versus immobilisation (Plaster-of-Paris). No differences were found using a clinical score as outcome measure.

\section{Comparison of different exercise therapy modes}

Hoiness et $\mathrm{al}^{3}$ compared two different modes of exercise therapy, using a bidirectional versus unidirectional pedal bicycle training program in patients with functional instability of the ankle. None of the outcome measures showed any difference.

Stasinopoulos ${ }^{42}$ compared wobble board exercises with a specific technical training program and found no difference in the incidence of recurrent ankle sprains. 


\section{Manual mobilisation}

Four studies investigated the effects of manual mobilisation versus placebo treatment $^{30,34}$ or usual care ${ }^{31,32}$. Green et al ${ }^{32}$ compared manual mobilisation on patients with acute ankle sprain. The intervention consisted of anterior-posterior mobilisation of the talus ( 3 sessions in total follow-up of two weeks). The authors found a positive effect on dorsiflexion range of motion during the first three treatment sessions. The authors also found an increase in stride speed (first and third session). At the second session the intervention group showed greater gains in step length symmetry. This difference had vanished at the third session. No differences were found for return to normal activity.

The effects of Mulligan's mobilisation with movement technique was studied by Collins et $\mathrm{al}^{30}$. The initial effects of manual mobilisation with sub-acute ankle sprains on dorsiflexion range of motion (both pressure pain and thermal pain) were evaluated. Using a cross-over design an initial effect of Mulligan's technique on dorsiflexion range of motion for pre- to post-application in one session was found, compared to placebo and control group.

Pellow and Brantingham ${ }^{34}$ studied the effect of a mortise separation adjustment, described by the authors as a chiropractic technique. A positive effect on dorsiflexion range of motion, pain and functional score until one month follow-up was found. Manual mobilisation using osteopathic manipulative technique was studied by Eisenhart et $\mathrm{al}^{31}$. A significant difference in delta-range of motion (difference between injured and contralateral ankle in range of motion from active plantarflexion to dorsiflexion) was found in favour of the experimental group, one week after injury.

It is likely (level 2) that manual mobilisation has an initial effect on dorsiflexion range of motion after ankle sprains.

\section{DISCUSSION}

\section{Prevention of recurrent injuries}

The main finding of this review is that exercise therapy is effective in the prevention of recurrent ankle sprains. This finding is both important for strategies in treating acute ankle sprains and functional instability. Verhagen et $\mathrm{al}^{44}$ suggest that the effect of exercise therapy is not only relevant for prevention of injuries but also may have a rehabilitative effect in the treatment of acute ankle sprains. This is in accordance with the study by Tropp et $\mathrm{al}^{43}$, who found that ankle disk training reduced the incidence of ankle sprains among soccer players with a history of ankle 
problems to the same level as men without history of ankle problems. Their studies indicate that exercise therapy is an effective prophylactic for people with acute ankle sprains and/or chronic functional instability, who are at risk for the incidence of recurrent injuries.

It is not clear from this review what mechanism lies underneath the effect of exercise therapy. Tropp et al $^{43}$ suggested that functional factors such as postural control are important in the development of functional instability and a predisposition to recurrent sprains. However, this review shows no effects of exercise therapy on postural sway.

The effects of exercise therapy on other outcome measures are unclear. Two studies ${ }^{33,38}$ show effects of exercise therapy on the subjective feeling of giving way, but their findings are not consistent during follow-up.

\section{Manual mobilisation}

This review shows that manual mobilisation has an (initial) effect on dorsiflexion range of motion. Two studies ${ }^{30,31}$ used a single session intervention to measure the effects with a follow-up of one week, while Green et $a^{32}$ describe an intervention of 3 sessions with a follow-up of 2 weeks. The clinical relevance of these initial effects may be limited, because the short-term follow-up does not give sufficient insight in functional consequences. Green et $\mathrm{al}^{32}$ found no effects on return to normal activity, while Collins et $\mathrm{al}^{30}$ assumed a wash-out of the effect after 24 hours in their cross-over design.

\section{Methodological limitations}

Since only six studies were considered high quality, the results must be viewed in perspective to the poor methodological quality of the individual studies. However, the nature of the interventions does not allow a design that meets all methodology criteria. For example: blinding of therapist and blinding of patients is usually impossible in studies with physiotherapy interventions. Therefore we used a low cut-off point (4 points) for considering a study as 'high quality'.

The best-evidence synthesis using a rating system based on the quality of the individual studies, has its limitations. Rating is to some extent subjective, and since systematic reviews were not considered in this study, an A1 quality level was impossible to score. However, by ranking the evidence base of the conclusions some insight is gained in the strength of the conclusions.

Two studies ${ }^{43,44}$ included cohorts of sports players. These studies include a high number of participants (range: 180-1127) and therefore provide a lot of power. However, these studies used a method of cluster randomisation (randomisation of 
teams) which may influence the outcome of the study. Analysis of individual participants while not regarding their cluster can be a potential bias.

This review includes patients with (sub)acute ankle sprains and with functional instability. In order to make valid conclusions different subgroups were considered in the analysis. However, no clear definition exists for the difference subgroups. Definitions of time-period after injury to distinguish between acute, sub-acute and chronic problems vary. Also the definition of functional instability is subject of debate. The conclusions of this review should be viewed in this perspective.

\section{Outcome measures}

The studies in this review show a variety of outcome measures for evaluating the effects of the interventions. Recurrent sprains and postural sway were each used as outcome measures in six studies, while range of motion was used in five studies. The nature of the main outcome measures are quite different and may also be of different quality and clinical relevance. The incidence of recurrent sprains seems to be a reliable, valid and clinical relevant measure, although the definitions used for 'recurrent sprains' were not clearly described in all studies.

Postural sway was measured using a force plate or balance system, measuring the sway (distance) from the center of gravity while standing on one leg. Reliability, validity and responsiveness of these systems are not described. Postural sway is a commonly used outcome measure to assess proprioceptive deficits. The relevance of postural sway to detect proprioceptive deficits in relation to functional ankle instability, as well as other outcome measures e.g. joint position sense, joint movement sense, reflex response time, is subject to debate. Stefanini and Marks conducted a narrative review to evaluate the relationship between proprioception and recurrent ankle inversion injuries ${ }^{45}$. Their review shows that postural sway seems to be impaired in ankle sprain populations, but the review also shows that the relationship between ankle sprain, proprioceptive deficits and the assessment of ankle proprioception remains unclear.

\section{Clinical relevance for physiotherapy practice}

Exercise therapy and manual mobilisation are common interventions in physiotherapy treatment. In twelve studies the intervention included exercise therapy, although only in five studies the intervention was carried out by a physiotherapist, while in two studies a physiotherapist gave only initial instructions for the exercise program. Therefore, not all interventions can be seen as a specific physiotherapy intervention, which may influence the clinical relevance of some studies for physiotherapy practice. 
Two studies on manual mobilisation ${ }^{31,34}$ concerned techniques which are not used by physiotherapists. Manual therapists also not commonly use these techniques. Therefore these studies have limited value for physiotherapy treatment, although the outcome may be used to increase the body of knowledge concerning manual mobilisation in physiotherapy.

These limitations for clinical practice must be considered in formulating recommendations in the Clinical Practice Guideline Ankle Injury.

The conclusions of this study are that it is likely (level 2) that exercise therapy, which includes the use of a wobble board, is effective for patients with functional instability in the prevention of recurrent ankle sprains. Other effects of exercise therapy are unclear. It is likely (level 2) that manual mobilisation has an (initial) effect of dorsiflexion range of motion, but the clinical relevance of these findings may be limited. The results of this review must be viewed in perspective to the poor methodological quality and heterogeneity of the studies. 


\section{REFERENCES}

1. Eils $E$, Rosenbaum D. A multi-station proprioceptive exercise program in patients with ankle instability. Med Sci Sports Exerc. 2001;33:1991-1998.

2. Freeman MA. Treatment of ruptures of the lateral ligament of the ankle. J Bone Joint Surg Br. 1965;47:661-668.

3. Hoiness $\mathrm{P}$, Glott $\mathrm{T}$, Ingjer $\mathrm{F}$. High-intensity training with a bi-directional bicycle pedal improves performance in mechanically unstable ankles--a prospective randomized study of 19 subjects. Scand J Med Sci Sports. 2003;13:266-271.

4. Moller-Larsen F, Wethelund JO, Jurik AG, De Carvalho A, Lucht U. Comparison of three different treatments for ruptured lateral ankle ligaments. Acta Orthop Scand. 1988;59:564-566.

5. Van Dijk CN. On diagnostic strategies in patients with severe ankle sprain (thesis). University of Amsterdam, 1994.

6. Van Moppes FI, Van den Hoogenband CR. Diagnostic and therapeutic aspects of inversion trauma of the ankle joint. Maastricht University, 1982.

7. Karlsson J, Eriksson BI, Sward L. Early functional treatment for acute ligament injuries of the ankle joint. Scand J Med Sci Sports. 1996;6:341-345.

8. Balduini FC, Vegso JJ, Torg JS, Torg E. Management and rehabilitation of ligamentous injuries to the ankle. J Sports Med. 1987;4:364-380.

9. Pope R, Herbert R, Kirwan J. Effects of ankle dorsiflexion range and pre-exercise calf muscle stretching on injury risk in Army recruits. Aust J Physiother. 1998;44:165-172.

10. Handoll HHG, Rowe BH, Quinn KM, De Bie R. Interventions for preventing ankle ligament injuries. Cochrane Database Syst Rev. 2001.

11. Kerkhoffs GMMJ, Handoll HHG, De Bie R, Rowe BH, Struijs PAA. Surgical versus conservative treatment for acute injuries of the lateral ligament complex of the ankle in adults. Cochrane Database Syst Rev. 2002.

12. Kerkhoffs GMMJ, Struijs PAA, Marti RK, Assendelft WJJ, Blankevoort L, Van Dijk CN. Different functional treatment strategies for acute lateral ankle ligament injuries in adults. Cochrane Database Syst Rev. 2002.

13. Kerkhoffs GM, Rowe BH, Assendelft WJ, Kelly K, Struijs PA, van Dijk CN. Immobilisation and functional treatment for acute lateral ankle ligament injuries in adults. Cochrane Database Syst Rev. 2002; CD003762.

14. Van der Windt DAWM, Van der Heijden GJMG, Van den Berg SGM, Ter Riet R, De Winter AF, Bouter LM. Ultrasound Therapy for acute ankle sprains. Cochrane Database Syst Rev. 2002.

15. Verhagen EALM, Van Mechelen W, De Vente W. The effect of preventive measures on the incidence of ankle sprains. Clin J Sports Med. 2000;10:291-296.

16. Gezondheidsraad. De effectiviteit van fysische therapie: elektrotherapie, lasertherapie, ultrageluidbehandeling. Den Haag: Gezondheidsraad, 1999.

17. Zoch C, Fialka-Moser V, Quittan M. Rehabilitation of ligamentous ankle injuries: a review of recent studies. Br J Sports Med. 2003;37:291-295.

18. van Os AG, Bierma-Zeinstra SM, Verhagen AP, de Bie RA, Luijsterburg PA, Koes BW. Comparison of conventional treatment and supervised rehabilitation for treatment of acute lateral ankle sprains: a systematic review of the literature. J Orthop Sports Phys Ther. 2005;35:95-105.

19. Smidt N, Assendelft WJJ, Van der Windt DAWM, Hay EM, Buchbinder R, Bouter LM. Corticosteroid injections for lateral epicondilytis: a systematic review. Pain. 2002;96:23-40.

20. Bahr R, Lian O, Bahr IA. A twofold reduction in the incidence of acute ankle sprains in volleyball after the introduction of an injury prevention program: a prospective cohort study. Scand J Med Sci Sports. 1997;7:172-177. 
21. Hart LE, Macintyre J. Passive joint mobilization for acute inversion sprains. Clinical J Sports Medicine. 2002;12:54.

22. Coetzer D, Brantinham J, Nook B. The relative effectiveness of piroxam compared to manipulation in the treatment of acute grade 1 and 2 inversion ankle sprains. J Neuromusculoskeletal Systems. 2001;9:1-12.

23. Ekstrand J, Gillquist J, Liljedahl SO. Prevention of soccer injuries. Am J Sports Med. 1983;116-120.

24. Matsusaka N, Yokoyama S, Tsurusaki T, Inokuchi S, Okita M. Effect of ankle disk training combined with tactile stimulation to the leg and foot on functional instability of the ankle. Am J Sports Med. 2001;29:25-30.

25. Paris DL, Baynes F, Gucker B. Effects of the neuroprobe in the treatment of second-degree ankle inversion sprains. Phys Ther. 1983;63:35-40.

26. Fryer GA, Mudge JM, McLaughlin PA. The effect of talocrural joint manipulation on range of motion at the ankle. J Manipulative Physiol Ther. 2002;25:384-390.

27. Soderman K, Werner S, Pietila T, Engstrom B, Alfredson H. Balance board training: prevention of traumatic injuries of the lower extremities in female soccer players? A prospective randomized intervention study. Knee Surg Sports Traumatol Arthrosc. 2000;8:356-363.

28. Wedderkopp N, Kaltoft M, Lundgaard B, Rosendahl M, Froberg K. Prevention of injuries in young female players in European team handball. A prospective intervention study. Scand J Med Sci Sports. 1999;9:41-47.

29. Kaminski TW, Buckley BD, Powers ME, Hubbard TJ, Ortiz C. Effect of strength and proprioception training on eversion to inversion strength ratios in subjects with unilateral functional ankle instability. Br J Sports Med. 2003;37:410-415.

30. Collins N, Teys P, Vincenzino B. The initial effects of Mulligan's mobilization with movement technique on dorsiflexion and pain in subacute ankle sprains. Manual Therapy. 2004;9:77-82.

31. Eisenhart AW, Gaeta TJ, Yens DP. Osteopathic Manipulative Treatment in the emergency department for patients with acute ankle injuries. J Am Ostheopath Assoc. 2003;103:417-421.

32. Green T, Refshauge K, Crosbie J, Adams R. A randomized controlled trial of a passive accessory joint mobilization on acute ankle inversion sprains. Phys Ther. 2001;81:984-994.

33. Oostendorp RAB. Functionele instabiliteit na het inversietrauma van de enkel en voet: een effectonderzoek van pleisterbandage versus pleisterbandage gecombineerd met fysiotherapie (Functional instability after ankle sprains; a trial of taping versus taping and exercise). Geneeskunde en Sport. 1987;20:45-55.

34. Pellow JE, Brantingham JW. The efficacy of adjusting the ankle in the treatment of Subacute and Chronic Grade I and Grade II Ankle Inversion Sprains. Journal of Manipulative and Physiological Therapeutics. 2001;24.

35. Brooks SC, Potter BT, Rainey JB. Treatment for partial tears of the lateral ligament of the ankle: a prospective trial. Br Med J (Clin Res Ed). 1981;282:606-607.

36. Holme E, Magnusson SP, Becher K, Bieler T, Aagaard P, Kjaer M. The effect of supervised rehabilitation on strength, postural sway, position sense and re-injury risk after acute ankle ligament sprain. Scand J Med Sci Sports. 1999;9:104-109.

37. Nilsson S. Sprains of the lateral ankle ligaments. J Oslo City Hosp. 1983;33:13-36.

38. Wester JU, Jespersen SM, Nielsen KD, Neumann L. Wobble board training after partial sprains of the lateral ligaments of the ankle: a prospective randomized study. J Orthop Sports Phys Ther. 1996;23:332-336.

39. Bernier JN, Perrin DH. Effect of coordination training on proprioception of the functionally unstable ankle. J Orthop Sports Phys Ther. 1998;27:264-275.

40. Hess DM, Joyce CJ, Arnold BL, Gansneder BM. The effect of a 4-week agility-training program on postural sway in the functionally unstable ankle. J Sport Rehabil. 2001;24:17-24. 
41. Powers ME, Buckley BD, Kaminski TW, Hubbard TJ, Ortiz C. Six weeks of strength and proprioception training does nof affect muscle fatigue and static balance in functional ankle instability. J Sport Rehabil. 2004;13:201-227.

42. Stasinopoulos D. Comparison of three preventive methods in order to reduce the incidence of ankle inversion sprains among female volleyball players. Br J Sports Med. 2004;38:182-185.

43. Tropp H, Askling C, Gillquist J. Prevention of ankle sprains. Am J Sports Med. 1985;13:259-262.

44. Verhagen EALM, Van der Beek AJ, Twisk JWR, Bouter LM, Bahr R, Van Mechelen W. The effect of a proprioceptive balance board training programme for the prevention of ankle sprains. Am J Sports Med. 2004;32:1385-1393.

45. Stefanini L, Marks R. Proprioception and recurrent ankle inversion injuries: A narrative review. $N Z \mathrm{~J}$ Physiother. 2003;31:25-39.

46. CBO. Evidence-based richtlijnontwikkeling. Handleiding voor werkgroepleden. Utrecht: Kwaliteitsinstituut voor de gezondheidszorg CBO, 2005. 


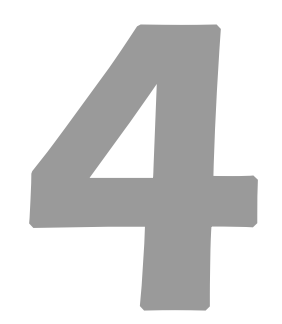

\section{Comparison of international guideline programs to evaluate and update the Dutch program for clinical guideline development in physical therapy}

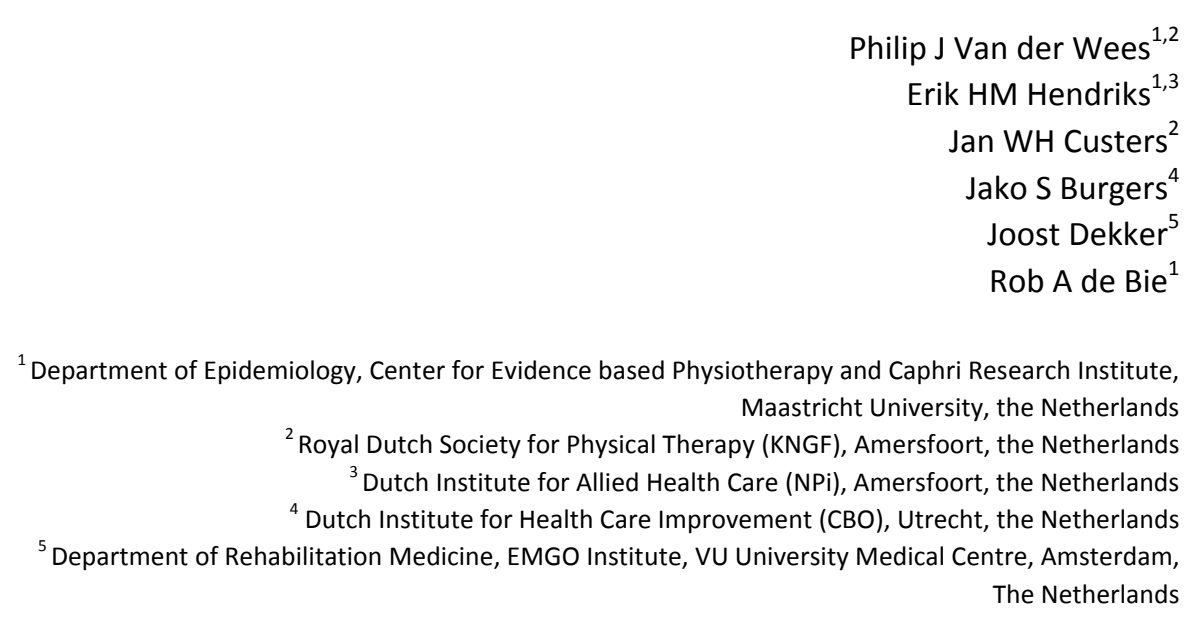

BMC Health Services Research 2007; 7:191 


\begin{abstract}

\section{Background}

Clinical guidelines are considered important instruments to improve quality in health care. Since 1998 the Royal Dutch Society for Physical Therapy (KNGF) produced evidence-based clinical guidelines, based on a standardized program. New developments in the field of guideline research raised the need to evaluate and update the KNGF guideline program.

Purpose of this study is to compare different guideline development programs and review the KNGF guideline program for physical therapy in the Netherlands, in order to update the program.
\end{abstract}

\title{
Method
}

Six international guideline development programs were selected, and the 23 criteria of the AGREE Instrument were used to evaluate the guideline programs. Information about the programs was retrieved from published handbooks of the organizations. Also, the Dutch program for guideline development in physical therapy was evaluated using the AGREE criteria. Further comparison the six guideline programs was carried out using the following elements of the guideline development processes: Structure and organization; Preparation and initiation; Development; Validation; Dissemination and implementation; Evaluation and update.

\section{Results}

Compliance with the AGREE criteria of the guideline programs was high. Four programs addressed 22 AGREE criteria, and two programs addressed 20 AGREE criteria. The previous Dutch program for guideline development in physical therapy lacked in compliance with the AGREE criteria, meeting only 13 criteria.

Further comparison showed that all guideline programs perform systematic literature searches to identify the available evidence. Recommendations are formulated and graded, based on evidence and other relevant factors. It is not clear how decisions in the development process are made. In particular, the process of translating evidence into practice recommendations can be improved.

\section{Conclusion}

As a result of international developments and consensus, the described processes for developing clinical practice guidelines have much in common. The AGREE criteria are common basis for the development of guidelines, although it is not clear how final decisions are made. Detailed comparison of the different guideline programs was used for updating the Dutch program. As a result the updated KNGF program complied with 22 AGREE criteria. International discussion is continuing and will be used for further improvement of the program. 


\section{BACKGROUND}

Development and implementation of evidence-based clinical guidelines are the main focus of health care policy in many countries. Clinical guidelines are 'systematically developed statements designed to help practitioners and patients to make decisions about appropriate health care for specific circumstances' ${ }^{1}$. Also in physical therapy clinical guidelines are considered important instruments to improve quality of care. Since 1998 the Royal Dutch Society for Physical Therapy (KNGF) has produced evidence-based clinical guidelines ${ }^{2}$. KNGF-guidelines were developed using a standardized procedure ${ }^{3,4}$. However, new developments in the field of guideline research raised the need to evaluate and update the current program.

An important reason for updating the development process was the publication of the AGREE Instrument which provides a framework, including 23 criteria, to assess the quality of clinical practice guidelines ${ }^{5}$. The instrument is based on international consensus about methods for developing evidence-based clinical guidelines ${ }^{6,7}$. It also helps guideline developers to structure and improve the process of guideline development. The Dutch network of guideline organizations adopted the AGREE Instrument, and reached consensus in methods for assessing and synthesizing the evidence $^{8,9}$. An international survey of 18 clinical guideline programs also showed a growing international consensus on the structure and working methods of those programs ${ }^{6}$. In 2002 the Guidelines International Network (G-I-N) was founded to promote systematic development of clinical guidelines ${ }^{10}$. The World Confederation for Physical Therapy (WCPT) also published frameworks for guideline development based on international developments ${ }^{11-13}$. Further refinement of the guideline development process is currently subject of international debate. The Advisory Committee on Health Research of the World Health Organization (WHO) has conducted a series of reviews to advise on ways to improve the use of research evidence in guidelines ${ }^{14}$.

One of the key issues in the debate is to formulate criteria for inclusion of considerations beyond the evidence from literature reviews ${ }^{15-17}$.

The aim of this study is to compare a selection of different guideline development programs in detail and to use these findings to review the previous KNGF guideline program in the Netherlands. The results are used to update the KNGF guideline program. 


\section{METHODS}

\section{Study design}

Burgers ${ }^{6}$ defined a guideline program as a structured and coordinated program, designed with the specific aim of producing several clinical practice guidelines. Based on an international survey of 18 clinical guideline programs by Burgers ${ }^{6}$ we selected guideline programs from five organizations: the Dutch Institute for health care improvement (CBO), Netherlands ${ }^{18}$; the National Health and Medical Research Council (NHMRC), Australia ${ }^{19}$; the New Zealand Guidelines Group (NZGG), New Zealand $^{20}$; the Scottish Intercollegiate Guidelines Network (SIGN), Scotland ${ }^{21}$; and the U.S. Preventive Services Task Force (USPSTF), USA ${ }^{22,23}$. Criterion for selection was a publicly available handbook for the development of guidelines, written in English or Dutch. Four of these programs ${ }^{19-23}$ were also included in the review of Schünemann ${ }^{24}$, in which guidelines for the development of guidelines were reviewed by the WHO Advisory Committee on Health Research. In addition we searched databases of the Guidelines International Network ${ }^{25}$, the National Guideline Clearinghouse ${ }^{26}$ and the World Confederation for Physical Therapy ${ }^{27}$, to identify guideline programs specifically aimed at physical therapy. This resulted in the addition of a sixth guideline program, published by the Chartered Society for Physiotherapy $(\mathrm{CSP})^{28}$. No other physical therapy guideline programs were identified. Basic characteristics of the selected guideline programs are shown in table 1.

\section{Data collection and analysis}

The 23 criteria of the AGREE instrument ${ }^{5}$ were used to evaluate the guideline programs, reviewing published handbooks of the six organizations. If necessary, additional information was retrieved from the websites of the organizations. The handbooks were screened by two reviewers to analyze whether the AGREE criteria were addressed in the guideline development process, resulting in positive (+) or negative (-) judgment. Disagreement between reviewers was followed by discussion, in order to reach consensus.

The previous Dutch program for guideline development in Physical Therapy was also evaluated using the AGREE criteria, to identify weaknesses that could lead to improvements of the program.

We further compared the different guideline programs in detail based on the guideline structure by Shekelle ${ }^{7}$. It includes the following elements: (1) Structure and organization; (2) Preparation and initiation; (3) Development; (4) Validation; (5) Dissemination and implementation; (6) Evaluation and update. Information from the handbooks was systematically extracted by one reviewer, and checked by a 
second reviewer. Disagreement between reviewers was followed by discussion, in order to reach consensus.

Table 1. Basic characteristics of guideline programs

\begin{tabular}{llll}
\hline Organization & Country & $\begin{array}{l}\text { Year of first } \\
\text { guideline }\end{array}$ & Total guidelines \\
\hline $\begin{array}{l}\text { CBO }^{18} \\
\begin{array}{l}\text { Dutch Institute for health care improvement } \\
\text { CSP }^{28}\end{array}\end{array}$ & Netherlands & 1980 & $>50$ \\
$\begin{array}{l}\text { Chartered Society for Physiotherapy } \\
\text { NHMRC }\end{array}$ & England & 1998 & $5-10$ \\
$\begin{array}{l}\text { National Health and Medical Research Council } \\
\text { NZGG }\end{array}$ & Australia & 1995 & $10-20$ \\
$\begin{array}{l}\text { New Zealand Guidelines Group } \\
\text { SIGN } \\
\text { Scottish Intercollegiate Guidelines Network }\end{array}$ & New Zealand & 1998 & $>50$ \\
$\begin{array}{l}\text { USPSTF } \\
\text { U.S. Preventive Services Task Force }\end{array}$ & Scotland & 1995 & $>50$ \\
\hline
\end{tabular}

Source: Burgers ${ }^{6}$, added and updated with own data via handbooks and websites

\section{RESULTS}

\section{Compliance with the AGREE criteria}

Compliance with the AGREE criteria in the descriptions of the guideline development process was high. Four organizations (CBO, NHMRC, NZGG, SIGN) complied with 22 out of 23 criteria. The other two organizations (CSP, USPSTF) complied with 20 criteria.

The criterion least met was 'The guideline has been piloted among target users'. In the handbooks of four organizations (CBO, NHMRC, SIGN, USPSTF) piloting of the guideline was not specifically described or recommended. Table 2 shows an overview of compliance to the AGREE criteria in the handbooks of the six organizations.

\section{Evaluation of the Dutch guideline program in physical therapy}

To evaluate the previous Dutch guideline program in physical therapy we also used the AGREE criteria. Identification of weaknesses could then subsequently be used to update the program. In table 3 compliance with the AGREE criteria of the previous Dutch program for clinical guideline development in Physical Therapy is shown. In the previous program only 13 AGREE criteria were met. Compliance was mainly lacking in specific and systematic formulation of recommendations, based on evidence and other considerations. Also, the previous Dutch program did not provide a procedure for updating guidelines. 
Table 2. Compliance to AGREE criteria of six guideline development programs

\begin{tabular}{llllll}
\hline AGREE criteria & CBO & CSP & NHMRC NZGG & SIGN & USPSTF
\end{tabular}

1. The overall objective(s) of the guideline is (are) specifically described.

2. The clinical question(s) covered by the guideline is (are) specifically described.

3. The patients to whom the guideline is meant to apply are specifically described.

4. The guideline development group includes individuals from all the relevant professional groups.

5. The patients' views and preferences have been sought.

6. The target users of the guideline are clearly defined.

7. The guideline has been piloted among target users.

8. Systematic methods were used to search for evidence.

9. The criteria for selecting the evidence are clearly described.

10. The methods used for formulating the recommendations are clearly described.

11. The health benefits, side effects and risks have been considered in formulating the recommendations.

12. There is an explicit link between the recommendations and the supporting evidence.

13. The guideline has been externally reviewed by experts prior to its publication.

14. A procedure for updating the guideline is provided.

15. The recommendations are specific and unambiguous.

16. The different options for management of the condition are clearly presented.

17. Key recommendations are easily identifiable.

18. The guideline is supported with tools for application.

19. The potential organizational barriers in applying the recommendations have been discussed.

20. The potential cost implications of applying the recommendations have been considered.

21. The guideline presents key review criteria for monitoring and/or audit purposes.

22. The guideline is editorially independent from the funding body.

23. Conflicts of interest of guideline development members have been recorded. 
Table 3. Compliance to AGREE criteria of previous and updated KNGF guideline program

\begin{tabular}{|c|c|c|c|}
\hline \multicolumn{2}{|c|}{ AGREE criteria } & \multirow{2}{*}{$\frac{\text { KNGF (previous) }}{+}$} & \multirow{2}{*}{$\frac{\text { KNGF (update) }}{+}$} \\
\hline 1. & $\begin{array}{l}\text { The overall objective(s) of the guideline is (are) specifically } \\
\text { described. }\end{array}$ & & \\
\hline 2. & $\begin{array}{l}\text { The clinical question(s) covered by the guideline is (are) } \\
\text { specifically described. }\end{array}$ & + & + \\
\hline 3. & $\begin{array}{l}\text { The patients to whom the guideline is meant to apply are } \\
\text { specifically described. }\end{array}$ & + & + \\
\hline 4. & $\begin{array}{l}\text { The guideline development group includes individuals } \\
\text { from all the relevant professional groups. }\end{array}$ & + & + \\
\hline 5. & The patients' views and preferences have been sought. & + & + \\
\hline 6. & The target users of the guideline are clearly defined. & + & + \\
\hline 7. & The guideline has been piloted among target users. & - & - \\
\hline 8. & Systematic methods were used to search for evidence. & + & + \\
\hline 9. & $\begin{array}{l}\text { The criteria for selecting the evidence are clearly de- } \\
\text { scribed. }\end{array}$ & + & + \\
\hline 10. & $\begin{array}{l}\text { The methods used for formulating the recommendations } \\
\text { are clearly described. }\end{array}$ & - & + \\
\hline 11. & $\begin{array}{l}\text { The health benefits, side effects and risks have been } \\
\text { considered in formulating the recommendations. }\end{array}$ & - & + \\
\hline 12. & $\begin{array}{l}\text { There is an explicit link between the recommendations } \\
\text { and the supporting evidence. }\end{array}$ & - & + \\
\hline 13. & $\begin{array}{l}\text { The guideline has been externally reviewed by experts } \\
\text { prior to its publication. }\end{array}$ & + & + \\
\hline 14. & A procedure for updating the guideline is provided. & - & + \\
\hline 15. & The recommendations are specific and unambiguous. & - & + \\
\hline 16. & $\begin{array}{l}\text { The different options for management of the condition are } \\
\text { clearly presented. }\end{array}$ & + & + \\
\hline 17. & Key recommendations are easily identifiable. & - & + \\
\hline 18. & The guideline is supported with tools for application. & + & + \\
\hline 19. & $\begin{array}{l}\text { The potential organizational barriers in applying the rec- } \\
\text { ommendations have been discussed. }\end{array}$ & + & + \\
\hline 20. & $\begin{array}{l}\text { The potential cost implications of applying the recommen- } \\
\text { dations have been considered. }\end{array}$ & - & + \\
\hline 21. & $\begin{array}{l}\text { The guideline presents key review criteria for monitoring } \\
\text { and/or audit purposes. }\end{array}$ & - & + \\
\hline 22. & $\begin{array}{l}\text { The guideline is editorially independent from the funding } \\
\text { body. }\end{array}$ & + & + \\
\hline 23. & $\begin{array}{l}\text { Conflicts of interest of guideline development members } \\
\text { have been recorded. }\end{array}$ & - & + \\
\hline
\end{tabular}




\section{COMPARISON OF GUIDELINE DEVELOPMENT PROGRAMS}

\section{Structure and Organization}

Table 4 shows a comparison of the guideline programs based on the six elements of the development process. Five programs are coordinated by a central organization responsible for developing the guidelines. CSP used to endorse guidelines by other groups, as described in the handbook, but started developing guidelines in their own organization recently. Three programs (CSP, NHMRC, NZGG) endorse guidelines developed by other organizations within their country.

\section{Preparation/ Initiation}

Two organizations collect topics through an open procedure (SIGN, USPSTF). Any group or individual may propose a guideline topic to SIGN. USPSTF solicits new topics for consideration from the field through a periodic notice and solicitation of professional liaison organizations. All programs describe criteria for selecting topics. These include: clinical relevance, the number of patients affected, undesired variation in healthcare practice, no existing guidelines available, available evidence to support the guidelines, acceptability of a guideline to potential users. NZGG uses a suitability screen to assess the potential success of a guideline in a particular clinical area. Their key criterion is the ability to demonstrate significant positive changes in outcomes, based on valid scientific studies.

USPSTF prioritizes topics using two specific criteria: the public health importance of the condition to be prevented, and the potential for the USPSTF to affect clinical practice.

\section{Development}

The actual development of a guideline can be divided into four steps: refining subject area and defining questions; identifying the evidence available; assessing and synthesizing the evidence; and translating evidence into recommendations.

Three programs (CBO, CSP, USPSTF) use the scope of the guideline as a framework to refine the subject area and to formulate or refine research questions. NZGG develops a series of key questions using PECOT (Patient-Exposure-ComparisonOutcome-Time).

Identification of the evidence is done by systematic literature search. All programs stress the importance of a well-defined search strategy as part of a systematic review to be performed. Medline, Cinahl, Embase, Cochrane, PEDro are examples of databases used for searching relevant literature. 
Table 4. Comparison of guideline programs

\begin{tabular}{|c|c|c|c|c|c|c|}
\hline & $\mathrm{CBO}$ & CSP & NHMRC & NZGG & SIGN & USPSTF \\
\hline \multicolumn{7}{|l|}{ Structure and Organization } \\
\hline Central coordination of development and program & + & - & + & + & + & + \\
\hline Endorsement of guidelines developed by others & - & + & + & + & - & - \\
\hline \multicolumn{7}{|l|}{ Preparation/initiation } \\
\hline Topics collected through open procedure & - & - & - & - & + & + \\
\hline Criteria described for selection of topics & + & + & + & + & + & + \\
\hline \multicolumn{7}{|l|}{ Development } \\
\hline Quantitative studies considered for analysis & + & + & + & + & + & + \\
\hline Qualitative studies considered for analysis & + & + & - & + & + & - \\
\hline Evidence tables produced to critically appraise studies & + & + & + & + & + & + \\
\hline Strength of evidence graded in levels of hierarchy & + & + & + & + & + & + \\
\hline Recommendations graded in levels linked to evidence & + & + & + & + & + & + \\
\hline \multicolumn{7}{|l|}{ Validation/ external review } \\
\hline Review by referees/ stakeholders & + & + & + & + & + & + \\
\hline Open meeting/conference & + & - & + & - & + & - \\
\hline Consultation of practitioners (peers) & + & + & + & + & + & - \\
\hline Draft guideline available on website for comments & + & - & - & - & + & - \\
\hline \multicolumn{7}{|l|}{ Dissemination /implementation } \\
\hline Publication on website & + & + & + & + & + & + \\
\hline Full guideline published & + & + & + & + & + & + \\
\hline Summary published & + & - & - & + & + & + \\
\hline Patient version published & - & - & - & + & - & - \\
\hline \multicolumn{7}{|l|}{ Evaluation and revision } \\
\hline Timescale for updating guidelines is stated & + & + & + & - & + & + \\
\hline Procedure for updating provided & + & + & + & + & + & + \\
\hline Steps in updating procedure described & + & - & + & - & + & + \\
\hline Continuous updating procedure available & + & - & - & - & - & - \\
\hline
\end{tabular}

The details in assessing the literature vary among the programs, although the approach is similar. All programs perform systematic literature reviews, in which the outcomes of relevant studies are described in evidence tables and related to the methodological quality of the study. The strength of the evidence is classified in levels of evidence, but the classification varies. Four programs explicitly mention the inclusion of qualitative studies in the literature review (CBO, CSP, NZGG, SIGN). The evidence from the studies is used to formulate recommendations, and recommendations are linked to the evidence by grading the recommendations in different levels. Beyond the evidence, other factors are considered in all programs, although USPSTF refrains from making recommendations if they cannot be supported by evidence. SIGN uses the concept of 'considered judgment' to cover these 
factors. A specific form is used to define specific recommendations considering changes to current practice, predicted impact on changes to current practice and economic issues and implications. NHMRC requires balancing of benefits and harms, to assist in formulating recommendations. Table 5 shows an overview of criteria and process of considered judgments by the different programs.

\section{Validation}

All programs organize an external review of draft guidelines by experts and stakeholders. Only two organizations (CBO, SIGN) publish draft guidelines on their website for comments.

\section{Dissemination and implementation}

All programs publish the full guidelines on their websites. NZGG is the only organization that publishes separate patient versions of the guideline.

\section{Evaluation and revision}

All programs describe the need for evaluation and revision of guidelines, but the steps of the updating process are not described in detail. Five programs provide a date for review in the guideline document. Length of update time varies depending on the topic and likelihood of new evidence. SIGN recommends assessment after two years, while $\mathrm{CBO}$ uses a five-year period.

CBO describes the concept of 'living guidelines', which follows a yearly cycle of reviewing the scope and clinical questions, performing an updated literature search identifying new evidence, and considering new factors and barriers in practice. 
Table 5. Considered judgment to formulate recommendations

\begin{tabular}{|c|c|c|}
\hline Organization & Criteria for considered judgment & Process \\
\hline $\mathrm{CBO}$ & $\begin{array}{l}\text { Clinical relevance } \\
\text { Safety } \\
\text { Patient perspective } \\
\text { Professional perspective } \\
\text { Available resources } \\
\text { Cost-effectiveness } \\
\text { Organization of care } \\
\text { Legal consequences } \\
\text { Ethical considerations } \\
\text { Commercial interest }\end{array}$ & $\begin{array}{l}\text { Considered judgment is described after description of } \\
\text { the evidence. Formulation of the recommendation is } \\
\text { based on the evidence and the considered judgment. } \\
\text { A checklist is available for the development group with } \\
\text { detailed criteria within ten domains as listed in this table. }\end{array}$ \\
\hline CSP & $\begin{array}{l}\text { Strength of evidence } \\
\text { Clinical relevance and applicability of } \\
\text { evidence } \\
\text { Acceptability to patients } \\
\text { Benefits and risks } \\
\text { Costs }\end{array}$ & $\begin{array}{l}\text { Development group should discuss considerations. When } \\
\text { possible quantitative analysis should be made to esti- } \\
\text { mate relative risks and benefits. Guideline document } \\
\text { should describe some of the discussion and clearly } \\
\text { describe the link between evidence review and recom- } \\
\text { mendations. }\end{array}$ \\
\hline NHMRC & $\begin{array}{l}\text { Applicability of the evidence } \\
\text { Probable outcome of intervention } \\
\text { Balance of benefits against risks } \\
\text { Alternative interventions } \\
\text { Economic appraisal }\end{array}$ & $\begin{array}{l}\text { A balance sheet is described to balance benefits and } \\
\text { harms. }\end{array}$ \\
\hline NZGG & $\begin{array}{l}\text { Volume of evidence } \\
\text { Consistency of the evidence } \\
\text { Applicability of the evidence } \\
\text { Clinical impact of the intervention }\end{array}$ & $\begin{array}{l}\text { A considered judgment form is used to link clinical ques- } \\
\text { tions, evidence and recommendation. The development } \\
\text { group needs to make a decision at the beginning of the } \\
\text { process about how to resolve differences. }\end{array}$ \\
\hline SIGN & $\begin{array}{l}\text { Quantity, quality and consistency of } \\
\text { evidence } \\
\text { Generalizability of study findings } \\
\text { Directness of application to target } \\
\text { population } \\
\text { Clinical impact } \\
\text { Implementability }\end{array}$ & $\begin{array}{l}\text { Development group summarizes view of considered } \\
\text { judgment using a form to record their main points. The } \\
\text { level of evidence is assigned to the judgment and a } \\
\text { graded recommendation is formulated. }\end{array}$ \\
\hline USPSTF & $\begin{array}{l}\text { Quality of studies, linkage to key } \\
\text { question using } 3 \text { criteria (internal } \\
\text { validity, external validity, consistency), } \\
\text { linkage to entire preventive service } \\
\text { Magnitude and weighing of benefits } \\
\text { and harms } \\
\text { Extrapolation and generalization } \\
\text { Other issues as cost effectiveness, } \\
\text { resource prioritization, logistical } \\
\text { factors, ethical and legal concerns, } \\
\text { patient and societal expectations } \\
\text { should be considered, but recommen- } \\
\text { dations reflect primarily the state of } \\
\text { the evidence. }\end{array}$ & $\begin{array}{l}\text { Guideline topic team assesses criteria using systematic } \\
\text { methods and rating systems. Recommendations reflect } \\
\text { primarily the state of evidence. Making recommenda- } \\
\text { tions is done with the understanding that clinicians and } \\
\text { policymakers must still consider additional factors in } \\
\text { making their own decisions. } \\
\text { Setting priorities in clinical practice (e.g. based on re- } \\
\text { source requirements) are beyond the scope of the re- } \\
\text { view. }\end{array}$ \\
\hline
\end{tabular}




\section{DISCUSSION}

\section{Limitations of the study}

The main purpose of this study was to compare different guideline programs and review the previous KNGF program for guideline development in physical therapy, based on an evidence-based approach. We collected information from handbooks and websites from six organizations that published guideline programs. We did not perform a random search for guideline programs, but based the selection on a previous survey by Burgers ${ }^{6}$.

Comparing methodology for guideline development from handbooks, using the AGREE criteria, does not imply that the clinical guidelines themselves actually meet the AGREE criteria as well. Comparison of the published clinical guidelines was beyond the scope of this study.

\section{Compliance with AGREE criteria}

All programs showed high compliance with the AGREE criteria, by means of addressing the criteria in the handbooks that describe the development process. Four of the six programs (CBO, CSP, NHMRC, NZGG) also explicitly mention the AGREE criteria as basis for their development process. The somewhat lower CSP score can be explained by their choice not to include steps for implementation in the handbook. The other lower score by USPSTF can be explained by their explicit choice to formulate recommendations strictly based on evidence, and not specifically involving the views of professionals and patients in the recommendations. Considerations beyond scientific evidence are not included in the scope of the reviews by USPSTF.

The previous Dutch program for guideline development in physical therapy complied only with 13 of the 23 AGREE criteria. These findings supported the need for updating the Dutch program. The lack of compliance with the AGREE criteria can partly be explained by the publication date in 1998, which was prior to publication of the AGREE instrument. Some changes were made in the development process, but were not yet published in an update of the handbook.

\section{Comparison of guideline programs}

Our study confirms the findings of Burgers ${ }^{6}$ that guideline programs share basic principles, but differ in details. Although the collected information provided a lot of details about the development process, it is often not clear how decisions in the development process are made. For instance, a list of criteria is used for topic selection in most programs, but it is unclear how final decisions about the topic are made. Oxman arrived at the same conclusion ${ }^{29}$. The difficulty of decision-making is 
also reflected in the formulation of recommendations. All programs describe the process for formulating recommendations in detail, supported by balance sheets or considered judgment forms. For example, Verkerk presented a list of 37 items grouped into ten domains for considered judgment, which is used in the CBO program $^{30}$. The final decision in formulating recommendations depends on discussions and consensus (formal and/or informal) within the guideline development group, weighing those different aspects in particular when evidence is lacking or contradictory $^{31,32}$.

All programs describe a procedure for weighing the evidence and grading recommendations using a hierarchy of levels of evidence. However, a large debate about the use of hierarchy levels is ongoing in the international guideline community ${ }^{33,34}$. Different grading systems exist and become more complicated, which hampers comparability. The international GRADE group has recently introduced and piloted a new system for grading the quality of evidence and the strength of recommendations $^{33,35}$. The World Health Organization (WHO) adopted this system for their guidelines $^{36}$.

\section{Update of the Dutch guideline program for physical therapy}

The update of the Dutch guideline program for physical therapy was based on evaluation of the current procedure and new insights. The framework of the updated Dutch program is shown in table 6 . The introduction of the AGREE Instrument and consensus by the Dutch Network resulted in several changes in the procedure of guideline development a few years ago. This concerned the inclusion of hierarchy of the evidence and grading of recommendations according to the Dutch network $^{8,9}$. However, other aspects of the program needed further evaluation in order to make explicit choices. We focused on several aspects of the protocol: organizational structure; procedure for topic selection and defining the scope of guidelines; patient involvement; formulation of recommendations and a procedure for updating guidelines. From analyzing the several guideline programs we concluded that central coordination is needed to ensure a structured and systematic approach.

In the Dutch guideline program for physical therapy patients and other disciplines are included in the external review group. This approach allows the development group to focus primarily on the physiotherapy process, while specific input from patients and other disciplines is ensured in the external review. As a result, the updated procedure complied with 22 AGREE criteria (table 3). 
Table 6. Updated Dutch program for guideline development in physical therapy

\begin{tabular}{|c|c|}
\hline Section & Description \\
\hline 1. Structure and organization & $\begin{array}{l}\text { Central professional organization in collaboration with other institutes. } \\
\text { Mono-disciplinary development group (5-10 members). Small group ( } 2 \text { - } \\
\text { 3) of employed staff within development group responsible for review } \\
\text { of literature and actual writing of the guideline. Patients involved in } \\
\text { external review group and focus groups. }\end{array}$ \\
\hline 2. Preparation/ initiation & $\begin{array}{l}\text { Special interest groups can propose topics using application form. } \\
\text { Procedure is described for prioritizing topics. Guideline committee } \\
\text { selects. KNGF board makes final decision. } \\
\text { Literature orientation on the subject. Barriers and needs of physio- } \\
\text { therapists and patients are described in application form. }\end{array}$ \\
\hline 3. Development & $\begin{array}{l}\text { Literature search using systematic strategy. Systematic review or meta- } \\
\text { analysis if no (recent) review is available. Quality of studies assessed } \\
\text { using different tools for diagnosis, intervention and systematic reviews. } \\
\text { Hierarchy of the evidence described in four levels according to Dutch } \\
\text { consensus. Grading of recommendations in four levels. Standardized } \\
\text { formulation of recommendations according to grading. } \\
\text { Outline of guideline divided in physical therapy diagnosis and treat- } \\
\text { ment based on clinical reasoning process. Use of International Classifi- } \\
\text { cation of Functioning (ICF) as nomenclature. }\end{array}$ \\
\hline 4. Validation & $\begin{array}{l}\text { Draft guideline sent to group of peers to test practicality, clarity and } \\
\text { acceptability. Draft guideline discussed in external review group (rele- } \\
\text { vant health care professionals, patients, stakeholders). Separate check } \\
\text { by patient advisory board. Final draft checked by Guideline Committee. } \\
\text { Endorsement by KNGF. Test piloting after endorsement. }\end{array}$ \\
\hline $\begin{array}{l}\text { 5. Dissemination and } \\
\text { Implementation }\end{array}$ & $\begin{array}{l}\text { Four products: practice guideline, review of the evidence, summary (in } \\
\text { flow chart), patient version. Publication as supplement of Dutch Jour- } \\
\text { nal for Physical Therapy. Sent to all members of KNGF. Translated into } \\
\text { English. Publication on website. Implementation plan with every guide- } \\
\text { line. }\end{array}$ \\
\hline 6. Evaluation and update & $\begin{array}{l}\text { No later than } 5 \text { years after publication decision about update, based on } \\
\text { new evidence, results from pilot, professional developments and } \\
\text { developments in guideline methodology. } \\
\text { Additional (systematic) review of literature. Weighing of the evidence } \\
\text { and recommendations adjusted or added if necessary. }\end{array}$ \\
\hline
\end{tabular}

\section{CONCLUSION}

As a result of international developments and consensus, the described processes for developing clinical practice guidelines have much in common. The AGREE criteria are common basis for the development processes in the different guideline programs. We learned that prioritizing topics, defining the scope of the guideline and the formulation of recommendations can be more clearly described. In particular, the process of translation of evidence into practice recommendations can be 
improved. The previous KNGF program for guideline development in physical therapy lacked compliance with the AGREE criteria. Detailed comparison of the different guideline programs was used for updating the KNGF guideline program, which reflects international consensus and describes explicit choices in those issues lacking consensus. As a result the updated KNGF program complied with 22 AGREE criteria. International discussion is continuing and will be used for further improvement of the program.

\section{Competing interests}

The authors declare that they have no competing interests.

\section{Authors' contributions}

PW and EH collected data and analyzed the guideline programs. PW, EH and JC updated the Dutch program for guideline development. JD, RB and JB critically revised the manuscript and contributed to the international perspective of the study. All authors read and approved the final manuscript. 


\section{REFERENCES}

1. Field MJ, Lohr K. Guidelines for clinical practice, from development to use. Washington DC: Institute of medicine. National Academic Press; 1992.

2. Van der Wees PJ, Hendriks HJM, Veldhuizen HJ. Quality assurance in the Netherlands: from development to implementation and evaluation. Dutch J Physiother. 2003;113:3-6.

3. Hendriks HJM, Bekkering GE, van Ettekoven H, Brandsma JW, Van der Wees PJ, de Bie RA. Development and implementation of national practice guidelines: a prospect for continuous quality improvement in physiotherapy. Physiotherapy. 2000;86:535-547.

4. Hendriks HJM, van Ettekoven H, Reitsma ER, Verhoeven ALJ, Van der Wees PJ. Methode voor centrale richtlijnontwikkeling en implementatie in de fysiotherapie. Amersfoort: Koninklijk Nederlands Genootschap voor Fysiotherapie (KNGF); 1998.

5. AGREE Collaboration. Appraisal of Guidelines for Research \& Evaluation (AGREE) Instrument. London: St George's Hospital Medical School; 2001.

6. Burgers JS, Grol R, Klazinga NS, Makela M, Zaat JOM. Towards evidence-based clinical practice: an international survey of 18 clinical guideline programs. Int J Qual Health Care. 2003;15:31-45.

7. Shekelle PG, Woolf SH, Eccles M, Grimshaw J. Developing guidelines. BMJ. 1999;593-596.

8. Evidence-based richtlijnontwikkeling. Een leidraad voor de praktijk. Houten: Bohn Stafleu Van Lochum; 2004.

9. Burgers JS, van Everdingen JJ. [Evidence-based guideline development in the Netherlands: the EBRO platform]. Ned Tijdschr Geneeskd. 2004;148:2057-2059.

10. Ollenschlager G, Marshall C, Qureshi S et al. Improving the quality of health care: using international collaboration to inform guideline programmes by founding the Guidelines International Network (G-I-N). Qual Saf Health Care. 2004;13:455-460.

11. Mead J, Van der Wees PJ. Clinical guidelines: An introduction. WCPT Keynotes. EBP ed. London: World Confederation for Physical Therapy (WCPT); 2006.

12. Van der Wees PJ, Mead J. Clinical guidelines 2: Developing the guidelines. WCPT Keynotes. EBP ed. London: World Confederation for Physical Therapy (WCPT); 2006.

13. Van der Wees PJ, Mead J. Framework for clinical guideline development. Brussels: European Region of World Confederation for Physical Therapy; 2004.

14. Oxman AD, Fretheim A, Schunemann HJ. Improving the use of research evidence in guideline development: introduction. Health Res Policy Syst. 2006;4:12.

15. Edejer TT. Improving the use of research evidence in guideline development: 11 . Incorporating considerations of cost-effectiveness, affordability and resource implications. Health Res Policy Syst. 2006;4:23.

16. Oxman AD, Schunemann HJ, Fretheim A. Improving the use of research evidence in guideline development: 12. Incorporating considerations of equity. Health Res Policy Syst. 2006;4:24.

17. Schunemann HJ, Fretheim A, Oxman AD. Improving the use of research evidence in guideline development: 10. Integrating values and consumer involvement. Health Res Policy Syst. 2006;4:22.

18. $\mathrm{CBO}$. Evidence-based richtlijnontwikkeling. Handleiding voor werkgroepleden. Utrecht: Kwaliteitsinstituut voor de gezondheidszorg CBO; 2006.

19. NHMRC. A guide to the development, implementation and evaluation of clinical practice guidelines. Canberra: National Health and Medical Research Council (NHMRC); 1999.

20. NZGG. Handbook for the preparation of explicit evidence-based clinical practice guidelines. The Terrace: New Zealand Guidelines Group (NZGG); 2003.

21. SIGN. SIGN 50 - A guidelines developers' handbook. Edinburgh: Scottish Intercollegiate Guidelines Network (SIGN); 2004. 
22. Guirguis-Blake J, Calonge N, Miller T, Siu A, Teutsch S, Whitlock E. Current processes of the U.S. Preventive Services Task Force: refining evidence-based recommendation development. Ann Intern Med. 2007;147:117-122.

23. Harris RP, Helfand M, Woolf SH et al. Current methods of the US Preventive Services Task Force: a review of the process. Am J Prev Med. 2001;20:21-35.

24. Schunemann HJ, Fretheim A, Oxman AD. Improving the use of research evidence in guideline development: 1. Guidelines for guidelines. Health Res Policy Syst. 2006;4:13.

25. Guidelines International Network (G-I-N). http://www.g-i-n.net 2007.

26. National Guideline Clearinghouse (NGC). http://www.guideline.gov 2007.

27. World Conferation for Physical Therapy (WCPT). http://www.wcpt.org 2007.

28. CSP. Guidance for developing guidelines. London: Chartered Society for Physiotherapy (CSP); 2003.

29. Oxman $A D$, Schunemann HJ, Fretheim A. Improving the use of research evidence in guideline development: 2. Priority setting. Health Res Policy Syst. 2006;4:14.

30. Verkerk K, Van VH, Severens JL, Hendriks EJ, Burgers JS. Considered judgement in evidence-based guideline development. Int J Qual Health Care. 2006;18:365-369.

31. Burgers JS, van Everdingen JJ. Beyond the evidence in clinical guidelines. Lancet. 2004;364:392393.

32. Raine R, Sanderson C, Hutchings A, Carter S, Larkin K, Black N. An experimental study of determinants of group judgments in clinical guideline development. Lancet. 2004;364:429-437.

33. Atkins D, Eccles $M$, Flottorp $S$ et al. Systems for grading the quality of evidence and the strength of recommendations I: critical appraisal of existing approaches The GRADE Working Group. BMC Health Serv Res. 2004;4:38.

34. Treadwell JR, Tregear SJ, Reston JT, Turkelson CM. A system for rating the stability and strength of medical evidence. BMC Med Res Methodol. 2006;6:52.

35. Atkins D, Best D, Briss PA et al. Grading quality of evidence and strength of recommendations. BMJ. 2004;328:1490.

36. Schunemann HJ, Fretheim A, Oxman AD. Improving the use of research evidence in guideline development: 9. Grading evidence and recommendations. Health Res Policy Syst. 2006;4:21. 



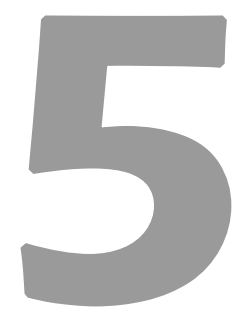

\title{
Multifaceted strategies may increase implementation of physiotherapy clinical guidelines: a systematic review
}

\author{
Philip J van der Wees ${ }^{1,2}$ \\ Gro Jamtvedt ${ }^{3}$ \\ Trudy Rebbeck ${ }^{4}$ \\ Rob A de Bie ${ }^{1}$ \\ Joost Dekker ${ }^{5}$ \\ Erik JM Hendriks ${ }^{1}$
}

\footnotetext{
${ }^{1}$ Department of Epidemiology, Maastricht University, The Netherlands

${ }^{2}$ Royal Dutch Society for Physical Therapy (KNGF), The Netherlands

${ }^{3}$ Norwegian Knowledge Center for the Health Services, Norway

${ }^{4}$ The University of Sydney, Australia

${ }^{5}$ VU University Medical Center, The Netherlands
}

Australian Journal of Physiotherapy 2008; 54:233-241 


\section{ABSTRACT}

\section{Question}

What is the effectiveness of strategies to increase the implementation of physiotherapy clinical guidelines?

\section{Design}

Systematic review.

\section{Participants}

Physiotherapists treating any type of patients.

\section{Intervention}

Single or multiple strategies to increase the implementation of physiotherapy clinical guidelines.

\section{Outcome measures}

Physiotherapy practice, patient health, and cost of care.

\section{Results}

Five papers reporting three cluster-randomised trials evaluated whether multifaceted strategies based on educational meetings increased the implementation of low back pain guidelines ( 2 trials) or whiplash guidelines (1 trial). Educational meetings were effective in increasing adherence to the following recommendations of low back pain guidelines: limiting the number of sessions ( $\mathrm{RD} 0.13,95 \% \mathrm{Cl} 0.03$ to 0.23 ), using active intervention ( $\mathrm{RD} 0.13,95 \% \mathrm{Cl} 0.05$ to 0.21 ), giving adequate information ( $\mathrm{RD} 0.0595 \%$ $\mathrm{Cl} 0.00$ to 0.11 ), increasing activity level (RD: $0.16,95 \% \mathrm{Cl} 0.02$ to 0.30 ), changing attitudes/beliefs about pain (RD $0.13,95 \% \mathrm{Cl} 0.01$ to 0.24 ). Educational meetings were effective in increasing adherence to the following recommendations of whiplash guidelines: reassuring the patient ( $\mathrm{RD} 0.40,95 \% \mathrm{Cl} 0.07$ to 0.74 ), advising the patient to act as usual ( $\mathrm{RD} 0.48,95 \% \mathrm{Cl} 0.15$ to 0.80 ), using functional outcome measures (RD $0.62,95 \% \mathrm{Cl} 0.32$ to 0.92 ). There was no evidence that patient health was improved or that the cost of care was reduced.

\section{Conclusion}

This review shows that multifaceted interventions based on educational meetings to increase implementation of clinical guidelines in physiotherapy may improve some outcomes of professional practice, but do not improve patient health or reduce cost of care. These findings are comparable with results among other health professions.

Key words: Guideline adherence, Practice guidelines, Review systematic, Physiotherapy (Speciality) 


\section{INTRODUCTION}

Development of clinical guidelines in health services is generally considered important for improving and managing the care process ${ }^{1-4}$. Clinical guidelines are 'systematically developed statements designed to help practitioners and patients to make decisions about appropriate health care ${ }^{5}$. Higher quality of care and improved cost-effectiveness are important goals in guideline development, optimally resulting in improved health outcomes ${ }^{6}$. Moreover, the process of guideline development addresses the need to decrease variability in clinical practice, and practitioners' desire to legitimise their profession in the eyes of external stakeholders $^{1-4,7,8}$. The concept of evidence-based practice, supported by clinical guidelines, is a common aspect of health care today.

\section{Clinical guidelines in physiotherapy}

The trend to carry out evidence-based practice affects the profession of physiotherapy and is the subject of discussion in the physiotherapy community ${ }^{9}$. In the last two decades the need for evidence-based practice in the physiotherapy profession resulted in a rapid increase in its body of knowledge ${ }^{10}$. The introduction of evidence-based clinical guidelines was a logical step to make explicit evidencebased recommendations for clinical practice, and was initiated by several professional organisations in physiotherapy. The Royal Dutch Society for Physical Therapy (KNGF) developed a national quality assurance program, including the development and implementation of clinical guidelines ${ }^{11,12}$, resulting in the publication of 18 evidence-based guidelines by 2007 . The Chartered Society for Physiotherapy (CSP) also developed and endorsed evidence-based clinical guidelines. The Australian Physiotherapy Association (APA) has produced a series of evidence-based clinical statements outlining the efficacy of physiotherapy for management of conditions such as low back pain ${ }^{13}$ and neck pain ${ }^{14}$. Collaboration between professional organisations within the World Confederation for Physical Therapy (WCPT) resulted in prioritising the development and implementation of clinical guidelines in order to facilitate evidence-based practice ${ }^{15-17}$.

\section{Effects of guideline implementation strategies in health care}

Grimshaw et $\mathrm{al}^{18}$ conducted a systematic review of the effectiveness and cost of different implementation strategies for health care guidelines from studies published up to 1998. Professional practice and patient health were considered, and economic outcomes were reviewed separately. They identified 235 studies evaluating guideline dissemination and implementation among medically-qualified healthcare professionals. Guidelines targeting physiotherapists were not included in the 
scope of the review. Overall, the majority of the studies observed improvements in the process of care (professional practice), but large variation both within and across interventions was noted. The improvements were small to moderate with a median improvement of $10 \%$ across all studies. One important result was that multifaceted interventions did not appear more effective than single interventions.

Within the Cochrane Collaboration, the Effective Practice and Organisation of Care (EPOC) Group has published many systematic reviews about the effects of guideline implementation. The results of some updated Cochrane reviews show that different interventions can be effective in improving professional practice, but the effects are generally small (median improvement of $10 \%$ or less). The use of opinion leaders (12 studies) showed a median improvement of $12 \%{ }^{19}$, audit and feedback (118 studies) showed a median improvement of $5 \%{ }^{20}$, educational outreach (69 studies) showed a median improvement of $6 \%{ }^{21}$ and educational meetings and workshops (81 studies) showed a median improvement of $6 \%{ }^{22}$.

Many factors can influence the adherence of professionals to guidelines. Barriers that may reduce adherence to guidelines can be professional, financial, organisational and regulatory ${ }^{23}$. A review by Shaw et $a^{24}$ showed that it is not clear which barriers are most important.

\section{Implementation of clinical guidelines in physiotherapy}

No reviews have been published which specifically review the effect of strategies to increase the implementation of guidelines in physiotherapy. In a study by Rebbeck et $\mathrm{al}^{25}$, the effects of implementation of clinical guidelines for spinal pain were reviewed. Although 14 trials were included in the review, only three included physiotherapy interventions.

Although the results of published reviews of implementation strategies in health care may be useful for the physiotherapy profession, there is a need to establish a body of knowledge for guideline implementation in physiotherapy. State of the art and evidence-based physiotherapy intervention contains specific characteristics and barriers that may require unique implementation strategies to influence adherence to guideline recommendations. Physiotherapy intervention usually comprises a series of sessions over a time and often requires behavioural change in the client; because of this complexity, adherence to recommendations from clinical guidelines is difficult. To assist physiotherapists to adhere to recommendations in their daily practice, the profession requires evidence of which strategies increase implementation. Therefore, the research question was:

What is the effectiveness of strategies to increase the implementation of physiotherapy clinical guidelines? 


\section{METHOD}

\section{Identification and selection of studies}

The following databases were searched until October 2007: MEDLINE (from 1966), EMBASE (from 1988), CINAHL (from 1982), PEDro, Cochrane Library (Issue 4, 2007). A broad search was performed to identify any type of publication, based on the assumption that only few studies were published about guideline implementation in physiotherapy. Subject search was restricted only to three criteria: Guidelines AND (Implementation OR Implement) AND (Physiotherapy OR Physical Therapy). Reference lists were screened to indentify additional studies.

Studies were included in the review if they were randomised trials, controlled trials, controlled before and after studies, or interrupted time series studies investigating the implementation of clinical guidelines by physiotherapists. The clinical guidelines included in this investigation needed to be produced under the auspices of a professional, health or government organisation, be publicly available and based on results of a systematic review ${ }^{26}$.

Studies that involved physiotherapists in clinical practice treating any type of patients were included. Studies were included if they involved strategies to increase the implementation of clinical guidelines by physiotherapists in order to improve professional practice and/or patient health or reduced cost of care. We examined any type of intervention as classified by the EPOC Group ${ }^{23}$ : distribution of educational materials, educational meetings, local consensus process, educational outreach visits, local opinion leaders, patient mediated interventions, audit and feedback, reminders, marketing, mass media. When interventions were combined, they were considered multifaceted.

\section{Assessment of quality of studies}

The methodological quality of the included randomised trials was evaluated using a checklist adapted from the EPOC Group data collection checklist ${ }^{27}$ which is shown in Table 1. Two reviewers independently assessed the methodological quality of the studies and disagreements were resolved by consensus or by consulting a third reviewer. 
Table 1. Criteria for assessment of methodological quality of studies based on EPOC Group data collection checklist ${ }^{27}$

\begin{tabular}{ll}
\hline Criteria & Definition \\
\hline 1. Concealment of allocation & $\begin{array}{l}\text { Allocation by institution, team or professional, and ran- } \\
\text { dom process described explicitly } \\
\text { Outcome measures obtained for } 80-100 \% \text { of subjects } \\
\text { 2. Follow-up of professionals }\end{array}$ \\
$\begin{array}{ll}\text { Outcome measures obtained for } 80-100 \% \text { of subjects } \\
\text { 3. Follow-up of patients }\end{array}$ & $\begin{array}{l}\text { Primary outcome variables were assessed blindly or out- } \\
\text { come variables are objective }\end{array}$ \\
4. Blinded assessment of outcome & $\begin{array}{l}\text { Performance or patient outcomes were measured prior to } \\
\text { the intervention } \\
\text { Two or more raters with at least } 90 \% \text { agreement or kappa } \\
\text { 6. Beliable primary outcome measures }\end{array}$ \\
7. Protection against contamination & $\begin{array}{l}\text { automated system } \\
\text { Allocation by community, institution or practice and it is } \\
\text { unlikely that controls received the intervention }\end{array}$ \\
\hline
\end{tabular}

\section{Data analysis}

Two reviewers independently extracted data from the original studies and data were analysed ${ }^{3}$. For dichotomous outcomes risk difference and risk ratio was calculated $(95 \% \mathrm{Cl})$, and for continuous data mean difference was calculated $(95 \% \mathrm{Cl})$. In addition, effect sizes were adjusted for baseline differences when possible. For dichotomous outcomes, we estimated the adjusted risk difference and adjusted risk ratio as follows:

Adjusted Risk difference $=$ the difference in adherence after the intervention minus the difference before the intervention. A positive risk difference indicates that adherence improved more in the intervention group than in the control group, e.g. an adjusted risk difference of 0.09 indicates an absolute improvement in care (improvement in adherence) of $9 \%$.

Adjusted Risk Ratio = the ratio of the relative probability of adherence after the intervention over the relative probability before the intervention. A risk ratio greater than one indicates that adherence improved more in the intervention group than in the control group, e.g. an adjusted risk ratio of 1.8 indicates a relative improvement in care (improvement in adherence) of $80 \%$.

For continuous outcomes we calculated the post mean difference and adjusted mean difference when possible. When applicable a random effects model was used to pool the outcomes of the studies.

\footnotetext{
${ }^{3}$ Review Manager (RevMan), Version 5, The Cochrane Collaboration
} 


\section{RESULTS}

The initial search resulted in 139 papers from Medline $(n=53)$, EMBASE $(n=54)$, CINAHL $(n=6)$, PEDro $(n=6)$, Cochrane Library $(n=20)$. After correction for double studies and scrutinizing retrieved abstracts, 12 full papers were retrieved for further analysis ${ }^{28-39}$. Three studies were excluded because they did not meet the design criteria ${ }^{34,38,39}$, one study did not meet the participants criteria $^{36}$, two studies did not meet the intervention criteria ${ }^{28,32}$, and one study described a protocol ${ }^{31}$. An overview of the selection process is show in Figure 1.

The five included papers were based on three separate randomised trials. The three trials evaluated strategies for increasing the implementation of whiplash guidelines in Australia ${ }^{35}$, low back pain guidelines in the Netherlands ${ }^{29,30,33}$, and low back pain guidelines in the $\mathrm{UK}^{37}$. The three trials included a total of 909 patients who were treated by 170 physiotherapists. An overview of all included studies is shown in Table 2 which describes the population, intervention, outcome measures, and findings as reported by the authors.

All three trials evaluated the effects of multifaceted intervention based on interactive educational meetings to increase the implementation of guidelines. One trial of whiplash guidelines ${ }^{35}$, compared an interactive educational meeting administered by opinion leaders ( 8 hours), followed by an educational outreach visit ( 2 hours) after six months, versus dissemination of the guideline only. The meetings included interactive sessions, practical sessions and problem solving. This trial included 27 physiotherapists, who treated 103 patients with whiplash injury. A trial of low back pain guidelines ${ }^{29,30,33}$ compared the effect of two interactive educational meetings administered by experts ( 2.5 hours each with a 4-week interval), versus dissemination of the guideline only. The meetings included didactic lectures, discussion, role playing, feedback and reminders. This trial included 113 physiotherapists who treated 500 patients with low back pain. Another trial of low back pain guidelines ${ }^{37}$ compared the effect of an evidence-based educational meeting administered by local opinion leaders ( 5 hours) versus a standard in-service educational meeting (5 hours). This trial included 30 physiotherapists who treated 306 patients with low back pain.

\section{Quality of studies}

The three trials scored a mean of 4 out of 7 points (range 3-5) on the EPOC Group criteria (Table 3). 


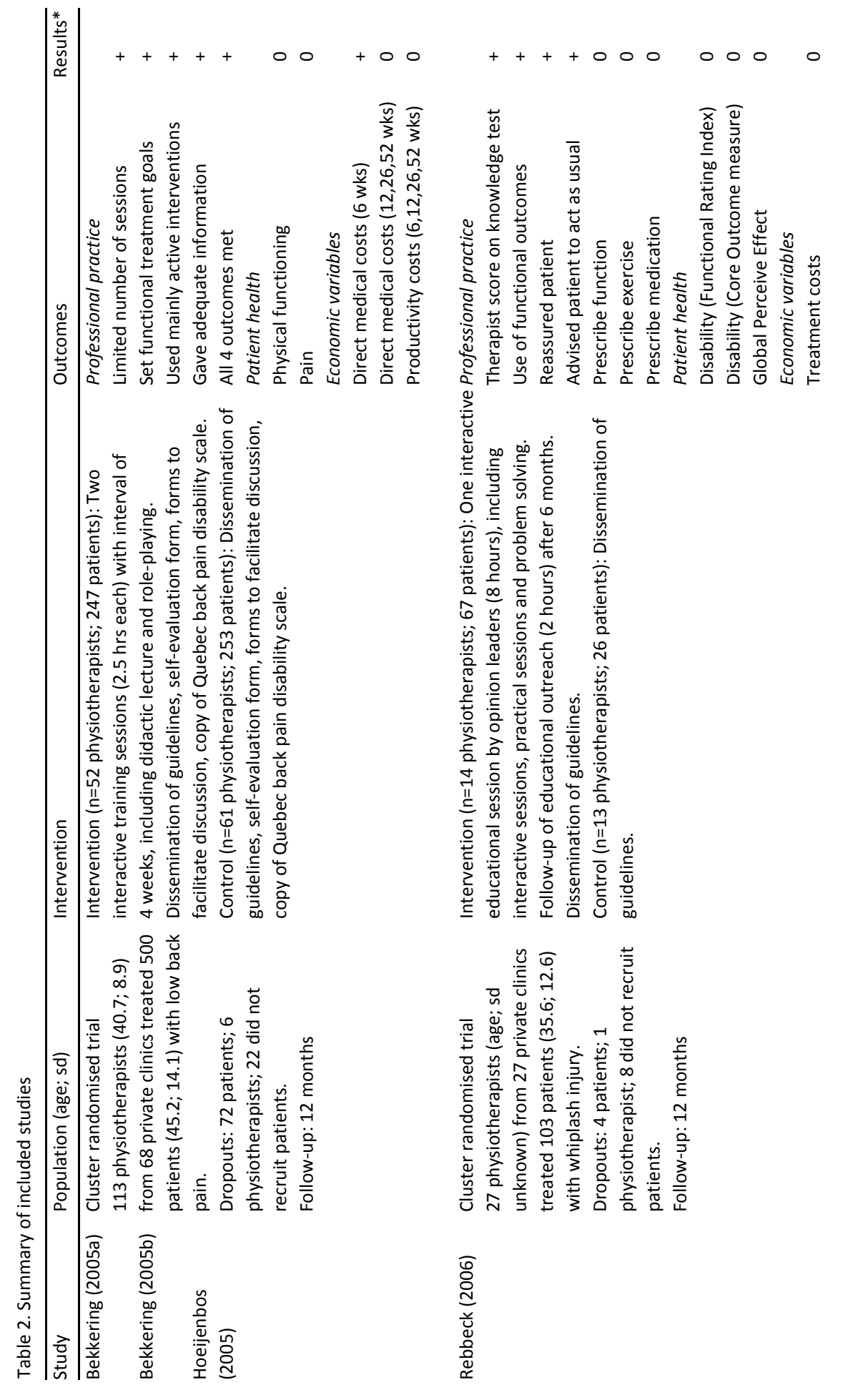


CHAPTER 5 - IMPLEMENTATION OF PHYSIOTHERAPY CLINICAL GUIDELINES

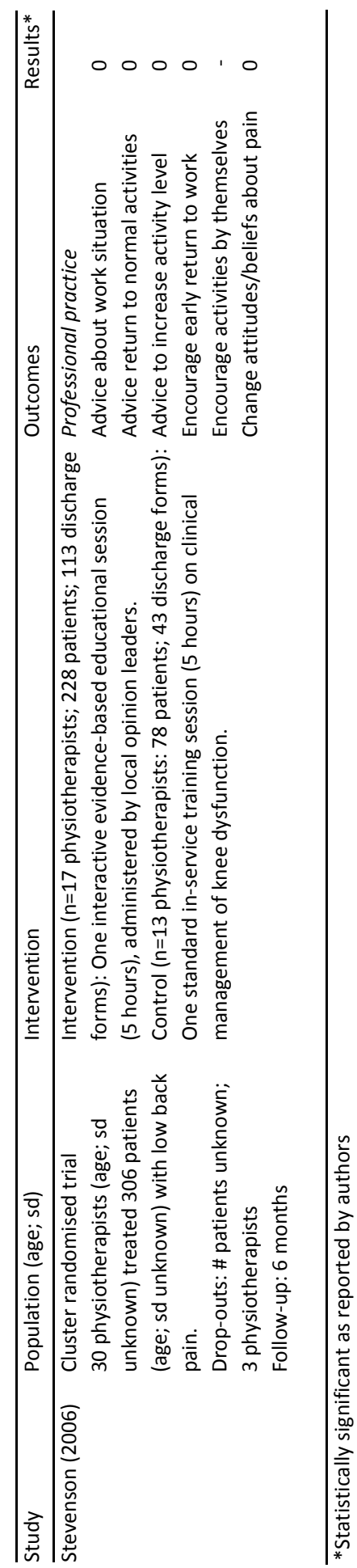


Table 3. Methodological quality of randomised trials

\begin{tabular}{lllllllll}
\hline Study (RCT) & 1 & 2 & 3 & 4 & 5 & 6 & 7 & Total \\
\hline $\begin{array}{l}\text { Bekkering 2005a } \\
\text { Bekkering 2005b } \\
\text { Hoeijenbos 2005 }\end{array}$ & $\mathrm{y}^{1}$ & $\mathrm{n}$ & $\mathrm{y}$ & $\mathrm{y}$ & $\begin{array}{l}\mathrm{y} \text { (patient) } \\
\mathrm{n} \text { (professional) }\end{array}$ & $\mathrm{n}$ & $\mathrm{y}$ & 5 \\
Rebbeck 2006 & $\mathrm{y}^{1}$ & $\mathrm{n}$ & $\mathrm{y}$ & $\mathrm{y}$ & $\begin{array}{l}\mathrm{y} \text { (patient) } \\
\mathrm{y} \text { (professional }\end{array}$ & $\mathrm{n}$ & $\mathrm{y}$ & 5 \\
Stevenson 2006 & $\mathrm{n}^{1}$ & $\mathrm{y}$ & $?$ & $\mathrm{n}$ & $\mathrm{y}$ (professional) & $\mathrm{n}$ & $\mathrm{y}$ & 3 \\
\hline
\end{tabular}

${ }^{1}$ cluster randomisation

Figure 1. Flow of studies through the review

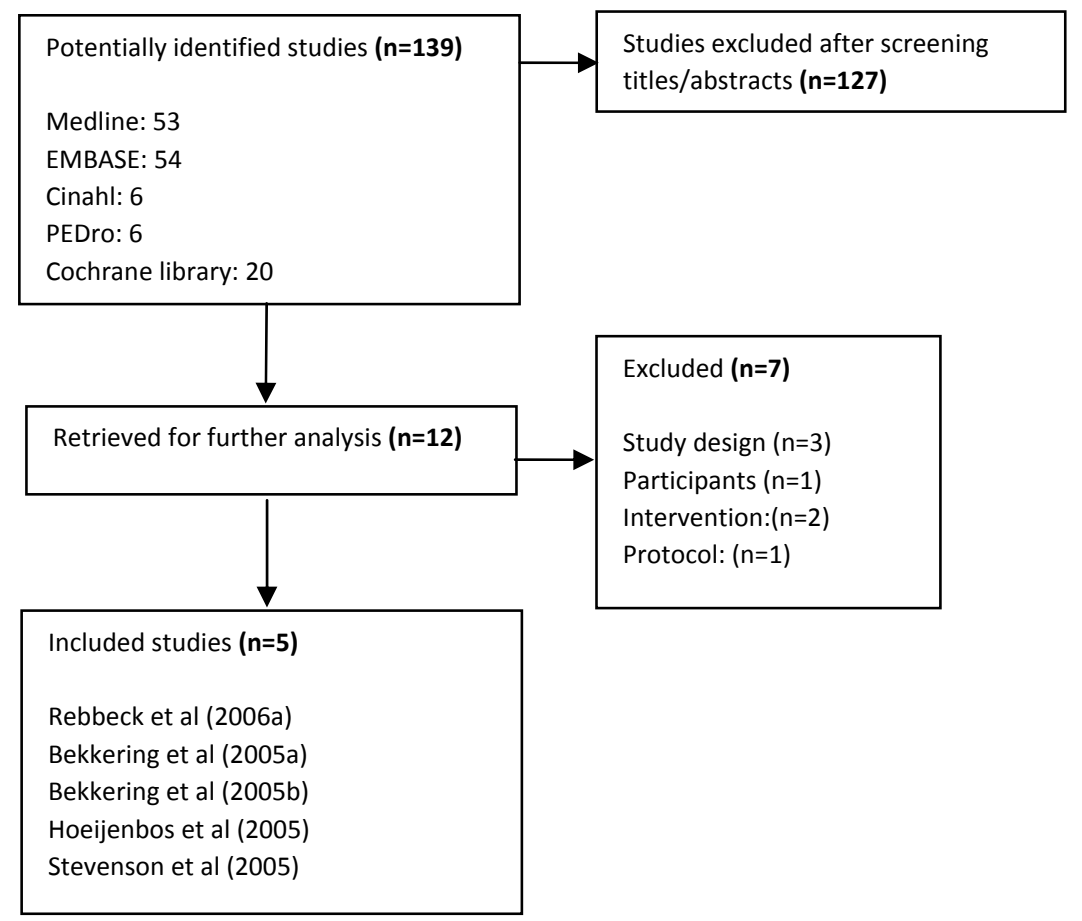

\section{Effect on professional practice}

Three trials evaluated the effect on professional practice of interactive educational meetings to increase implementation of guidelines ${ }^{30,35,37}$. The relative risk and risk difference for professional practice are presented in Table 4. Due to heterogeneity of interventions and outcome measures, outcomes were not pooled. 


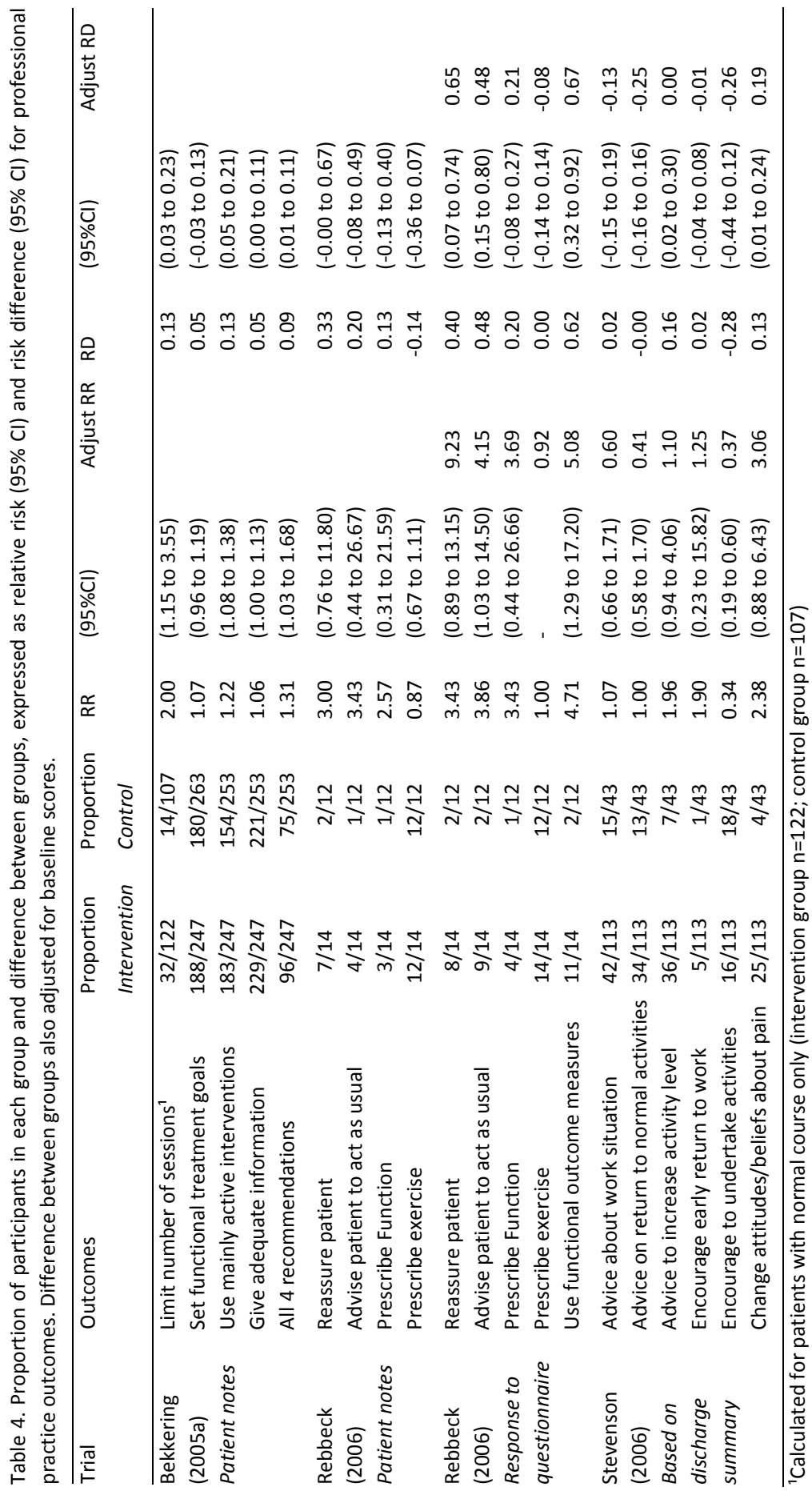


Bekkering et al $^{30}$ evaluated professional practice by measuring adherence to four recommendations of low back pain guidelines, derived from patient notes: limiting the number of sessions, setting functional treatment goals, using mainly active interventions, and giving adequate information. Physiotherapists in the intervention group limited the number of sessions (RD $0.13 ; 95 \% \mathrm{Cl} 0.03$ to 0.23 ), used active interventions ( $\mathrm{RD} 0.13 ; 95 \% \mathrm{Cl} 0.05$ to 0.21 ), gave adequate information (RD $0.05 ; 95 \% \mathrm{Cl} 0.00$ to 0.11 ), and complied with all four recommendations of the guideline (RD 0.09; 95\% $\mathrm{Cl} 0.01$ to 0.11 ) more than physiotherapists in the dissemination group.

Rebbeck et al $^{35}$ evaluated professional practice by measuring adherence to six recommendations of whiplash guidelines: using functional outcomes, reassuring patients, advising patients to act as usual, prescribing function, prescribing exercise, and prescribing medication by auditing patient notes and by using a questionnaire. Physiotherapists in the implementation group reassured the patient (RD 0.40; 95\% $\mathrm{Cl} 0.07$ to 0.74 ), advised patients to act as usual (RD $0.48 ; 95 \% \mathrm{Cl} 0.15$ to 0.80 ), used functional outcome measures (RD $0.62 ; 95 \% \mathrm{Cl} 0.32$ to 0.92 ) more than physiotherapists in the dissemination group. There was no difference between the implementation group and the dissemination group for the other three recommendations. Furthermore, physiotherapists in the implementation group scored higher than those in the dissemination group on a questionnaire testing knowledge of the whiplash guidelines: MD 5.1 ( $95 \% \mathrm{Cl} 2.48$ to 7.72 ).

Stevenson et $\mathrm{al}^{37}$ evaluated professional practice by measuring adherence to six recommendations of low back pain guidelines by analysing the discharge summaries in patient notes: advice about work situation, return to normal activities, advice to increase activity level, encourage early return to work, encourage to undertake activities by patients themselves, and change attitudes/beliefs about pain.

Physiotherapists in the evidence-based implementation group advised to increase activity level (RD $0.16 ; 95 \% \mathrm{Cl} 0.02$ to 0.30 ) and changed attitudes/beliefs about pain (RD $0.13 ; 95 \% \mathrm{Cl} 0.01$ to 0.24 ) more than physiotherapists in the standard implementation group.

\section{Effect on patient health}

Two trials evaluated the effect on patient health of interactive educational meetings to increase implementation of guidelines ${ }^{29,35}$. The mean differences for patient health are presented in Table 5. Due to heterogeneity of interventions and outcome measures, outcomes were not pooled. No differences between the implementation group and the dissemination group on any outcome measure of patient health at any time were found for whiplash patients ${ }^{35}$ or low back pain patients ${ }^{29}$. 
Table 5. Mean difference $(95 \% \mathrm{Cl})$ between groups for patient health

\begin{tabular}{lll}
\hline Trial & Outcome & MD (95\% Cl) \\
\hline Bekkering (2005b) & Disability (QBPDS 0-100) at 6 wks & $1.96(-1.44 \text { to } 5.37)^{1}$ \\
& Pain (NRS 0-10) at 6 wks & $0.16(-0.35 \text { to } 0.69)^{1}$ \\
& Disability (QBPDS 0-100) at $52 \mathrm{wks}$ & $3.55(-0.25 \text { to } 7.35)^{1}$ \\
Rebbeck (2006a) & Pain (NRS 0-10) at 52 wks & $0.55(-0.02 \text { to } 1.11)^{1}$ \\
& Disability (FRI 0-40) at 6 wks & $1.00(-3.12$ to 5.12) \\
& Disability (FRI 0-40) at 52 wks & $-0.60(-5.13$ to 3.93) \\
\hline
\end{tabular}

${ }^{1}$ Mean Difference based on Multilevel Regression Coefficients as reported by authors (Bekkering et al 2005c).

\section{Effect on cost of care}

Two trials evaluated the effect of interactive educational meeting to increase implementation of guidelines on cost of care ${ }^{33,35}$. In the trial of whiplash guidelines ${ }^{35}$, cost of care for patients in the implementation group was not different from the dissemination group. In the trial of low back pain guidelines ${ }^{33}$ direct medical costs and productivity costs for the implementation group were not different from the dissemination group.

\section{DISCUSSION}

\section{Strategies to increase implementation of physiotherapy guidelines}

The main outcome of this review is that multifaceted interventions based on interactive educational meetings can improve some outcomes of professional physiotherapy practice, but the results are not consistent and vary between studies and outcomes. No differences were found for patient outcomes or costs of care.

The studies of Bekkering et $\mathrm{al}^{30}$ and Rebbeck et $\mathrm{al}^{35}$ showed that professional practice can be improved by active implementation when compared with dissemination only. However, the outcomes of the two studies were variable. The lack of effect for some outcomes can be explained by high adherence to the guidelines at baseline. For example, in the study of Rebbeck et $\mathrm{al}^{35}$, there was high adherence to the recommendation to prescribe exercises at baseline $(100 \%$ in the experimental group and $92 \%$ in the control group), which leaves little room for improvement. Stevenson et $\mathrm{al}^{37}$ did not find any benefit for professional practice. Rebbeck et $\mathrm{al}^{25}$ suggested this was because Stevenson et $\mathrm{al}^{37}$ used a single educational meeting, as opposed to the two multifaceted educational meetings used by Bekkering et al ${ }^{30}$ and Rebbeck et $\mathrm{al}^{35}$. Another explanation might be that both intervention and control group received an educational session in Stevenson's study, albeit with different content (evidence-based content versus standard content), suggesting a lack of 
contrast between the two groups. Overall this suggests that the quality and quantity of the strategies aimed at increasing implementation of physiotherapy guidelines may influence the degree to which professional practice changes.

This review found no effect on patient health as a result of strategies aimed at increasing implementation of physiotherapy guidelines. Rebbeck et $\mathrm{al}^{35}$ suggested that this was the result of the high quality of current intervention, providing no opportunity for health to improve. Similarly Bekkering et $\mathrm{al}^{29}$ concluded that it is possible that no further benefit was to be expected for patients with low back pain. The outcomes in both groups showed an important improvement in the first 12 weeks, and it may be difficult to further improve these results. In general it might be plausible that improvement on patient health outcomes is too small to detect. These findings are similar to a systematic review of the effectiveness of implementing clinical guidelines for spinal pain ${ }^{25}$ that included 14 trials of clinical guidelines for general practitioners, physiotherapists and surgeons. It found that implementation was effective in terms of professional practice (11 trials), but not in terms of patient health ( 3 trials) or cost of care ( 2 trials).

\section{Limitations of this study}

The limited number of trials included in this study makes it difficult to draw explicit conclusions. Only five studied based on three separate cluster-randomised trials were included, and there is variability in the findings across studies. More studies are needed to further explore the effects of implementation strategies of clinical guidelines.

Most studies only concern the process of care, and therefore mainly provide information for improvement of professional practice. Most interventions are effective under some circumstances but none are under all circumstances. It is not clear what the best intervention strategy is and what factors may explain the variance. Our study confirms the positive effects of interactive educational meetings on professional practice in physiotherapy, although the findings might not be relevant to all professions in health care.

\section{Factors that influence adherence to guideline recommendations}

It has been noted ${ }^{4}$ that certain barriers must be overcome if change of professional behaviour is to result. The key message is that barriers must be identified and systematically addressed by a diversity of well-chosen activities, which have shown to be effective. There are many different types of barriers that prevent implementation of clinical guidelines ${ }^{23}$.

Alternatively, if potential barriers to guideline adherence are not identified, it is difficult to determine whether the lack of effect can or cannot be explained by 
these barriers. Poorer guideline adherence in physiotherapy has been related to less physiotherapy experience and patient characteristics ${ }^{38}$. In this systematic review, such characteristics were not consistently measured in the primary studies.

\section{Implications for the physiotherapy profession}

Although physiotherapy is following the current trend towards evidence-based practice by producing many guidelines, it lags behind the medical profession in evaluating the effects of implementing these guidelines. There is a wealth of research on the effects on guideline implementation; however, these studies have usually concerned themselves with guidelines on interventions for specific medical diagnoses. In addition, most clinical guidelines are not specific to a particular discipline and have been developed in a multidisciplinary context. To date there are only three separate trials reporting on the effects of implementation of clinical guidelines in physiotherapy, highlighting the need for further implementation trials in our profession.

This review has shown that multifaceted interventions based on educational meetings aimed at increasing the implementation of physiotherapy clinical guidelines may improve professional practice, but not patient health or cost of care. These findings are in keeping with results of reviews among other health care professions and add to the argument for the further development of strategies to increase the implementation of guidelines. Evaluation of the effect of strategies to increase the implementation of guidelines is necessary so that conclusions can be drawn about how future guidelines in physiotherapy can be implemented effectively and efficiently. It is only by carefully evaluating the effect of implementing clinical guidelines that we can identify the specific barriers and impediments that need to be overcome in the successful implementation of guidelines.

\section{Acknowledgements}

The authors thank Judy Mead (retired) and Ralph Hammond of the Chartered Society of Physiotherapy (CSP), United Kingdom, for their support in initiating and completing this paper. 


\section{REFERENCES}

1. Grimshaw J, Eccles M, Russell I. Developing clinically valid practice guidelines. J Eval Clin Pract. 1995;1:37-48.

2. Grimshaw J, Freemantle N, Wallace $S$ et al. Developing and implementing clinical practice guidelines. Qual Health Care. 1995;4:55-64.

3. Grol R, Grimshaw J. From best evidence to best practice: effective implementation of change in patients' care. Lancet. 2003;362:1225-1230.

4. Grol R, Wensing M, Eccles M. Improving patient care; the implementation of change in clinical practice. London: Elsevier; 2005.

5. Field MJ, Lohr K. Guidelines for clinical practice, from development to use. Washington DC: Institute of medicine. National Academic Press; 1992.

6. Woolf SH, Grol R, Hutchinson A, Eccles M, Grimshaw J. Potential benefits, limitations and harms of clinical guidelines. BMJ. 1999;527-530.

7. Eddy DM. Clinical decision making: from theory to practice. Guidelines for policy statements: the explicit approach. JAMA. 1990;263:2239-40, 2243.

8. Grimshaw JM, Hutchinson A. Clinical practice guidelines--do they enhance value for money in health care? Br Med Bull. 1995;51:927-940.

9. Herbert RD, Maher CG, Moseley AM, Sherrington C. Effective physiotherapy. BMJ. 2001;323:788790.

10. Moseley AM, Herbert RD, Sherrington C, Maher CG. Evidence for physiotherapy practice: a survey of the Physiotherapy Evidence Database (PEDro). Aust J Physiother. 2002;48:43-49.

11. Hendriks HJM, Bekkering GE, Ettekoven van H, Brandsma JW, Van der Wees PJ, De Bie RA. Development and implementation of national practice guidelines: a prospect for continuous quality improvement in physiotherapy. Physiotherapy. 2000;86:535-547.

12. van der Wees PJ, Hendriks HJM, Veldhuizen HJ. Quality assurance in the Netherlands: from development to implementation and evaluation. Dutch J Physiother. 2003;113:3-6.

13. Rebbeck, T. Low back pain position statement. Melbourne, Australia: Australian Physiotherapy Association; 2002.

14. Costello, J and Jull, G. Neck pain position statement. Melbourne, Australia: Australian Physiotherapy Association; 2000.

15. Mead J, Van der Wees PJ. Clinical guidelines: An introduction. WCPT Keynotes. EBP ed. London: World Confederation for Physical Therapy (WCPT); 2006.

16. van der Wees, P. J. and Mead J. Framework for clinical guideline development. Brussels: European Region of World Confederation for Physical Therapy; 2004.

17. van der Wees PJ, Mead J. Clinical guidelines 2: Developing the guidelines. WCPT Keynotes. EBP ed. London: World Confederation for Physical Therapy (WCPT); 2006.

18. Grimshaw JM, Thomas RE, MacLennan $\mathrm{G}$ et al. Effectiveness and efficiency of guideline dissemination and implementation strategies. Health Technol Assess. 2004;8:iii-72.

19. Doumit G, Gattellari M, Grimshaw J, O’brien M. Local opinion leaders: effects on professional practice and health care outcomes. Cochrane Database Syst Rev. 2007;CD000125.

20. Jamtvedt G, Young JM, Kristoffersen DT, O'Brien MA, Oxman AD. Audit and feedback: effects on professional practice and health care outcomes. Cochrane Database Syst Rev. 2006;CD000259.

21. O'brien M, Rogers S, Jamtvedt G et al. Educational outreach visits: effects on professional practice and health care outcomes. Cochrane Database Syst Rev. 2007;CD000409.

22. Forsetlund L, Bjorndal A, Rashidian A et al. Continuing education meetings and workshops: effects on professional practice and health care outcomes. Cochrane Database Syst Rev (submitted). 2008.

23. EPOC. Effective Practice and Organisation of Care Group; Scope. www.epoc.cochrane. org/en/scope/html. 2008. 
24. Shaw B, Cheater F, Baker R et al. Tailored interventions to overcome identified barriers to change: effects on professional practice and health care outcomes. Cochrane Database Syst Rev. 2005;CD005470.

25. Rebbeck T, Maher CG, Refshauge KM. Implementation of clinical guidelines for spinal pain: a systematic review. Unpublished data. 2007.

26. PEDro. Physiotherapy Evidence Database. www.pedro.fhs.usyd.edu.au. 2008.

27. EPOC. The Data Collection Checklist. Cochrane Effective Practice and Organisation of Care Group. www.epoc.cochrane.org/en/handsearchers html. 2008.

28. Bekkering GE, Hendriks HJ, van Tulder MW et al. Prognostic factors for low back pain in patients referred for physiotherapy: comparing outcomes and varying modeling techniques. Spine. 2005;30:1881-1886.

29. Bekkering GE, van Tulder MW, Hendriks EJ et al. Implementation of clinical guidelines on physical therapy for patients with low back pain: randomized trial comparing patient outcomes after a standard and active implementation strategy. Phys Ther. 2005;85:544-555.

30. Bekkering GE, Hendriks HJ, van Tulder MW et al. Effect on the process of care of an active strategy to implement clinical guidelines on physiotherapy for low back pain: a cluster randomised controlled trial. Qual Saf Health Care. 2005;14:107-112.

31. Evans DW, Foster NE, Underwood M, Vogel S, Breen AC, Pincus T. Testing the effectiveness of an innovative information package on practitioner reported behaviour and beliefs: the UK Chiropractors, Osteopaths and Musculoskeletal Physiotherapists Low back pain ManagemENT (COMPLeMENT) trial [ISRCTN77245761]. BMC Musculoskelet Disord. 2005;6:41.

32. Fritz JM, Cleland JA, Brennan GP. Does Adherence to the Guideline Recommendation for Active Treatments Improve the Quality of Care for Patients With Acute Low Back Pain Delivered by Physical Therapists? Med Care. 2007;45:973-980.

33. Hoeijenbos M, Bekkering T, Lamers L, Hendriks E, van TM, Koopmanschap M. Cost-effectiveness of an active implementation strategy for the Dutch physiotherapy guideline for low back pain. Health Policy. 2005;75:85-98.

34. Leemrijse $\mathrm{CJ}$, Plas $\mathrm{GM}$, Hofhuis $\mathrm{H}$, van den Ende $\mathrm{CH}$. Compliance with the guidelines for acute ankle sprain for physiotherapists is moderate in the Netherlands: an observational study. Aust J Physiother. 2006;52:293-299.

35. Rebbeck T, Maher CG, Refshauge KM. Evaluating two implementation strategies for whiplash guidelines in physiotherapy: a cluster randomised trial. Aust J Physiother. 2006;52:165-174.

36. Rebbeck TJ, Refshauge KM, Maher CG. Use of clinical guidelines for whiplash by insurers. Aust Health Rev. 2006;30:442-449.

37. Stevenson K, Lewis M, Hay E. Does physiotherapy management of low back pain change as a result of an evidence-based educational programme? J Eval Clin Pract. 2006;12:365-375.

38. van der Wees PJ, Hendriks EJ, Jansen MJ, van BH, de Bie RA, Dekker J. Adherence to physiotherapy clinical guideline acute ankle injury and determinants of adherence: a cohort study. BMC Musculoskelet Disord. 2007;8:45.

39. Willigendael EM, Bendermacher BL, van der BC et al. The development and implementation of a regional network of physiotherapists for exercise therapy in patients with peripheral arterial disease, a preliminary report. BMC Health Serv Res. 2005;5:49. 



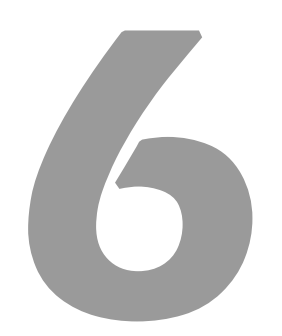

\section{Validity and Responsiveness of the Ankle Function Score after acute ankle injury}

\footnotetext{
Philip J van der Wees ${ }^{1,2}$

Erik JM Hendriks ${ }^{1}$

Hans van Beers ${ }^{1}$

Rogier M van Rijn ${ }^{3}$

Joost Dekker ${ }^{4}$

Rob A de Bie ${ }^{1}$

${ }^{1}$ Department of Epidemiology, Centre for Evidence Based Physiotherapy and Caphri Research Institute, Maastricht University, the Netherlands ${ }^{2}$ Royal Dutch Society for Physical Therapy (KNGF), Amersfoort, the Netherlands ${ }^{3}$ Department of General Practice, Erasmus MC, Rotterdam, the Netherlands ${ }^{4}$ Department of Rehabilitation Medicine, EMGO Institute, VU University Medical Center, Amsterdam, the Netherlands

Submitted
} 


\section{ABSTRACT}

\section{Background}

The Ankle Function Score (AFS) was developed to distinguish between light and severe acute ankle injuries. Since its initial development no further studies were conducted to further validate AFS to monitor progress in functional ability.

\section{Purpose}

To further validate AFS by studying the construct validity, prognostic validity and responsiveness.

\section{Study Design}

Cohort Study

\section{Methods}

Data were collected using an electronic web-based registration system. AFS was compared to Olerud \& Molander Score, Patient Specific Complaints, and Global Perceived Effect. Sensitivity and specificity were calculated to estimate prognostic validity; correlation was calculated for construct validity. Effect Size, Standardized Response Mean, Responsiveness Ratio, and Area Under the Curve of receiver operating characteristic were calculated to estimate responsiveness.

\section{Results}

Sensitivity and specificity of AFS at baseline, for prognosis of recovery two weeks after injury, were $88 \%$ and $57 \%$ respectively. Pearson's correlation between AFS and Olerud \& Molander Score at baseline, end of treatment, and difference was $0.82,0.70$ and 0.79 respectively. Spearman's correlation with Patient Specific Complaints was $0.26,0.49$ and 0.37 for the three comparisons. Effect Size of AFS (2.00) was close to Effect Sizes of Olerud \& Molander Score (2.08) and Patient Specific Complaints (2.14), while Standardized Response Mean of AFS (2.10) was between Olerud \& Molander Score (2.23) and Patient Specific Complaints (1.71). AFS showed Responsiveness Ratio of 2.15 and 3.35, when compared to Global Perceived Effect and AFS as external criteria. Area Under the Curve of AFS (0.69) was higher than Olerud \& Molander Score (0.54) and Patient Specific Complaints (0.55).

\section{Conclusion}

The results show a moderate outcome for prognostic validity of the AFS, and mixed results for construct validity and responsiveness. AFS can be used as instrument in addition to subjective clinical judgment as prognostic tool for recovery after ankle injury and to evaluate progress in patient functioning.

Key terms: Ankle Injuries, Reproducibility of Results, Prognosis, Recovery of Function 


\section{INTRODUCTION}

The Ankle Function Score (AFS) was developed in 1997 by De Bie et al ${ }^{1}$, and aimed to distinguish between light and severe acute ankle injuries. The instrument was derived from the Lysholm score for patients with knee injuries ${ }^{2}$ and adjusted for ankle injuries. The study of De Bie et al, among 35 patients with acute ankle injury at the first-aid department in a hospital setting, showed that the AFS is an excellent instrument for prognosis, well able to distinguish light from severe ankle sprains. Sensitivity and specificity for prognosis of recovery at two weeks after injury were $97 \%$ and $100 \%$ respectively. ${ }^{1}$ A score of $>35$ points (of a total of 100 points) within five days after injury can be considered a light injury which leads to recovery of functional ability within two weeks ( $\geq 75$ points on AFS). AFS is presented in Table 1. In modifying the AFS the cut-off point was raised to 40 points, and is now recommended as outcome measure in the clinical guideline Ankle injury for Dutch physical therapists. ${ }^{3}$

Several outcome measures have been published to evaluate functional ability. Haywood et $\mathrm{al}^{4}$ identified and reviewed evidence of outcome measures for the conservative management of lateral ligament injuries of the ankle. They concluded that a disappointing lack of evidence for measurement properties suggests that any measure should be used with caution until appropriate evidence is provided. The AFS was not included in their review. Based on the limited evidence they identified the Kaikkonen Functional Scale ${ }^{5}$, Karlsson Ankle Function Score ${ }^{6}$ and Olerud \& Molander Score ${ }^{7,8}$ as promising outcome measures for evaluation of function. However, these instruments were not developed as tools for prognosis of functional recovery of ankle sprains. In a meta-analysis of outcome rating scales in foot and ankle surgery, Button et al concluded that no rating scale was identified that demonstrated validity in patients with a variety of foot and ankle conditions. ${ }^{9}$ Eechaute et $\mathrm{al}^{10}$ studied the clinimetric qualities of instruments for measuring chronic ankle instability. They identified two patient self-assessed instruments as the most appropriate tools to quantify functional disabilities in patients with chronic ankle disability: Foot and Ankle Disability Index, and Functional Ankle Ability Measure.

Subsequent to the study of De Bie et $\mathrm{al}^{1}$, no further studies have been published to validate the AFS on its measurement properties as a prognostic tool. Also, the AFS is not assessed for evaluative characteristics to monitor progress in functional ability over time. The objective of this study is to further validate the AFS by studying the construct validity, prognostic validity and responsiveness of the AFS. 
Table 1: Function score

\begin{tabular}{|c|c|c|}
\hline \multirow[t]{8}{*}{ Pain } & No pain during sport & 35 \\
\hline & Pain during or after sport & 30 \\
\hline & Pain when running on uneven surface & 25 \\
\hline & Pain when running on even surface/ non-sports & 20 \\
\hline & Pain when walking on uneven surface & 15 \\
\hline & Pain when walking on even surface & 10 \\
\hline & Pain when weight bearing on injured leg & 5 \\
\hline & Constant pain at rest & 0 \\
\hline \multirow[t]{6}{*}{ Stability } & Never giving way during sport & 25 \\
\hline & Sometimes giving way during sport & 20 \\
\hline & Frequently giving way during sport/ non-sports & 15 \\
\hline & Sometimes giving way during ADL & 10 \\
\hline & Frequently giving way during ADL & 5 \\
\hline & Giving way at every step & 0 \\
\hline Weight & Jumping possible on one leg & 20 \\
\hline \multirow[t]{4}{*}{ bearing } & Toe-stance possible on injured leg & 15 \\
\hline & Standing on injured leg possible & 10 \\
\hline & Standing on both legs possible & 5 \\
\hline & Weight bearing impossible & 0 \\
\hline \multirow[t]{4}{*}{ Swelling } & No swelling & 10 \\
\hline & Light swelling & 6 \\
\hline & Moderate swelling & 3 \\
\hline & Severe swelling & 0 \\
\hline \multirow[t]{4}{*}{$\overline{\text { Gait }}$} & Running is possible & 10 \\
\hline & Walking is possible & 6 \\
\hline & Walking with light limp & 3 \\
\hline & Walking with severe limp & 0 \\
\hline Total & & 100 \\
\hline
\end{tabular}

Derived from De Bie et al, $1997^{1}$

\section{METHODS}

\section{Study design}

A prospective cohort study was performed to measure the quality of usual physical therapy intervention for patients with ankle injury. Data registration was derived from recommendations in the clinical guideline Ankle injury, published by the Royal Dutch Society for Physical Therapy (KNGF) ${ }^{3}$. From a randomized sample, 300 physical therapists working in primary care practice were asked to participate in the study. Based on an expected intake of at least one patient with ankle injury per month, 30 physical therapists agreed to participate. Data were collected by 20 physical therapists in a period of 20 months (July 2006- March 2008). Reasons for not collecting data were lack of time $(n=3)$ or change of work setting $(n=7)$. 
The physical therapists collected data of consecutive patients with acute ankle injury and with functional instability. Criteria for inclusion were acute inversion trauma of the ankle or functional instability after recurrent injury. Criteria for exclusion were severe trauma (fracture).

Patients were informed by the physical therapists about the objective of the study, and were asked to give their informed consent to use their data for the study. Ethical approval for this study was granted by Maastricht University Hospital, Maastricht, Netherlands.

The participating physical therapists were prepared for the study in two meetings, during which the guideline Ankle injury was discussed and instructions were given for registration of patient data. The first meeting took place prior to data collection, with eight weeks time between both meetings.

\section{Data collection}

Data were collected using FastGUIDE ${ }^{\circledR}$, which is an online web-based electronic registration system for patient data, based on clinical guidelines. ${ }^{11}$ Patient characteristics and course of treatment was systematically registered, based on usual care of the participating physical therapists. The outcome measures were integrated in the registration system, and could be filled out electronically. The AFS was compared to the Olerud \& Molander Score (OMS), Patient Specific Complaints (PSC) and Global Perceived Effect (GPE) to estimate the construct validity, prognostic validity and responsiveness of the AFS. Physical therapists were asked to measure AFS, OMS and PSC at baseline and every two weeks after baseline. GPE was measured at two weeks after baseline and at the end of treatment.

The Olerud \& Molander Score (OMS) was originally developed as a patientassessed scoring scale for symptom evaluation after ankle fracture ${ }^{7}$, and later also used for evaluation after acute ankle injuries. ${ }^{8}$ OMS was chosen because of comparability with the AFS and evidence for validity. ${ }^{4}$ OMS consists of nine subjective parameters on a scoring scale from 0-100. The Patient Specific Complaints (PSC) was developed by Beurskens et al to measure changes over time of the main complaints of patients with low back pain. ${ }^{12,13}$ With the PSC the patient chooses the main complaint(s) with functioning, and uses a visual analog scale (100mm VAS) to estimate the severity of the complaint. The PSC is a responsive instrument for measuring the main complaint in daily practice. The Global Perceived Effect (GPE) is a commonly used global rating scale as an often used external criterion to score the perceived change of patients after intervention. ${ }^{14,15}$ A 7-point scale was used (1= completely recovered, $7=$ worse than ever). Patients who scored 1 were considered recovered versus patients who scored 2-7 who were considered as not recovered. 


\section{Data analysis}

The validity was studied by measuring prognostic validity, construct validity and responsiveness of the Function Score. Prior to the analysis we described hypotheses for each item about strength and direction of correlations. Hypotheses were based on the earlier study by De Bie et al. ${ }^{1}$ SPSS (version 15.0) was used for statistical analysis.

Prognostic validity (criterion validity): Prognostic value of the AFS at baseline (0-5 days after injury) was compared with the AFS and Global Perceived Effect (GPE) at two weeks after injury, as external criteria to validate prognosis of recovery. Hypothesis was that a score on the AFS of $\leq 40$ points at intake $0-5$ days after injury, would lead to a score on the AFS of $<75$ points at 2 weeks after injury, and GPE of $\geq 2$ (on a scale of $1-7$ ). Sensitivity and specificity was hypothesized at $60-80 \%$, since the patient population in primary care was expected to be different from the population in the hospital setting of De Bie et al. ${ }^{1}$

Construct validity: The evaluative value of the AFS was measured by comparing the construct of the AFS with the Olerud \& Molander Score (OMS) and the Patient Specific Complaints (PSC). Correlation was calculated by (paired) comparison of scores at baseline and at the end of the intervention episode, and the change in scores between baseline and at the end of the intervention episode. Pearson's $r$ for linear correlation was calculated for correlation between the AFS and the OMS. Spearman's rho for non-linear correlation was calculated for correlation between the AFS and the PSC. Correlation is considered excellent with scores of 0.60 or higher, adequate between 0.31 and 0.59 , and poor with scores $\leq 0.30^{16}$. Based on the similarities between the domains of the two scores, hypothesis was that correlation between the AFS and the OMS would be $\geq 0.70$. Correlation between AFS and PSC was expected to be lower $(\geq 0.50)$, due to basic differences between these two outcome measures.

Responsiveness: To study the clinical relevance of the AFS, three different analyses were used: (a) Effect Size (ES: average score change/SD of initial score) ${ }^{17,18}$ and Standardized Response Mean (SRM: average score change/SD of score change) ${ }^{16}$, in which the AFS was compared with the OMS and the PSC; (b) Responsiveness Ratio of Guyatt (GRI: average change of recovered patients/SD of average change of nonrecovered patients $)^{19}$. Difference between recovered and non-recovered patients was measured using GPE (GPE=1 vs. GPE=2-7 respectively), and the AFS at end of treatment episode (recovered when $\geq 75$ points; (c) Receiver Operating characteristic (ROC) was used by calculating the Area Under the Curve (AUC). ROC-AUC analyses are considered excellent with scores $\geq 0.90$, adequate with scores between 0.70-0.89 and poor with scores $<0.70^{16}$. The effect sizes for all outcomes were expected to be higher than $1^{18}$. Hypothesis was that for all comparisons, responsive- 
ness of the AFS would be equal to or lower than the OMS and the PSC. AUC was expected to be $>0.70$.

\section{RESULTS}

Characteristics of patients with acute ankle injury are shown in Table 2. The majority of the patients was male (61\%), $30 \%$ of all patients did not perform sports activities, and $3 \%$ were professional athletes. Average number of treatment sessions per episode of care was 5.2 (sd: 3.2) with duration of treatment of 6.6 weeks (sd: 5.8 ) (Table 3).

Prognostic validity (criterion validity): Sensitivity and specificity of the AFS at baseline, for prognosis of recovery at two weeks after injury, was respectively $88 \%$ and $57 \%$ using the AFS as criterion, and $76 \%$ and $63 \%$ using the GPE as criterion (Table 4).

Construct validity: Average baseline score for the AFS was 43.2 (sd: 23.8). The OMS and the PSC scores were 38.4 (sd: 26.7) and 73.9 (sd: 29.0) respectively. Mean score at the end of intervention episode for the AFS was 88.5 (sd: 14.0), and for the OMS and PSC mean end scores were 91.1 (sd: 12.5) and 15.0 (sd: 27.0) respectively. Pearson's correlation for the AFS with the OMS at baseline, end of treatment episode and change score (end-baseline) were $0.82,0.70$ and 0.79 respectively. Spearman's correlation for the AFS with the PSC at baseline, end of intervention and change score (baseline-end) were $0.26,0.49$ and 0.37 respectively (Table 5). Spearman's correlation between the OMS and the PSC varied between 0.36 and 0.41.

Responsiveness: Effect Sizes (ES) and Standardized Response Means (SRM) are presented in Table 6. Both ES (2.00) and SRM (2.10) of the AFS were close to the OMS, with an ES and SRM of 2.08 and 2.23 respectively. SRM of the AFS was higher (2.10) than the PSC (1.71). Responsiveness Ratio (GRI) of the AFS was 2.15 and 3.35, when compared to respectively the GPE and the AFS as criteria for recovered patients (Table 7). The Area under the Curve (AUC) of the Receiver Operating Characteristic (ROC) for the AFS was 0.69 and higher than the OMS (0.54) and the PSC (0.55) (Table 8). 
Table 2: Patient Characteristics with acute ankle injury $(\mathrm{N}=106)$

\begin{tabular}{llrrrr}
\hline & & $\mathrm{N}$ & $(\%)$ & $\mathrm{X}$ & (SD) \\
\hline Gender & Male & 65 & $(61)$ & & \\
& Female & 41 & $(39)$ & & \\
Age (years) & & & 31.9 & $(14.6)$ \\
Duration of complaints (days) & & & & \\
Injury & Light (FS $>40)$ & 52 & $(49)$ & & \\
& Severe (FS $\leq 40)$ & 53 & $(50)$ & & \\
Sports activities & Missing & 1 & $(1)$ & & \\
& None & 32 & $(30)$ & & \\
& Recreation & 47 & $(44)$ & & \\
& Prestation & 24 & $(23)$ & & \\
Load in ADL & Maximal (top) & 3 & $(3)$ & \\
& Light & 25 & $(24)$ & \\
& Normal & 47 & $(44)$ & \\
\hline
\end{tabular}

Table 3: Treatment characteristics $(\mathrm{N}=106)$

\begin{tabular}{lrr}
\hline & $\mathrm{X}$ & $(\mathrm{sd})$ \\
\hline Expected \# of treatment sessions & 6.3 & $(3.2)$ \\
Expected duration of treatment episode (wks) & 5.9 & $(2.8)$ \\
Realized \# of treatment sessions & 5.2 & $(3.2)$ \\
Realized duration of treatment episode & 6.6 & $(5.8)$ \\
Function score at Baseline & 43.2 & $(23.9)$ \\
Function score at End of treatment episode & 88.5 & $(14.0)$ \\
\hline
\end{tabular}

Table 4: Prognostic validity: Ankle Function Score (AFS) at baseline (0-5 days after injury) compared with AFS and GPE at two weeks after injury.

\begin{tabular}{lllll}
\hline Ankle Function Score (AFS) & Not recovered at 2 & Recovered at 2 wks & & \\
& wks (AFS $<75)$ & $(\mathrm{AFS} \geq 75)$ & 24 & Pred. value (+): $63 \%$ \\
Severe injury (AFS $\leq 40)$ & 15 & 9 & 14 & Pred. value (-): $86 \%$ \\
Light injury (AFS $>40)$ & 2 & 21 & 38 & \\
& 17 & Specificity: $57 \%$ & & \\
Global Perceived Effect (GPE) & Sensitivity: $88 \%$ & & & \\
& Not recovered at 2 & Recovered at 2 wks & & \\
Severe injury (AFS $\leq 40)$ & wks (GPE=2-7) & $($ GPE=1) & 22 & Pred value (+): $86 \%$ \\
Light injury (AFS $>40)$ & 19 & 3 & 11 & Pred. value (-): $45 \%$ \\
& 6 & 5 & 33 & \\
\hline
\end{tabular}


Table 5: Correlation for Ankle Function Score (AFS) with OMS and PSC

\begin{tabular}{lll}
\hline & OMS* & PSC** \\
\hline AFS (Baseline) & 0.82 & 0.26 \\
AFS (End of treatment episode) & 0.70 & 0.49 \\
AFS difference (End-Baseline) & 0.79 & 0.37 \\
\hline
\end{tabular}

* Pearson's r (linear)

** Spearman's rho (non-linear)

Table 6: Effect Size (ES) and Standardized Response Mean (SRM)

\begin{tabular}{llllll}
\hline & Mean change & SD (baseline) & SD (change) & ES & SRM \\
AFS $(n=85)$ & 47.66 & 23.86 & 22.69 & 2.00 & 2.10 \\
OMS $(n=86)$ & 55.51 & 26.68 & 24.89 & 2.08 & 2.23 \\
PSC $(n=86)$ & 61.93 & 28.96 & 36.29 & 2.14 & 1.71 \\
\hline
\end{tabular}

Table 7: Responsiveness Ratio (GRI)

\begin{tabular}{|c|c|c|c|c|c|c|}
\hline & $\begin{array}{l}\text { Mean Change } \\
(\mathrm{AFS} \geq 75)\end{array}$ & $\begin{array}{l}\text { SD mean Change } \\
(\mathrm{AFS}<75)\end{array}$ & $\begin{array}{l}\text { Mean change } \\
(\mathrm{GPE}=1)\end{array}$ & $\begin{array}{l}\text { SD Mean Change } \\
\text { (GPE2-7) }\end{array}$ & $\begin{array}{l}\text { GRI } \\
\text { (AFS) }\end{array}$ & $\begin{array}{l}\mathrm{GRI} \\
\text { (GPE) }\end{array}$ \\
\hline$\overline{\mathrm{AFS}}$ & 50.28 & 15.02 & 51.83 & 23.89 & 3.35 & 2.15 \\
\hline OMS & 56.20 & 21.07 & 58.50 & 24.52 & 2.67 & 2.39 \\
\hline PSC & 66.38 & 45.00 & 71.50 & 33.59 & 1.48 & 2.13 \\
\hline
\end{tabular}

Table 8: Receiver Operating Characteristic: Area Under the Curve (AUC)

\begin{tabular}{llll}
\hline & Average change & AUC (GPE) & AUC (AFS) \\
\hline AFS & 47.66 & 0.58 & 0.69 \\
OMS & 55.51 & 0.53 & 0.54 \\
PSC & 61.93 & 0.60 & 0.55 \\
\hline
\end{tabular}

\section{DISCUSSION}

Main outcome of this study is that sensitivity and specificity of the AFS is moderate for prognosis of recovery at two weeks after acute ankle injury. Sensitivity for prognosis of non-recovery in two weeks was higher for the AFS as external criterion than GPE, while specificity for prognosis of recovery within two weeks was in the same range. These results are lower than sensitivity and specificity found in the study of De Bie et al. ${ }^{1}$ The study of De Bie et al was conducted in the emergency department setting of a hospital, compared to a primary care setting in our study. Because of the differences between the two settings our hypothesis was that sensitivity and specificity of $60-80 \%$ was to be expected. One out of four outcomes for sensitivity and specificity in our study was below $60 \%$. It can be expected that a hospital setting shows an over-representation of severe injuries, and de Bie et al included 28 out of 33 patients with severe injuries in their analyses (85\%) compared to 24 out of 38 in our study (63\%). Prognostic values for recovery in the study 
of de Bie et al predominantly showed that patients with severe injuries will not recover within two weeks (prognostic value of $100 \%$ ), compared to the prognosis that patients with light injury will recover within two weeks (prognostic value of $80 \%$ ). Our study showed higher outcomes of prognostic values for will recover in light injuries, as for will not recover in severe injuries (86\% versus $63 \%$ respectively).

Analysis of the construct validity showed excellent correlation of the AFS with Olerud \& Molander Score (OMS), but low correlation with Patient Specific Complaints (PSC). Our hypothesis was that correlation between the AFS and the OMS would be higher than 0.7 , since the constructs of the two scores are comparable with similarities in domains (pain, swelling, gait, weight bearing) and number of points (0100). Based on limited evidence Haywood et al concluded that the OMS was one of the promising outcome measures for evaluating function ${ }^{4}$. The high correlation between the AFS and the OMS in our study supports the value of the AFS to evaluate specific ankle functioning. The correlation between the AFS and the PSC was lower than the hypothesized correlation of 0.5. The PSC is an instrument that measures general change of the main complaint(s) of the patient with functioning over time, and is based on a different construct than the AFS. This is confirmed by the low correlation between the OMS and the PSC.

Responsiveness of the AFS in comparison with the OMS and the PSC, to study clinical relevance, showed some variability in outcomes. Effect Size (ES) of the AFS was close to the OMS and the PSC. Standardized Response Mean (SRM) was higher than the PSC but lower than the OMS. The AFS showed the highest Area Under the Curve (AUC) with a value of 0.69 , but is lower than the threshold of 0.70 in order to be considered adequate. ${ }^{16}$ The results confirm our hypothesis that responsiveness of the AFS would be equal to or lower than the OMS and the PSC.

\section{Limitations of this study}

Data were collected in a non-controlled cohort study, registering care by physical therapists that were trained in two interactive educational meetings. The electronic data collection with FastGUIDE ${ }^{\circledR}$ did not control registration, but left room for physical therapists to choose treatment options and to use (or not use) outcome measures. Main advantage of this setting is that registration resembles daily practice in this group of physical therapists and therefore reflects usual care. Disadvantage of this setting is that physical therapists were not obliged to fill out all details of care, which resulted in missing data. For example, from the 106 included patients in this study we only could calculate prognostic validity using data from 68 patients. This may have caused potential bias in this study. 
This study lacks a (random) sample of physical therapists that were not trained in using the clinical guideline. The educational sessions may have caused an 'implementation effect' in this specific group of physical therapists. This may reduce generalization of the outcome of this study.

\section{Relevance for clinical practice}

This study found limited evidence for the Function Score as diagnostic and evaluative instrument. These findings are in conjunction with Haywood et $\mathrm{al}^{4}$ who concluded that a disappointing lack of evidence for measurement properties suggests that any measure should be used with caution until appropriate evidence is provided. On the other hand the Function Score is a relatively simple instrument based on basic functional outcomes, which are usually included in the assessment by the clinician (pain, stability, weight bearing, swelling, and gait). It can therefore easily be used as instrument in addition to subjective clinical judgment. The need for use of objective outcome measures is widely accepted in health care, and the Function Score may be added to the available recourses to diagnose and evaluate ankle injuries. It is a recommended measurement instrument in the Dutch clinical guideline for physical therapists, which is an important basis for the further use and evaluation of the Function Score. For daily practice the Function Score can both be used as diagnostic tool to predict recovery and to evaluate progress in functioning.

\section{CONCLUSION}

The results of this study show a moderate outcome for predictive validity of the Function Score and mixed results for construct validity and responsiveness. Generalization of the outcome may be limited due to the specific setting of the study. These findings are in conjunction with other validation studies of measurement instruments that evaluate functioning after ankle injury. The Function Score can be used as instrument in addition to subjective clinical judgment as prognostic tool to predict recovery and to evaluate progress in functioning of the patient. 


\section{REFERENCES}

1. de Bie RA, de Vet HC, van den Wildenberg FA, Lenssen T, Knipschild PG. The prognosis of ankle sprains. Int J Sports Med. 1997;18:285-289.

2. Lysholm J, Gillquist J. Evaluation of knee ligament surgery results with special emphasis on use of a scoring scale. Am J Sports Med. 1982;10:150-154.

3. van der Wees PhJ, Lenssen A.F., Feijts YAEJ et al. KNGF-richtlijn Enkelletsel. Ned Tijdschr Fysioth. 2006;116.

4. Haywood KL, Hargreaves J, Lamb SE. Multi-item outcome measures for lateral ligament injury of the ankle: a structured review. J Eval Clin Pract. 2004;10:339-352.

5. Kaikkonen A, Kannus P, Jarvinen M. A performance test protocol and scoring scale for the evaluation of ankle injuries. Am J Sports Med. 1994;22:462-469.

6. Karlsson J, Peterson L. Evaluation of ankle joint function. The use of a scoring scale. Foot. 1991;11:15-19.

7. Olerud C, Molander H. A scoring scale for symptom evaluation after ankle fracture. Arch Orthop Trauma Surg. 1984;103:190-194.

8. Rose A, Lee RJ, Williams RM, Thomson LC, Forsyth A. Functional instability in non-contact ankle ligament injuries. Br J Sports Med. 2000;34:352-358.

9. Button G, Pinney S. A meta-analysis of outcome rating scales in foot and ankle surgery: is there a valid, reliable, and responsive system? Foot Ankle Int. 2004;25:521-525.

10. Eechaute C, Vaes P, Van AL, Asman S, Duquet W. The clinimetric qualities of patient-assessed instruments for measuring chronic ankle instability: a systematic review. BMC Musculoskelet Disord. 2007;8:6.

11. Centre for Evidence Based Physiotherapy (CEBP). www.cebp.nI. 2008.

12. Beurskens AJ, de Vet HC, Koke AJ. Responsiveness of functional status in low back pain: a comparison of different instruments. Pain. 1996;65:71-76.

13. Beurskens AJ, de Vet $\mathrm{HC}$, Koke AJ et al. A patient-specific approach for measuring functional status in low back pain. J Manipulative Physiol Ther. 1999;22:144-148.

14. Bombardier C. Outcome assessments in the evaluation of treatment of spinal disorders: summary and general recommendations. Spine. 2000;25:3100-3103.

15. Ostelo RW, de Vet HC. Clinically important outcomes in low back pain. Best Pract Res Clin Rheumatol. 2005;19:593-607.

16. Fitzpatrick R, Davey C, Buxton MJ, Jones DR. Evaluating patient-based outcome measures for use in clinical trials. Health Technol Assess. 1998;2:i-74.

17. Deyo RA, Diehr P, Patrick DL. Reproducibility and responsiveness of health status measures. Statistics and strategies for evaluation. Control Clin Trials. 1991;12:142S-158S.

18. Kazis LE, Anderson JJ, Meenan RF. Effect sizes for interpreting changes in health status. Med Care. 1989;27:S178-S189.

19. Guyatt G, Walter S, Norman G. Measuring change over time: assessing the usefulness of evaluative instruments. J Chronic Dis. 1987;40:171-178. 


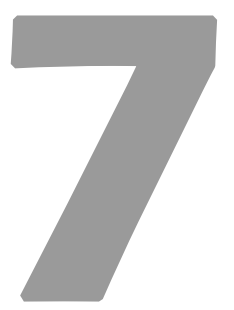

\title{
Applicability of the Ottawa ankle rules in primary care: results from a pilot study
}

\author{
Philip J van der Wees ${ }^{1,2}$ \\ Erik JM Hendriks ${ }^{1}$ \\ Vivian Bruls ${ }^{1}$ \\ Joost Dekker ${ }^{3}$ \\ Rob A de Bie ${ }^{1}$
}

1 Department of Epidemiology, Centre for Evidence Based Physiotherapy and Caphri Research Institute, Maastricht University, the Netherlands 2 Royal Dutch Society for Physical Therapy (KNGF), Amersfoort, the Netherlands 3Department of Rehabilitation Medicine, EMGO Institute, VU University Medical Center, Amsterdam, the Netherlands

Submitted 


\section{ABSTRACT}

\section{Background}

The Ottawa Ankle Rules (OAR) is an excellent instrument to exclude fractures after acute ankle sprain in an emergency department setting. Applicability of OAR in a primary care setting is unknown. This study assessed whether OAR are applicable in primary care by Physiotherapists (PTs), and if PT characteristics influence interpretation of test results.

\section{Methods}

Twenty PTs collected data of 107 patients with acute ankle sprain. Course of treatment was registered electronically, with details about application of OAR. Characteristics of PTs were collected in a written survey. A telephone survey was conducted to identify possible fractures during or after course of treatment. Association between PT characteristics and outcome of OAR was calculated using logistic regression.

\section{Results}

OAR was positive in 17 patients with self-referral to the PT within one week after injury and without prior X-ray. Five patients were referred to a General Practitioner (GP): none of these patients were diagnosed with a fracture. Twelve patients were not referred to a GP: no fractures were identified for these patients during or after course of treatment.

PTs with more experience showed less positive outcomes of OAR (OR: 0.09 ( $95 \% \mathrm{Cl}: 0.01$ to 0.61$)$ ). PT with specific education referred less patients with positive OAR to a GP (OR: 0.22 ( $95 \% \mathrm{Cl}: 0.05$ to 0.95$)$ ).

\section{Conclusion}

False-positive rate of OAR used by PTs in primary care is very high, and suggests OAR cannot be generalized for use in a primary care setting. Specific setting and patient mix in primary care may require more subtle clinical decision making when applying OAR. 


\section{INTRODUCTION}

Most patients who visit an emergency department after acute ankle sprain undergo radiography to identify fractures, although prevalence of fractures in these patients is less than $15 \%{ }^{1-4}$. The Ottawa ankle rules (OAR) is an excellent instrument to exclude fractures ${ }^{2}$, and may reduce the number of radiographs by $30-40 \% \%^{2,5,6}$ and reduce medical costs ${ }^{1}$. The instrument consists of a questionnaire for assessment of ankle and foot and covers the ability to walk four steps immediately after injury and notes localized tenderness of lateral or medial malleolus, navicular bone, or the base of the fifth metatarsal. The instrument has a sensitivity of almost $100 \%$ and a modest specificity (median specificity: $31.5 \%)^{2}$. Although sensitivity of the instrument reduces in the first days ( $>48$ hours) after injury, it can be applied in the first week after injury. The OAR is also a valid instrument to exclude fractures ${ }^{7-9}$ in athletes. Application of the instrument is considered important for clinicians to assist in decision making for additional diagnostic tests like radiographs. However, it is important that the test is applied correctly. Studies show a high variability of the specificity of the OAR caused by clinical experience and setting, interpretation of the test and cultural differences ${ }^{2,5,10}$. The modest specificity of the OAR indicates a high rate of false-positive results (i.e. positive outcome of OAR, while no fracture is apparent). Although the OAR are among the most validated and implemented clinical prediction rules, they have proved unsuccessful in some populations ${ }^{11-13}$. Glas et $\mathrm{al}^{14}$ suggested that the severity of ankle injury might vary between populations, because of various thresholds for seeking medical assistance.

Published studies to validate the OAR are performed in an emergency department setting ${ }^{2}$. We have found no studies that assessed the applicability of the OAR as a decision tool in primary care. Bachmann et al $^{2}$ advocate dissemination of the OAR among general practitioners and people supervising sports activities. For physiotherapists the OAR are relevant, because they can be the first contact practitioner in primary care. In $200628 \%$ of all patients in the Netherlands contacted a primary care physiotherapist by self-referral ${ }^{15}$.

The use of the OAR is recommended as clinical decision rule in the clinical guideline Ankle sprain of the Royal Dutch Society for Physical Therapy (KNGF) ${ }^{16}$. The guideline recommends applying the rules in patients who visit the physiotherapist the first week after injury, when no X-ray has been taken and/or is not seen by a physician. When the OAR are positive, the patient should be referred to a general practitioner for further (radiographic) diagnosis. It is not clear how the OAR is applied by physiotherapists in primary care.

The objective of this pilot study is to analyze the applicability of the OAR in primary care by physiotherapists with research question: is the OAR applicable in primary 
care by physiotherapists and do physiotherapist characteristics influence interpretation of the test results?

\section{METHODS}

\section{Study design}

A prospective cohort study was performed to evaluate the quality of usual physiotherapy intervention for patients with ankle injury. Data registration was derived from recommendations in the clinical guideline Ankle sprain, published by the Royal Dutch Society for Physical Therapy $(\mathrm{KNGF})^{16}$. From a random sample, 300 physiotherapists in primary care practice were asked to participate. Criterion for inclusion was an expected intake of at least one patient with ankle injury per month, and 30 physiotherapists agreed to participate. Data were collected by 20 physiotherapists in a period of 20 months (July 2006- March 2008). Reasons for not collecting data were lack of time $(n=3)$ or change of work setting $(n=7)$.

The physiotherapists collected data of consecutive patients with acute ankle injury and with functional instability. Criteria for inclusion were acute inversion trauma of the ankle or functional instability after recurrent injury.

Patients were informed by the physiotherapists about the objective of the study, and were asked to give their informed consent to use their data for the study. Ethical approval for this study was granted by Maastricht University Hospital.

The participating physiotherapists were prepared for the study in two meetings, during which the guideline Ankle sprain was discussed and instructions were given for registration of patient data. The OAR were specifically presented and discussed at the meetings. The first meeting took place prior to data collection, with eight weeks time between both meetings.

\section{Data collection}

Data for physiotherapy diagnosis and treatment were collected using FastGUIDE ${ }^{\circledR}$, a web-based electronic registration system for patient data, based on clinical guidelines ${ }^{17}$. Patient characteristics and course of treatment was systematically registered, based on usual care of the participating physiotherapists. Specific details about diagnosis and treatment were collected. The OAR were included in the screening process during intake, and in the electronic registration form the physiotherapists were reminded to apply the OAR until one week after acute ankle sprain. Other aspects of data collection were derived from the clinical guideline Ankle sprain $^{16}$ and general requirements for patient notes: referral, X-ray, red flags, recurrent injury, co-morbidity, duration of complaint, function, activities, participa- 
tion, recovery, treatment goals, intervention, accomplished treatment goals, treatment sessions, duration of treatment. Specific outcome measures were: Ankle Function Score $(\mathrm{AFS})^{18}$, Olerud \& Molander Score $(\mathrm{OMS})^{19,20}$, Patient Specific Complaints (PSC) ${ }^{21,22}$, and Global Perceived Effect (GPE) $)^{23,24}$.

Characteristics of participating physiotherapists were collected in a written survey and included gender, age, years of experience, working hours per week, work setting, and continuing education.

After data collection a telephone survey was conducted to collect information from participating physiotherapists, who identified a positive outcome of the OAR in the first week after injury, but did not refer the patient back to the general practitioner. Two specific questions were asked: (1) what was the reason for not referring the patient to the general practitioner; and (2) was a fracture identified during or after the course of treatment?

\section{Data analysis}

Patient characteristics, physiotherapist characteristics, and outcomes of the OAR were described using descriptive statistics.

To investigate correlations between physiotherapist characteristics and the use of the OAR, univariate logistic regression was carried out between prognostic (independent) physiotherapist variables and two dependent variables: the outcome of the OAR (negative or positive), and the decision (no or yes) to refer the patient to the general practitioner when a positive outcome of the OAR was found. The following physiotherapist variables were considered: age, years of experience $(\leq 10 \mathrm{yr} />10 \mathrm{yr})$, working hours per week $(\leq 30 />30)$, registration as sports physiotherapist (no/yes), work setting (solo/group practice), specific education in ankle injury (no/yes).

Regression coefficient (B), Standard Error of Mean (SE), and statistical significance ( $p$-value) were calculated. Prognostic factors with $p$-values of $<0.10$ were included in multivariable logistic regression analysis using the enter model. Odds Ratio using $e^{B}, 95 \%$ Confidence Interval, and $p$-value were calculated for each prognostic variable.

SPSS (version 15.0) was used for statistical analysis.

\section{RESULTS}

Data of 107 patients with acute ankle sprain were collected. Table 1 shows characteristics of patients. Average age was 31.9 years (sd:14.6). Sports activities were performed by 74 patients (69\%). Almost half (49\%) of all patients were referred by 
a general practitioner or other physician, while $14 \%$ of the patients were advised by a physician to see a physiotherapist without a written referral. Average duration of complaints at intake was 8.7 days (sd: 9.0 ).

All participating physiotherapists were registered in the national register of the Royal Dutch Society for Physical Therapy (KNGF) as general physiotherapist, with a variety in additional registration as specialist (Table 2). The majority $(n=14)$ had more than 10 years of experience.

\section{Application of Ottawa ankle rules}

The OAR were taken in 100 patients (93\%), and showed positive outcomes in 57 patients (53\%). Pain at palpation of the lateral malleolus, as one of the five rules, was most frequently positive (38 patients; $36 \%$ ) (Table 3 ). The OAR were taken in all patients $(n=52)$ who visited the physiotherapist within one week after injury and without prior X-ray (Table 4). Average duration of complaints for these patients was 3.8 days (sd: 2.2). The OAR were also taken in 20 out of 21 patients who did have a prior X-ray before their visit to the physiotherapist in the first week after injury. Five out of 17 patients with positive OAR and without prior radiography were referred to the general practitioner. After screening by a general practitioner none of these patients were diagnosed with a fracture, and they were referred back for physiotherapy treatment. None of the 12 patients with positive OAR, who were not referred to a general practitioner, were diagnosed with an ankle fracture during or after course of physiotherapy treatment. 
Table 1: Patient Characteristics with acute ankle sprain ( $\mathrm{N}=107)$

\begin{tabular}{llrrr}
\hline & & $\mathrm{N}(\%)$ & $\mathrm{X}$ & (SD) \\
\hline Gender & Male & $65(61)$ & & \\
Age (years) & Female & $42(39)$ & & \\
Duration of complaints (days) & & & 31.9 & $(14.6)$ \\
Sports activities & None & & 8.7 & $(9.0)$ \\
& Recreation & $33(31)$ & & \\
& Prestation & $47(44)$ & & \\
Load in ADL & Maximal (top) & $24(22)$ & \\
& Light & $3(3)$ & & \\
Neferral & Normal & $25(23)$ & & \\
& Heavy & $48(45)$ & & \\
& No & $34(32)$ & \\
& Advised by GP & $41(38)$ & \\
& Yes & $14(13)$ & \\
\hline
\end{tabular}

Table 2: Characteristics of physiotherapists $(\mathrm{N}=20)$

\begin{tabular}{|c|c|c|c|c|}
\hline & & $\mathrm{N}$ & $\mathrm{x}$ & (SD) \\
\hline \multirow[t]{2}{*}{ Gender } & Male & 18 & & \\
\hline & Female & 2 & & \\
\hline Age (years) & & & 40.5 & $(11.1)$ \\
\hline \multirow[t]{2}{*}{ Registered } & Yes & 20 & & \\
\hline & No & 0 & & \\
\hline \multirow[t]{6}{*}{ Type of Register } & General & 9 & & \\
\hline & General + Sports & 3 & & \\
\hline & General + Manual Therapy & 5 & & \\
\hline & General + Oedema & 1 & & \\
\hline & General + Psychosomatic & 1 & & \\
\hline & General + Sports + Manual Therapy & 1 & & \\
\hline \multirow[t]{3}{*}{ Experience } & $0-5 \mathrm{yr}$ & 3 & & \\
\hline & $5-10 y r$ & 3 & & \\
\hline & $>10 \mathrm{yr}$ & 14 & & \\
\hline \multirow[t]{4}{*}{ Working hours/wk } & $<10$ & 0 & & \\
\hline & $10-20$ & 1 & & \\
\hline & $20-30$ & 5 & & \\
\hline & $>30$ & 14 & & \\
\hline \multirow[t]{3}{*}{ Worksetting } & Solo practitioner & 2 & & \\
\hline & Group practice & 16 & & \\
\hline & Health center & 2 & & \\
\hline \multirow[t]{2}{*}{ Specific Education } & Yes & 12 & & \\
\hline & No & 8 & & \\
\hline
\end{tabular}


Table 3. Characteristics of intake and screening ( $\mathrm{N}=107)$

\begin{tabular}{lccc}
\hline & No N (\%) & Yes N (\%) & Missing N (\%) \\
\hline Patient referred by GP & $41(38) 14(13)^{*}$ & $52(49)$ & \\
X-ray taken & $71(66)$ & $36(34)$ & \\
Ottawa ankle rules taken & $7(7)$ & $100(93)$ & \\
Ottawa ankle rules (OAR) positive & $43(40)$ & $57(53)$ & $7(6)$ \\
Ability weight bearing positive & $79(74)$ & $21(20)$ & $7(6)$ \\
Pain lateral malleolus positive & $62(58)$ & $38(36)$ & $7(6)$ \\
Pain medial malleolus positive & $84(79)$ & $16(15)$ & $7(6)$ \\
Pain metatarsal V positive & $94(88)$ & $6(6)$ & $7(6)$ \\
Pain navicular positive & $97(91)$ & $3(3)$ & $7(6)$ \\
Patient referred to GP & $91(85)$ & $15(14)$ & $1(1)$ \\
Referral GP back to physiotherapist $(\mathrm{n}=15)$ & $0(0)$ & $15(100)$ & \\
\hline
\end{tabular}

*patient advised by GP to go to a physiotherapist, but no written referral

Table 4: Ottawa ankle rules (OAR) in relation to prior X-ray and referral to GP

\begin{tabular}{llllc}
\hline OAR taken (intake $\leq 7$ days after injury) & & Without X-ray & With X-ray & Total \\
\hline & OAR not taken & 0 & 1 & 1 \\
& OAR taken & 52 & 20 & 72 \\
& Total & 52 & 21 & 73 \\
Patient referred to GP when OAR positive? & & Not referred to & Referred to GP \\
(intake $\leq 7$ days after injury; no X-ray, no & & GP & & \\
referral) & & & 0 & 15 \\
& OAR negative & 15 & 5 & 17 \\
& OAR positive & 12 & 5 & 32 \\
\hline
\end{tabular}

Table 5: Univariate logistic regression for physiotherapists' characteristics on positive Ottawa Ankle Rules (OAR) and decision to refer patient to General Practitioner (GP)

\begin{tabular}{|c|c|c|c|c|}
\hline Outcomes & Prognostic variables & $\mathrm{B}^{1}$ & $\mathrm{SE}^{2}$ & $p$-value \\
\hline \multirow[t]{6}{*}{ OAR positive } & Age & -0.06 & 0.03 & 0.02 \\
\hline & Experience $(\leq 10 \mathrm{yr} />10 \mathrm{yr})$ & -2.20 & 0.78 & $<0.05$ \\
\hline & Working hours/wk $(\leq 30 />30)$ & -0.34 & 0.44 & 0.44 \\
\hline & Sports physical therapist (no/yes) & 0.23 & 0.45 & 0.61 \\
\hline & Work setting (solo/group) & -0.03 & 0.54 & 0.95 \\
\hline & Specific education (no/yes) & 0.31 & 0.44 & 0.48 \\
\hline \multirow[t]{6}{*}{ Patient referred to $\mathrm{GP}^{3}$} & Age & 0.03 & 0.04 & 0.53 \\
\hline & Experience $(\leq 10 \mathrm{yr} />10 \mathrm{yr})$ & 20.66 & 12710 & 0.99 \\
\hline & Working hours/wk $(\leq 30 />30)$ & -1.15 & 0.73 & 0.12 \\
\hline & Sports physical therapist (no/yes) & 0.08 & 0.74 & 0.92 \\
\hline & Work setting (solo/group) & 1.16 & 1.14 & 0.31 \\
\hline & Specific education (no/yes) & -1.53 & 0.75 & 0.04 \\
\hline \multicolumn{5}{|c|}{${ }^{1}$ regression coefficient; ${ }^{2}$ standard error of the mean; ${ }^{3}$ intake $\leq 7$ days after injury } \\
\hline \multirow{2}{*}{\multicolumn{2}{|c|}{ Physiotherapist characteristic }} & (1) & Ar & DA \\
\hline & & $95 \% \mathrm{Cl}$ & $\mathrm{p}$-value & \\
\hline \multicolumn{2}{|l|}{ Age } & 0.94 to 1.08 & 0.88 & \\
\hline \multicolumn{2}{|c|}{ Experience (<10yrs/>10yrs) } & 0.01 to 0.61 & 0.01 & \\
\hline
\end{tabular}




\section{Prognostic factors for applying the Ottawa ankle rules}

Outcomes of regression analysis for prognostic factors are presented in tables 5 and 6. Univariate logistic regression for positive outcomes of the OAR resulted in a $p$-value below the threshold of 0.10 for two factors: age and years of work experience. Multivariable analysis showed that physical therapists with more than 10 years of work experience scored less positive outcomes of the OAR (OR: 0.09 (95\% Cl: 0.01 to 0.61$)$ ).

For referring the patient to the general practitioner as outcome, one prognostic factor (specific education) resulted in a p-value below the threshold of 0.10 . Univariate logistic regression showed that physiotherapists with specific education referred less patients with positive OAR to the general practitioner (OR: 0.22 (95\% Cl: 0.05 to 0.95$)$ ).

\section{DISCUSSION}

\section{Application of the Ottawa ankle rules in primary care}

This study indicates that the false-positive rate of the OAR in a primary care setting by physiotherapists is very high. None of the 17 patients with a positive outcome of the OAR in the first week after injury were identified with a fracture. Five patients were referred to a general practitioner, and were referred back to the physiotherapist after diagnostic screening. For 12 patients the physiotherapists decided that consultation of the general practitioner was not necessary. The telephone survey showed that the physiotherapists did not consult the general practitioner, based on their interpretation of the positive outcomes of the OAR. Generalized swelling causing pain at palpation was mentioned as main reason for scoring a positive outcome, but in combination with clinical judgment no signs of fracture were identified. The results of this pilot study suggest that the OAR cannot be generalized for use by physiotherapists in a primary care setting.

It has been identified that the accuracy of a diagnostic test depends on the particular setting and population in which the test is validated, and sensitivity and specificity are likely to change in another setting ${ }^{25,26}$. In primary care the accuracy of diagnostic tests may be reduced as a result of a lower prevalence ${ }^{27}$. The case mix of patients in a primary care setting may require more subtle clinical decision making in the application of the OAR. At an emergency department setting it can be expected that patients present themselves with severe ankle injuries for diagnostic purposes to identify fractures, consequently with a relative high risk of fractures. In a physiotherapy setting in primary care it can be expected that patients seek help for rehabilitation and not primarily to identify fractures, consequently with a low 
risk of fractures. Also, a prolonged time after injury when visiting a physiotherapist in primary care, may provide additional information about the course of recovery, with room for clinical judgment whether or not to suspect a fracture. These factors together may lead to a different case mix of patients in a primary care setting, and consequently may explain a low specificity of the OAR.

\section{Interpretation of the Ottawa ankle rules}

The results of this study imply that the OAR may be difficult to interpret in a primary care physiotherapy setting, and contribute to a high false-positive rate of the rules. In $53 \%$ of all patients the OAR were positive, while for none of the patients fractures were identified. Pain on palpation of the lateral malleolus was found most positive. This has also been recognized by Bachmann et al $^{2}$ who explained the low specificity of the rules, and the large variation therein, by the subtlety of palpation techniques. An important factor that may increase difficulty for interpretation of the OAR is that intake took place on average 8.7 days after injury, while the rules optimally should be applied directly after injury. Acute ankle injury usually concerns distortion or rupture of the lateral ligaments which, together with generalized swelling, may explain increased pain on palpation over time.

Logistic regression showed that work experience of physiotherapists of more than 10 years was associated with a less frequent positive outcome of the OAR. Work experience may increase clinical skills for interpretation of the OAR in a primary care setting. The analysis also showed that physiotherapists with specific education regarding ankle injuries referred fewer patients to the general practitioner when the OAR were positive. Our hypothesis is that physiotherapists with more knowledge and skills are more competent to interpret the Ottawa ankle rules, and may be more confident that no fracture is present. Besides specific skills and knowledge based on experience and education, it is known that a large (international) variety exists with regard to knowledge, use and attitudes toward the $\mathrm{OAR}^{5}$.

\section{Limitation of this study}

Main limitation of this study is that no standard X-ray diagnosis was carried out as golden standard to verify whether or not a fracture was present. No fractures were identified during or after treatment, based on original data collection information and additional information collected by telephone survey for every patient $(n=17)$ with a positive OAR in the first week after injury. The original data were checked for results of treatment for these patients. For all patients treatment results showed that treatment goals were mostly or completely achieved. Based on the consistent results we concluded that no fractures were apparent in any of the patients. 
Second limitation of this pilot study is the small dataset of both patients and physiotherapists. A larger dataset would increase possibilities for more robust analyses. However, this pilot is the first study on the use of the OAR in primary care, and therefore very relevant for clinical practice.

In $93 \%$ of all patients the physiotherapists applied the OAR. This was in line with the recommendation in the guideline for patients who visited the physiotherapist in the first week after injury without prior X-ray. However, the OAR were applied unnecessary for patients who did receive X-ray diagnosis prior to the visit to the physiotherapist. The electronic data registration may have influenced clinical decision making, because physiotherapists were invited to follow the on-screen options for electronic registration.

\section{CONCLUSION}

This pilot study shows that the false-positive rate of the OAR used by physiotherapists in a primary care setting is very high, and suggests that the OAR cannot be generalized for use in a primary care setting. The specific setting and patient mix in primary care may require more subtle clinical decision making in applying the OAR. This is supported by findings in this study that increased work experience and specific education improved interpretation of the OAR. Further research with larger datasets should focus on the use of X-ray diagnosis as golden standard, study case mix differences between patients in emergency department and primary care setting. 


\section{REFERENCES}

1. Anis AH, Stiell IG, Stewart DG, Laupacis A. Cost-effectiveness analysis of the Ottawa Ankle Rules. Ann Emerg Med. 1995;26:422-428.

2. Bachmann LM, Kolb E, Koller MT, Steurer J, Ter Riet G. Accuracy of Ottawa ankle rules to exlude fractures of the ankle and mid-foot: systematic review. BMJ. 2003;326:417-423.

3. Diehr $\mathrm{P}$, Highley $\mathrm{R}$, Dehkordi $\mathrm{F}$ et al. Prediction of fracture in patients with acute musculoskeletal ankle trauma. Med Decis Making. 1988;8:40-47.

4. Stiell IG, McDowell I, Nair RC et al. Use of radiography in acute ankle injuries: physicians' attitudes and practice. CMAJ. 1992;147:1671-1678.

5. Graham ID, Stiell IG, Laupacis A et al. Awareness and use of the Ottawa ankle and knee rules in 5 countries: can publication alone be enough to change practice? Ann Emerg Med. 2001;37:259-266.

6. Stiell I, Wells G, Laupacis A et al. Multicentre trial to introduce the Ottawa ankle rules for use of radiography in acute ankle injuries. Multicentre Ankle Rule Study Group. BMJ. 1995;311:594-597.

7. Leddy JJ, Smolinski RJ, Lawrence J, Snyder JL, Priore RL. Prospective evaluation of the Ottawa Ankle Rules in a university sports medicine center. With a modification to increase specificity for identifying malleolar fractures. Am J Sports Med. 1998;26:158-165.

8. Leddy JJ, Kesari A, Smolinski RJ. Implementation of the Ottawa ankle rule in a university sports medicine center. Med Sci Sports Exerc. 2002;34:57-62.

9. Papacostas E, Malliaropoulos N, Papadopoulos A, Liouliakis C. Validation of Ottawa ankle rules protocol in Greek athletes: study in the emergency departments of a district general hospital and a sports injuries clinic. Br J Sports Med. 2001;35:445-447.

10. Pijnenburg AC, Glas AS, De Roos MA et al. Radiography in acute ankle injuries: the Ottawa Ankle Rules versus local diagnostic decision rules. Ann Emerg Med. 2002;39:599-604.

11. Kelly $A M$, Richards $D$, Kerr $L$ et al. Failed validation of a clinical decision rule for the use of radiography in acute ankle injury. N Z Med J. 1994;107:294-295.

12. Perry S, Raby N, Grant PT. Prospective survey to verify the Ottawa ankle rules. J Accid Emerg Med. 1999;16:258-260.

13. Tay SY, Thoo FL, Sitoh YY, Seow E, Wong HP. The Ottawa Ankle Rules in Asia: validating a clinical decision rule for requesting X-rays in twisting ankle and foot injuries. J Emerg Med. 1999;17:945947.

14. Glas AS, Pijnenburg BA, Lijmer JG et al. Comparison of diagnostic decision rules and structured data collection in assessment of acute ankle injury. CMAJ. 2002;166:727-733.

15. Leemrijse CJ, Swinkels IC, Veenhof C. Direct access to physical therapy in the Netherlands: results from the first year in community-based physical therapy. Phys Ther. 2008;88:936-946.

16. van der Wees PhJ, Lenssen A.F., Feijts YAEJ et al. KNGF-richtlijn Enkelletsel. Ned Tijdschr Fysioth. 2006;116.

17. Centre for Evidence Based Physiotherapy. www.cebp.nl. 2008.

18. de Bie RA, de Vet HC, van den Wildenberg FA, Lenssen T, Knipschild PG. The prognosis of ankle sprains. Int J Sports Med. 1997;18:285-289.

19. Olerud C, Molander H. A scoring scale for symptom evaluation after ankle fracture. Arch Orthop Trauma Surg. 1984;103:190-194.

20. Rose A, Lee RJ, Williams RM, Thomson LC, Forsyth A. Functional instability in non-contact ankle ligament injuries. Br J Sports Med. 2000;34:352-358.

21. Beurskens AJ, de Vet HC, Koke AJ. Responsiveness of functional status in low back pain: a comparison of different instruments. Pain. 1996;65:71-76.

22. Beurskens AJ, de Vet HC, Koke AJ et al. A patient-specific approach for measuring functional status in low back pain. J Manipulative Physiol Ther. 1999;22:144-148. 
23. Bombardier $\mathrm{C}$. Outcome assessments in the evaluation of treatment of spinal disorders: summary and general recommendations. Spine. 2000;25:3100-3103.

24. Ostelo RW, de Vet HC. Clinically important outcomes in low back pain. Best Pract Res Clin Rheumatol. 2005;19:593-607.

25. Bossuyt PM, Leeflang MM. Developing Criteria for including studies. Cochrane handbook for systematic reviews of diagnostic test accuracy Version 0.4. Cochrane Collaboration; 2008.

26. Sackett DL, Haynes RB. The architecture of diagnostic research. BMJ. 2002;324:539-541.

27. Bouter LM, van Dongen MCIM. Diagnostiek. Epidemiologisch onderzoek. Opzet en interpretatie. Houten/Diegem: Bohn Stafleu Van Lochum; 2000. 



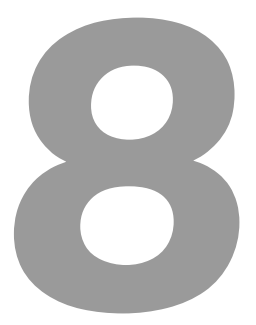

General Discussion 


\section{INTRODUCTION}

This thesis describes the cyclic process of developing, implementing, evaluating, and updating clinical guidelines (Figure 1), a process described by other authors as 'practice guidelines development cycle $^{\prime 1,2}$ or 'guideline cascade' ${ }^{3}$. The studies we performed were chosen to reflect the elements of this cycle, with ankle sprain as a specific case example. Section 8.1 discusses the main results of the research underlying this thesis, distinguishing two main parts of the cycle: (a) developing and updating (Chapters 2, 3, and 4 of this thesis); and (b) implementing and evaluating (Chapters 5, 6, and 7 of this thesis). Methodological reflections and recommendations for further research are offered in section 8.2. Section 8.3 describes a model for the implementation of guidelines, as an exploration of possible further steps in guideline implementation. This discussion ends by exploring further strategies for guideline development and implementation. In section 8.4, implications for further strategy are discussed and recommendations are formulated for the Royal Dutch Society for Physical Therapy (KNGF), while section 8.5 explores the international perspective, focusing on the World Confederation for Physical Therapy (WCPT).

Figure 1: Cycle of developing, implementing, evaluating, and updating guidelines

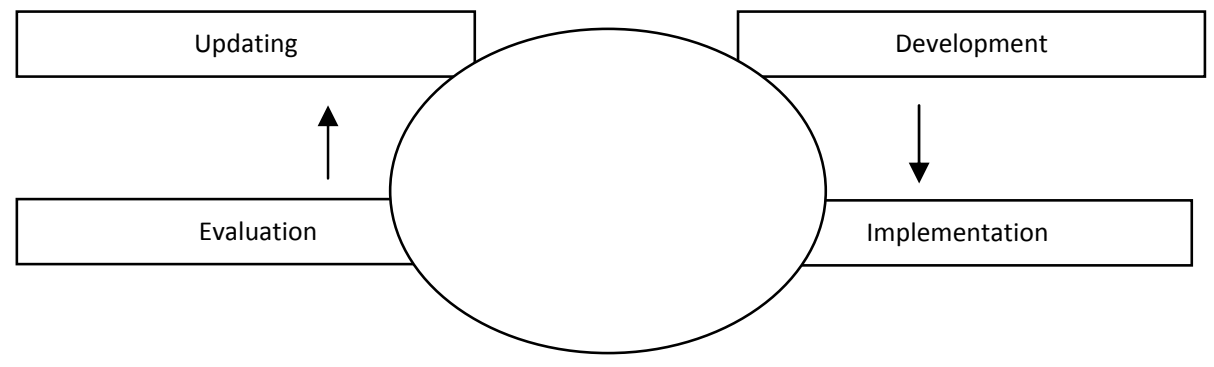

\section{Developing and updating clinical guidelines}

The KNGF procedure for clinical guideline development in physical therapy was published in $1998^{4}$, based on a draft standardized procedure which was tested during the development of the first two physical therapy guidelines (Ankle Sprain and Urinary Incontinence). Clinical guidelines were developed as part of KNGF's Quality Assurance Program, to increase the quality and evidence base of physical therapists' routine practice ${ }^{5-7}$.

New developments in the field of guideline research have resulted in the need to update the procedure for clinical guideline development. An important reason for updating the development process was the publication of the AGREE instrument, which provides a framework, including 23 criteria, to assess the quality of clinical 
guidelines ${ }^{8}$. The instrument is based on an international consensus on methods to develop evidence-based clinical guidelines ${ }^{9,10}$. Another reason was that the earlier KNGF procedure did not provide a specific protocol for updating guidelines. Shekelle et al $^{11}$ described a model for updating guidelines based on various situations which may lead to decisions about updating, such as changes in evidence, changes in outcome, changes in interventions, and available resources.

These developments resulted in a project to study the current programs for guideline development in detail and to update the KNGF procedure for guideline development. The updated procedure was used to update the ankle sprain guideline. Results from the studies presented in this thesis on adherence to the clinical guideline, and the review of the effectiveness of exercise therapy and manual mobilization, were used to update the guideline.

\section{Implementing and evaluating clinical guidelines}

Since the ankle sprain guideline was the first guideline developed by the Royal Dutch Society for Physical Therapy (KNGF), we were interested to know whether the guideline was applicable in routine practice and in the extent to which therapists adhere to it. Prior to our study, we had little knowledge about the applicability of the guideline. The Netherlands Institute for Health Services Research (NIVEL) evaluated the implementation of the ankle sprain guideline after its initial publication $^{12}$. Results from the NIVEL survey among 229 physical therapists showed that 161 physical therapists actually treated patients with ankle sprain. Of this group of 161 therapists, 152 responded that they were to some extent or fully aware of the specific recommendations in the guideline, while 123 therapists undertook activities to acquire a more thorough understanding of the guideline, the most important being that of discussing the guideline with colleagues in their Audit \& Feedback Group.

The results of the NIVEL study were based on opinions of physical therapists about the use of the ankle sprain guideline, and did not necessarily reflect actual daily practice. Nor did they provide detailed information about the applicability of and adherence to the guideline. The research underlying this thesis studied the applicability of the ankle sprain guideline using data collected electronically or on paper from patient records. Adherence to recommendations in the guideline was studied, as was the value of two specific instruments from the guideline: the Ankle Function Score (AFS) and the Ottawa Ankle Rules (OAR). 


\subsection{MAIN RESULTS}

\section{Developing and updating clinical guidelines}

One of the optional steps in the KNGF procedure for guideline development is to perform a prospective cohort study to investigate the applicability of guidelines based on data collected from patient records. The outcomes of such a cohort study can then be used to update the guidelines ${ }^{13}$. In our assessment of the first published guideline on ankle sprain, we collected patient data using a paper recording form. Information from the cohort study was used to update the ankle sprain guideline. The results of this study (Chapter 2 ) showed that the guideline is applicable in daily practice, and the results were promising as regards further implementation $^{14}$. Adherence to individual recommendations ranged from $71 \%$ to $100 \%$. Several patient characteristics (recurrent sprain, co-morbidity, female sex) were found to be associated with the necessity for physical therapists to exceed the expected number of treatment sessions. It is not clear why female patients needed more sessions.

The procedure to update the ankle sprain guideline started with a systematic review of the literature to collect evidence for the effectiveness of exercise therapy and manual mobilization in acute ankle sprain and functional instability (Chapter 3 ). The review showed that exercise therapy was effective in reducing the risk of recurrent injuries after acute ankle sprain, and with functional instability. This was an important result for the formulation of recommendations in the updated ankle sprain guideline. Manual mobilization has an initial effect on dorsiflexion range of motion. The studies on manual mobilization may have limited value for physical therapy treatment, since the mobilization techniques studied in them are not commonly used by physical therapists or manual therapists. We therefore concluded that these limitations in terms of clinical practice should be considered in the ankle sprain guideline. The updated guideline on ankle sprain was published separately from this thesis ${ }^{15}$, and is also available to the public in an English version.

In our effort to review and update the KNGF procedure for guideline development, we compared various guideline programs (Chapter 4). A comparison of six guideline programs in various countries showed that most of them adhered to the AGREE criteria for development procedures ${ }^{16}$. The AGREE instrument closely reflects the international consensus about methods for developing evidence-based clinical guidelines, and the various programs met this standard. The Dutch procedure, however, met only 13 of the 23 criteria. Compliance was mainly lacking as regards specific and systematic formulation of recommendations, based on evidence and 
other considerations. Nor did the Dutch program provide a specific procedure for updating guidelines.

Based on the outcome of our study, a project was started to improve the KNGF procedure, which resulted in an updated procedure, published separately from this thesis ${ }^{13}$. Analyses showed that after publication of the initial KNGF procedure, many AGREE criteria were included in the development process, although they were not formally included in the procedure. The updated guideline development procedure complies with 22 of the AGREE criteria.

\section{Implementing and evaluating clinical guidelines}

We examined the implementation of clinical guidelines in physical therapy by performing a systematic review of the literature (Chapter 5 ) to study the effectiveness of strategies to enhance this implementation. Five papers, reporting on three cluster-randomized trials, evaluated whether implementation strategies increased the implementation of low back pain guidelines ( 2 trials) or whiplash guidelines ( 1 trial). The main outcome of the review was that multifaceted strategies, based on educational meetings, increased the adherence to a number of recommendations in low back pain guidelines and whiplash guidelines. There was no evidence that the implementation strategies had improved patient health or that these strategies had changed the cost of care. Our findings were comparable with results among other health professions.

Following the first study on adherence to the ankle sprain guideline, we performed a second cohort study based on the updated guideline. Data in this second cohort study were electronically collected using FastGUIDE ${ }^{\circledR}$, an online web-based electronic recording system for patient assessment and treatment data, developed by the Centre for Evidence Based Physiotherapy (CEBP) at Maastricht University ${ }^{17}$. The data were used to study two specific measurement instruments included in the ankle sprain guideline: the Ankle Function Score and the Ottawa Ankle Rules.

The Ankle Function Score (AFS) is recommended in the ankle sprain guideline as a measurement instrument. The AFS was developed by De Bie et al, and their study showed that the AFS, as a prognostic instrument, is well able to distinguish between mild and severe sprains ${ }^{18}$. After this initial publication, however, no further studies were published to validate the AFS in terms of its properties as a prognostic tool. In the present research project, we further validated the AFS by studying its construct validity, prognostic validity, and responsiveness (Chapter 6). The results show a moderate prognostic validity of the AFS: sensitivity and specificity for the prognosis of recovery two weeks after injury were $88 \%$ and $57 \%$, respectively. The instrument showed mixed results as regards construct validity and responsiveness. Our conclusion was that the AFS can be used in addition to subjective clinical judg- 
ment, as a prognostic tool for recovery after acute ankle sprain and to evaluate progress in patient functioning.

The Ottawa Ankle Rules (OAR) are an excellent instrument to exclude fractures after acute ankle sprain in an emergency department setting ${ }^{19}$, and the ankle sprain guideline recommends the use of this instrument as a clinical decision rule for physical therapists. It was unknown, however, whether the OAR could be usefully applied in a primary care setting. Our pilot study assessed whether the OAR can be used in primary care by physical therapists, and if physical therapists' characteristics influence the interpretation of the test results (Chapter 7). The pilot study showed that the use of the OAR by physical therapists in primary care results in very high numbers of false-positives, and suggests that the OAR cannot be generalized for use in a primary care setting. The specific setting and patient mix in primary care may require more subtle clinical decision making when using the OAR.

\subsection{METHODOLOGICAL REFLECTIONS FOR FURTHER RESEARCH}

\section{Systematic reviews}

Two chapters in this thesis concern systematic reviews of the literature. Chapter 3 examines the effectiveness of exercise therapy and manual mobilization in acute ankle sprain and functional instability, while chapter 5 discusses the effectiveness of strategies to increase the implementation of clinical guidelines for physical therapy. Systematic reviews use explicit and rigorous methods to identify, critically appraise, and synthesize relevant studies ${ }^{20,21}$. In healthcare, systematic reviews typically investigate the effects of interventions for prevention, treatment, and rehabilitation. The process of systematic reviews has been described in detail by the Cochrane Collaboration, with the aim of providing a reliable synthesis of the available evidence on a given topic ${ }^{22}$. In addition there is the QUOROM statement checklist for quantitative analysis, developed to improve the quality of reports on meta-analyses ${ }^{23}$. For our review on implementation strategies we used information available from the Cochrane Effective Practice and Organization of Care Group $(E P O C)^{24}$, which produces systematic reviews of educational, behavioral, financial, regulatory, and organizational interventions designed to improve health professional practice and the organization of healthcare services.

Despite the rigorous and well-documented procedures, several methodological problems are encountered in systematic reviews ${ }^{25}$. Like many other reviews, ours showed considerable variety in the quality of the studies assessed. We used a $10-$ point scale based on the Amsterdam-Maastricht consensus list ${ }^{26}$ for our review on the effectiveness of exercise therapy and manual mobilization, and found a low 
average score of 3.1 points (range 1-7) in 17 studies. Our best-evidence synthesis must thus be viewed in the perspective of the poor methodological quality of the individual studies. However, the nature of the interventions in physical therapy does not allow a design that meets all methodological criteria (e.g. blinding of therapist and patient). We used a low cut-off point (4 points) above which we considered a study to be of 'high quality'. Although decisions made when providing a best-evidence synthesis, such as the use of cut-off points, are to some extent subjective, ranking the evidence base affords some insight into the strength of the conclusions.

The main limitation of our review on the effectiveness of the implementation of clinical guidelines was the limited number of trials included in it. Only three trials were identified which evaluated strategies to increase the implementation of clinical guidelines in physical therapy. This small number of studies allowed only a very cautious formulation of our conclusions. Evidently, more studies are needed to further explore the effectiveness of implementation strategies in physical therapy. Our study makes it clear that there is a need to establish a body of knowledge on guideline implementation in physical therapy.

\section{Cohort studies}

Data for three studies in this thesis were derived from prospective cohort studies. Our cohort study on adherence to the first KNGF ankle sprain guideline (chapter 2) used a paper recording form to collect patient data. Data for the second cohort study, based on the updated ankle sprain guideline, were electronically collected using FastGUIDE ${ }^{\circledR}$. The data were used to study specific measurement instruments referred to in the ankle sprain guideline: the Ankle Function Score (Chapter 6) and the Ottawa Ankle Rules (Chapter 7).

The main limitation of these cohort studies was that the datasets were small, with only a limited number of physical therapists and patients participating in the studies. The first results from the cohort studies should therefore be regarded as pilots, with the objective of expanding the data collection to continuous electronic registration as a part of routine practice. However, electronic data collection is not part of everyday practice yet, and we will continue to promote the use of electronic patient files, which is also one of KNGF's targets.

Our aim is to create large datasets for various clinical guidelines. The advantage of observational studies is that they reflect routine practice, and form an excellent basis to study determinants of adherence to clinical guidelines. These datasets will therefore be very valuable for implementation strategies and will provide opportunities to combine implementation with research. A regional network of physical therapists for peripheral arterial disease (intermittent claudication) has already 
been established for this purpose ${ }^{27}$. At the same time, longitudinal data collection will provide opportunities for clinical trials using prospective cohorts, and to identify subgroups, offering opportunities to stratify for co-morbidity. Recently, a study was started at Maastricht University to investigate the potential of guideline-driven physical therapy treatment as a supportive measure to prevent acute exacerbations in COPD patients. A cohort-nested, prospective, randomized controlled trial with a 2-year follow-up was started to assess the efficacy and cost-effectiveness of physical therapy treatment in patients who have recently suffered a COPD exacerbation $^{28}$. Data from this study will also be used to examine the implementation of COPD healthcare based on adherence to the clinical guideline and standard of care for COPD patients.

\subsection{A MODEL FOR IMPLEMENTING GUIDELINES}

Grol and Wensing ${ }^{29}$ noted that attempts to change professional behavior require certain barriers to be overcome. Many different types of barriers may prevent implementation of clinical guidelines, including insufficient knowledge of the guidelines, lack of motivation to adhere to them or a lack of respect for them, lack of time or means, resistance by third parties, and organizational impediments. Each type of barrier requires a specific intervention. Within the Cochrane Collaboration, the Effective Practice and Organization of Care (EPOC) group has classified interventions to enhance adherence to guidelines into four categories: professionoriented, financial, organizational and regulatory ${ }^{24}$. A classification of interventions intended for health professionals is presented in table 1.

Wensing and $\mathrm{Grol}^{30}$ and Duff et al ${ }^{31}$ distinguished between interventions intended to increase expertise or knowledge (e.g., providing information, education, educational materials) and interventions intended to improve existing practice (e.g., providing feedback, peer review, reminders). Although interventions can be aimed at individual professionals, it is also important to relate barriers to the innovation itself, to the patient, and to the social, organizational, economic, and political contexts ${ }^{29}$. Grol, Wensing, and Eccles ${ }^{29,32,33}$ described a 10-step model describing the sequential steps used to affect behavioral change and relating them to barriers and incentives for implementation. Their key message is that barriers at various levels must be identified and systematically addressed with a diversity of activities that have proved effective. The steps in this model are summarized in Table 2. 
Table 1. Summary of interventions intended for health professionals

Educational materials - Distribution of published or printed recommendations for clinical care (such as clinical practice guidelines, audio-visual materials, electronic publications)

(Interactive) educational meetings - Healthcare providers who have participated in conferences, lectures, workshops, or traineeships; interactive meetings include participation of health care providers by discussion or practice

Local consensus process - Inclusion of healthcare providers in discussions to ensure that they agree that the clinical problem chosen is important and the approach is appropriate

Educational outreach visits - A personal visit by a trained person to healthcare providers in their own practice settings to give information with the intent of changing practice

Local opinion leaders - Use of healthcare providers nominated by their colleagues as being educationally influential

Patient-mediated interventions - New clinical information collected directly from patients and given to healthcare providers (e.g. scores from a measurement instrument)

Audit and feedback - Any summary of clinical performance of health care over a specified period of time; the summary may also include recommendations for clinical action; the information may be obtained from medical records, computerized databases, or patient observations

Reminders - Patient- or encounter-specific information, provided verbally, on paper or on a computer screen, which is designed or intended to prompt a health professional to recall information Marketing - Use of personal interviewing, group discussions (focus groups) or a survey of targeted providers to identify barriers to change, and the subsequent design of an intervention to address the identified barriers

Mass media - Use of a variety of communication instruments to reach large numbers of people, including television, radio, newspapers, posters, leaflets, and booklets

Source: Classification of professional interventions from EPOC taxonomy ${ }^{24}$.

When implementing clinical guidelines, it is important to bear the above steps in mind and to apply them when developing or adjusting interventions. The largest effects occur when interventions help to overcome a variety of barriers. Generally, this implies the use of a combination of interventions, as recommended by a number of studies ${ }^{30,31,33-38}$, although a systematic review by Grimshaw et al showed no clear evidence in favor of multifaceted interventions ${ }^{39}$.

Grol, Wensing, and Eccles ${ }^{32,33}$ developed a six-step model to design and operate strategies for interventions within an implementation plan:

1. Development of a proposal for implementation.

2. Analysis of current care and setting goals for improvement.

3. Analysis of problems in target group and setting.

4. Development and selection of intervention strategies.

5. Development, testing, and execution of implementation plan.

6. Continuous evaluation and adjustment of implementation plan. 
Table 2. Sequential steps to change professional behavior

\begin{tabular}{|c|c|}
\hline Steps & Barriers/incentives for implementation \\
\hline \multicolumn{2}{|l|}{ Orientation } \\
\hline 1. Promote awareness of innovation & - level of interest in reading and continuous education \\
\hline \multirow[t]{2}{*}{ 2. Stimulate interest and involvement } & - degree of contact with colleagues \\
\hline & - perceived need for innovation \\
\hline \multicolumn{2}{|l|}{ Insight } \\
\hline \multirow[t]{2}{*}{ 3. Create understanding } & - available knowledge and skills \\
\hline & - ability to remember information \\
\hline \multirow[t]{2}{*}{ 4. Develop insight into own routines } & - attitude (open-minded or defensive) \\
\hline & - willingness to acknowledge gaps in performance \\
\hline \multicolumn{2}{|l|}{ Acceptance } \\
\hline \multirow[t]{5}{*}{ 5. Develop positive attitude to change } & - ability to perceive advantages of change \\
\hline & - opinion on scientific merit of change \\
\hline & - opinion on credibility of innovation source \\
\hline & - degree of involvement in development process \\
\hline & - degree of confidence in own skills \\
\hline 6. Create positive intentions to change & - perception of problems when putting change into practice \\
\hline \multicolumn{2}{|l|}{ Change } \\
\hline \multirow[t]{2}{*}{ 7. Try out change in practice } & - perception of practical barriers \\
\hline & - opportunity to try change on a small scale \\
\hline \multirow[t]{3}{*}{ 8. Confirm value of change } & - whether first experiences are positive or negative \\
\hline & - degree of cooperation experienced \\
\hline & - side effects \\
\hline \multicolumn{2}{|l|}{ Maintaining change } \\
\hline 9. Integrate new practice into routines & - willingness and ability to redesign processes \\
\hline \multirow[t]{3}{*}{ 10.Embed new practice in organization } & - whether procedures are in place for frequent reminding \\
\hline & - availability of supportive resources \\
\hline & - degree of support from management \\
\hline
\end{tabular}

Source: Grol, Wensing and Eccles

This 6-step model for effective implementation can be used to design and apply implementation strategies, using the 10 -step model to select specific interventions to induce change in professional behavior. Section 8.4 offers recommendations for guideline implementation strategies in physical therapy, based on the 6-step model.

\section{Implementation starts with development of guidelines}

The acceptance and use of clinical guidelines are closely connected with the way in which they are developed and introduced. For example, evidence-based recommendations and precisely defined recommendations are more likely to be adhered to in practice ${ }^{40,41}$. Effective implementation can be promoted by testing the feasibility and acceptance of the guidelines among the target group ${ }^{40,41}$. Based on a review

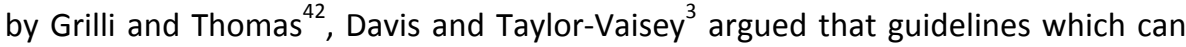
be tried out by the professionals are more likely to be adhered to. Some authors 
have also recommended involving future guideline users as much as possible in the development process ${ }^{43,44}$ and have reported that professionals are able to exert a great deal of influence on guideline implementation.

\section{Quality indicators}

When developing guidelines we recommend identification of quality indicators to assess the process and outcome of actual care, in order to examine the gap between actual care and intended care. Information derived from indicators can be used to develop implementation strategies, and such indicators show physical therapists whether they are adhering to clinical guidelines ${ }^{14,45,46}$. Quality indicators are elements of healthcare for which there is evidence or consensus that they are indicative of the quality of healthcare. They are usually categorized into structure, process, and outcome indicators ${ }^{47,48}$. Structure and process indicators are based on recommendations for practice and interventions, while outcome indicators represent the results of care. Insights into the level of adherence to clinical guidelines obtained by using indicators are important to identify barriers and provide information for further implementation of guidelines ${ }^{49}$.

\subsection{IMPLICATIONS FOR FURTHER STRATEGY}

Physical therapy will, and in fact will have to, follow the current trend towards evidence-based practice. The clinical guidelines currently under development are testimony to this. However, only a proportion of all published guidelines, consensus documents and standards in healthcare are based on scientific evidence. Although substantial research has been performed on the effects of guideline implementation, these studies have usually concerned guidelines on interventions for specific diagnoses. Also, most clinical guidelines are not specifically related to a particular discipline and have been developed in a multidisciplinary context $^{31,34-37,43,50,51}$. However, it seems plausible that what applies to other medical professionals will also apply to physical therapists.

The 6-step model for effective implementation described in section 8.3 can be used to design and carry out implementation strategies. We recommend that KNGF use this model to create a structured approach for the implementation of clinical guidelines. Below, we briefly explore each of the six steps to formulate recommendations for further strategy. 


\section{Development of a proposal for implementation}

A proposal for implementation implies the development of a 'product' that requires implementation, and the products for implementation in this thesis are clinical guidelines. As a result of international research, procedures for clinical guideline development have improved dramatically in recent years and these developments are expected to continue. Scientific, professional, and societal developments require constant adjustments of the guideline development procedure. For example, the AGREE instrument is currently under revision for an update. Since databases of guidelines are growing, e.g. the Guidelines International Network (G-I$\mathrm{N})^{52}$ or the National Guideline Clearinghouse (NGC) ${ }^{53}$, existing guidelines can be used to enhance efficiency by avoiding duplication of work. This can be achieved by using the framework offered by the ADAPTE Collaboration to adjust clinical practice guidelines as an alternative to de novo guideline development ${ }^{54}$.

The guideline development procedure should be flexible to easily facilitate the integration of new insights and should focus on acceptance by the users of guidelines. Our recommendation is that KNGF should continue its attempts to simplify the procedure. An example of further experiments with the guideline development procedure is the development of so-called 'living guidelines', which are updated in a short (annual) cycle. In this system, evidence statements can be developed for topics that do not require a full clinical guideline. And clinical guidelines should also be presented in a more practical way. Presentation of guidelines in short documents and electronic patient files offers numerous opportunities. Interactive presentation via the internet allows guidelines to be published as web-based applications with supported tools, e.g. e-learning, links to literature, downloadable instruments, and audiovisual tools.

\section{Analyzing current care and setting goals for improvement}

Analysis of current care requires systematic recording of care. Quality indicators can be used to assess the structure, process, and outcome of actual care, in order to examine the gap between actual care and intended care. Quality indicators should be included in physical therapy guidelines, and should be related to recommendations in the guidelines. If quality indicators are integrated in clinical guidelines, they can be linked directly to assessments of the process and outcome of current care. Methods to develop quality indicators are still under development, and require specific research methods ${ }^{48,55}$. KNGF should follow these developments to produce valid, reliable, and useful indicators.

We also recommend further development of procedures for electronically collecting patient data based on clinical guidelines. Collecting data as a part of normal daily practice in electronic patient files will allow continuous evaluation of current 
care, and will provide valuable information that can be used to implement and update guidelines. Collection of data at a national level can be used for benchmarking the structure, process, and outcome of physical therapy treatment, based on quality indicators. The benchmarking results of individual physical therapists or groups of physical therapists can subsequently be used for audit \& feedback tools within KNGF's Quality Assurance Program. These tools can be used by the Audit \& Feedback Groups, or in formal audits between physical therapy practices or clinics. However, the cohorts in our studies showed that the datasets are small, with only a limited number of participating physical therapists and patients. We therefore recommend further analysis of the apparent reluctance of physical therapists to participate, and designing interventions to ensure that electronic data collection becomes part of the routine practice of physical therapists.

\section{Analysis of problems relating to target group and setting}

Section 8.3 argued that various types of barriers may prevent the implementation of clinical guidelines. These barriers can be individual, social, organizational, economic, or political, and they can best be identified if professionals working in the field are involved in developing and updating clinical guidelines. Ideally, this can be achieved by involving physical therapists in evaluations of the draft guidelines, in terms of their content, scientific validity, usefulness, and acceptability, and by obtaining information from them about any discrepancies between current clinical practice and recommendations in the guidelines ${ }^{40,41,56}$. In the KNGF procedure, physical therapists participate in guideline development groups, and draft guidelines are reviewed by a sample of 30-60 therapists. This participation of therapists offers excellent opportunities for specific emphasis on the identification of barriers during the development process.

The Dutch research institute TNO Quality of life has studied conditions for guideline implementation in physical therapy ${ }^{57}$, under the supervision of the KNGF's Scientific Council for Physical Therapy. They identified barriers at an organizational level that are not addressed by KNGF policy. Strategies should therefore be focused on interventions targeted at organizations, e.g. managing directors of physiotherapy practices or networks of physical therapists. TNO Quality of life also identified another important barrier at an economic level: physical therapists do not feel supported by KNGF in negotiating with health insurance companies. These barriers should be addressed in designing implementation strategies, both in terms of general policy and in the implementation of specific guidelines. 


\section{Development and selection of intervention strategies}

In addition to the efforts needed to disseminate guidelines, a multitude of methods will have to be developed to implement them, preferably aimed at overcoming perceived barriers to implementation. These methods will depend on the topic of a guideline and take into account the steps that have to be taken and the barriers that have to be overcome. Grol, Wensing, and Eccles ${ }^{29,32,33}$ describe three main areas for the development and selection of intervention strategies: (a) outcomes of a diagnostic analysis of the target group; (b) existing knowledge about effective implementation strategies; and (c) phases in the implementation process and stages in the process of changing professional behavior. These stages-of-change are integrated in the 10-step model for the development and selection of implementation strategies.

Diagnostic analysis can be of great value for guideline implementation in physical therapy. One method for diagnostic analysis and intervention development is intervention mapping. In this method, a systematic problem analysis precedes the construction of a matrix (intervention map), which combines the objectives of an intervention program and the behavioral and environmental determinants of practical care ${ }^{58}$. The objectives that are derived from this matrix underpin the choice of methods and strategies to enhance guideline implementation. In physical therapy, intervention mapping is currently being studied for the low back pain guideline at IQ Healthcare, Nijmegen Medical Centre, based on assessment of motivational and organizational determinants ${ }^{59}$. We recommend diagnostic analysis as a prominent step in the development and selection of intervention strategies for physical therapy guidelines, for which intervention mapping may be a valuable method.

\section{Developing, testing, and conducting the implementation plan}

The actual implementation of clinical guidelines should be based on a plan for each guideline in which objectives are described, activities are planned and conditions are arranged. KNGF has a structured plan for the dissemination of clinical guidelines, but systematic plans for implementation have not yet been developed. The study by TNO Quality of life shows a great need to develop a clear strategy for the implementation of clinical guidelines, and to provide capacity and budget. The implementation of clinical guidelines will only succeed if KNGF develops a clear focus in its activities towards implementation.

In view of the limited resources, we recommend that KNGF prioritize implementation projects for a limited number of specified guidelines in its (annual) strategic plan. External funding may create opportunities for additional projects. 


\section{Continuous evaluation and adjustment of implementation plan}

Studies evaluating the implementation of clinical guidelines for physical therapy have been scarce ${ }^{60}$. Evidently, more studies are needed to further explore the effectiveness of implementation strategies in physical therapy, and many research designs are available to evaluate this effectiveness. Randomized Controlled Trials (RCTs) are the gold standard for the evaluation of interventions, as they minimize confounding ${ }^{61}$. Implementation studies often use cluster randomization at the level of professionals or organizations, to reduce the risk of contamination ${ }^{33}$. However, RCTs are complex and expensive, and therefore not always feasible. Section 8.2 argued that observational cohort studies can be used to study current practice, and form an excellent basis to study the determinants of adherence to clinical guidelines, with the option of including controlled trials. In a study that recently started at Maastricht University, we aim to investigate the efficacy of guideline-driven physical therapy treatment for COPD patients in a cohort-nested, prospective, randomized controlled trial ${ }^{28}$. IQ Healthcare (Nijmegen Medical Centre) is studying determinants of adherence to the low back pain guidelines using validated clinical vignettes, and intervention mapping is being studied for diagnostic analysis ${ }^{59,62}$.

Creating a body of knowledge about implementation strategies for clinical guidelines in physical therapy requires further collaboration between universities. Additional knowledge can be acquired in a joint approach, in which researchers and guideline developers collaborate with KNGF as a professional body, to implement the guidelines. Systematic collaboration between universities and KNGF can create a clear link between implementation strategies and research to evaluate implementation strategies.

\subsection{INTERNATIONAL PERSPECTIVE: RECOMMENDATIONS FOR WCPT}

The World Confederation for Physical Therapy (WCPT) has a strong policy in place to enhance evidence-based practice. WCPT has over 100 member organizations that represent the profession of physical therapy in their respective countries. Although its resources are limited, WCPT can play an important role in promoting the development and implementation of clinical guidelines. Recent activities resulted in several publications by WCPT ${ }^{63,64}$ and its European Region ${ }^{65}$, intended to assist Member Organizations in developing and implementing clinical guidelines. However, since guideline development is time-consuming and expensive, it cannot be expected that all Member Organizations of WCPT will be able to develop guidelines themselves. It would also not be very efficient if every single member of WCPT reinvented the wheel. 
To further promote the development of clinical guidelines in the international field of physical therapy, we recommend that WCPT strengthen its policy in a number of respects. These recommendations can be effectuated by WCPT or by regions within WCPT, like its European Region, a very active region in the field of guideline development:

- WCPT should promote adaptation of existing guidelines for national or local use, in order to enhance efficiency by avoiding duplication of work. This can be done by promoting and assisting in the use of the framework developed by the ADAPTE Collaboration for the adaptation of clinical practice guidelines as an alternative to de novo guideline development.

- WCPT should continue participation in the Guidelines International Network (G-I-N) and to promote the role of physical therapy within multidisciplinary healthcare and clinical guidelines that reflect multidisciplinary healthcare practice.

- WCPT should increase participation of physical therapists in multidisciplinary guideline development by providing information and assistance to Member Organizations, with the aim of stimulating participation in national guideline development programs.

- WCPT should publish articles and statements about guideline implementation and to use the world physical therapy congress as a platform for presentations and discussions.

- WCPT should stimulate Member Organizations to develop and operate tailored strategies for the implementation of clinical guidelines. 


\section{REFERENCES}

1. Browman GP, Levine MN, Mohide EA et al. The practice guidelines development cycle: a conceptual tool for practice guidelines development and implementation. J Clin Oncol. 1995;13:502-512.

2. Hayward RS, Laupacis A. Initiating, conducting and maintaining guidelines development programs. CMAJ. 1993;148:507-512.

3. Davis DA, Taylor-Vaisey A. Translating guidelines into practice. A systematic review of theoretic concepts, practical experience and research evidence in the adoption of clinical practice guidelines. CMAJ. 1997;157:408-416.

4. Hendriks HJM, Ettekoven van H, Reitsma ER, Verhoeven ALJ, Wees PhJ van der. Methode voor centrale richtlijnontwikkeling en implementatie in de fysiotherapie. Amersfoort: Koninklijk Nederlands Genootschap voor Fysiotherapie (KNGF); 1998.

5. Hendriks HJM, Bekkering GE, van Ettekoven H, Brandsma JW, Van der Wees PJ, de Bie RA. Development and implementation of national practice guidelines: a prospect for continuous quality improvement in physiotherapy. Physiotherapy. 2000;86:535-547.

6. Hendriks HJM. Implementeren van richtlijnen: een brug tussen kennis en praktijk? In: Hullegie W, Lettinga A, Verhagen A, eds. Fysiotherapie en wetenschap: over de gespannen verhouding tussen theorie, onderzoek en praktijk. Maarsen: Elsevier Gezondheidszorg; 2003.

7. Van der Wees PJ, Hendriks HJM, Veldhuizen HJ. Quality assurance in the Netherlands: from development to implementation and evaluation. Dutch J Physiother. 2003;113:3-6.

8. AGREE Collaboration. Appraisal of Guidelines for Research \& Evaluation (AGREE) Instrument. London: St George's Hospital Medical School; 2001.

9. Burgers JS, Grol R, Klazinga NS, Makela M, Zaat JOM. Towards evidence-based clinical practice: an international survey of 18 clinical guideline programs. Int J Qual Health Care. 2003;15:31-45.

10. Shekelle PG, Woolf SH, Eccles M, Grimshaw J. Developing guidelines. BMJ. 1999;593-596.

11. Shekelle P, Eccles MP, Grimshaw JM, Woolf SH. When should clinical guidelines be updated? BMJ. 2001;323:155-157.

12. Plas M, Hofhuis H, Dorgelo M, Dekker J, van den Ende E. Kwaliteitsbevordering Paramedische Zorg. Evaluatie richtlijnen, standaarden en protocollen. Utrecht: Nivel, 2001.

13. Van der Wees PJ, Hendriks HJM, Custers J, Burgers JS, Dekker J, de Bie RA. A structured program for clinical guideline development in physiotherapy (Methode voor ontwikkeling, implementatie, en bijstelling van KNGF-richtlijnen). Amersfoort/Maastricht: KNGF; 2007.

14. van der Wees PJ, Hendriks EJ, Jansen MJ, van Beers H, de Bie RA, Dekker J. Adherence to physiotherapy clinical guideline acute ankle injury and determinants of adherence: a cohort study. $B M C$ Musculoskelet Disord. 2007;8:45.

15. van der Wees PhJ, Lenssen A.F., Feijts YAEJ et al. KNGF-richtlijn Enkelletsel. Ned Tijdschr Fysioth. 2006;116.

16. Van der Wees PJ, Hendriks EJ, Custers JW, Burgers JS, Dekker J, de Bie RA. Comparison of international guideline programs to evaluate and update the Dutch program for clinical guideline development in physical therapy. BMC Health Serv Res. 2007;7:191.

17. Centre for Evidence Based Physiotherapy (CEBP). Maastricht University. www.cebp.nl. 2008.

18. de Bie RA, de Vet HC, van den Wildenberg FA, Lenssen T, Knipschild PG. The prognosis of ankle sprains. Int J Sports Med. 1997;18:285-289.

19. Bachmann LM, Kolb E, Koller MT, Steurer J, Ter Riet G. Accuracy of Ottawa ankle rules to exlude fractures of the ankle and mid-foot: systematic review. BMJ. 2003;326:417-423.

20. Antman EM, Lau J, Kupelnick B, Mosteller F, Chalmers TC. A comparison of results of meta-analyses of randomized control trials and recommendations of clinical experts. Treatments for myocardial infarction. JAMA. 1992;268:240-248.

21. Oxman AD, Guyatt GH. The science of reviewing research. Ann N Y Acad Sci. 1993;703:125-133. 
22. Higgins JPT, Grees Se. Cochrane Handbook for Systematic Reviews of Interventions Version 5.01 (updated September 2008). The Cochrane Collaboration; 2008.

23. Moher D, Cook DJ, Eastwood S, Olkin I, Rennie D, Stroup DF. Improving the quality of reports of meta-analyses of randomised controlled trials: the QUOROM statement. Quality of Reporting of Meta-analyses. Lancet. 1999;354:1896-1900.

24. EPOC. The Data Collection Checklist. Cochrane Effective Practice and Organisation of Care Group. www.epoc.cochrane.org/en/handsearchers html. 2008.

25. Bouter LM, van Dongen MCIM. Diagnostiek. Epidemiologisch onderzoek. Opzet en interpretatie. Houten/Diegem: Bohn Stafleu Van Lochum; 2000.

26. Smidt N, Assendelft WJJ, van der Windt DAWM, Hay EM, Buchbinder R, Bouter LM. Corticosteroid injections for lateral epicondilytis: a systematic review. Pain. 2002;96:23-40.

27. Willigendael EM, Bendermacher $\mathrm{BL}$, van der $\mathrm{BC}$ et al. The development and implementation of a regional network of physiotherapists for exercise therapy in patients with peripheral arterial disease, a preliminary report. BMC Health Serv Res. 2005;5:49.

28. de Bie, R. A. and van Schayk, C. P. Reducing exacerbations in patients with chronic obstructive pulmonary disease with physiotherapy: a randomised controlled trial. Protocol to be embedded in a joint project with other chairs in physiotherapy and allied health. Maastricht: Caphri Research Institute, Maastricht University; 2008.

29. Grol R, Wensing M. What drives change? Barriers to and incentives for achieving evidence-based practice. Med J Aust. 2004;180:S57-S60.

30. Wensing $M$, Grol R. Single and combined strategies for implementing changes in primary care: a literature review. Int J Qual Health Care. 1994;6:115-132.

31. Duff LA, Kitson AL, Seers K, Humphris D. Clinical guidelines: an introduction to their development and implementation. J Adv Nurs. 1996;23:887-895.

32. Grol R, Wensing M, Eccles M. Improving patient care; the implementation of change in clinical practice. London: Elsevier; 2005.

33. Grol R, Wensing M. Implementatie: effectieve verbetering van de patientenzorg. Maarssen: Elsevier Gezondheidszorg; 2006.

34. Davis DA, Thomson MA, Oxman AD, Haynes RB. Evidence for the effectiveness of CME. A review of 50 randomized controlled trials. JAMA. 1992;268:1111-1117.

35. Davis DA, Thomson MA, Oxman AD, Haynes RB. Changing physician performance. A systematic review of the effect of continuing medical education strategies. JAMA. 1995;274:700-705.

36. Grimshaw JM, Russell IT. Effect of clinical guidelines on medical practice: a systematic review of rigorous evaluations. Lancet. 1993;342:1317-1322.

37. Grimshaw JM, Russell IT. Achieving health gain through clinical guidelines II: Ensuring guidelines change medical practice. Qual Health Care. 1994;3:45-52.

38. Grimshaw JM, Shirran L, Thomas R et al. Changing provider behavior: an overview of systematic reviews of interventions. Med Care. 2001;39:II2-45.

39. Grimshaw JM, Thomas RE, MacLennan G et al. Effectiveness and efficiency of guideline dissemination and implementation strategies. Health Technol Assess. 2004;8:iii-72.

40. Grol R, Grimshaw J. From best evidence to best practice: effective implementation of change in patients' care. Lancet. 2003;362:1225-1230.

41. Grol R, Dalhuijsen J, Thomas S, Veld C, Rutten G, Mokkink H. Attributes of clinical guidelines that influence use of guidelines in general practice: observational study. BMJ. 1998;317:858-861.

42. Grilli R, Lomas J. Evaluating the message: the relationship between compliance rate and the subject of a practice guideline. Med Care. 1994;32:202-213.

43. Grimshaw J, Freemantle N, Wallace $S$ et al. Developing and implementing clinical practice guidelines. Qual Health Care. 1995;4:55-64. 
44. Grol R. Successes and failures in the implementation of evidence-based guidelines for clinical practice. Med Care. 2001;39:II46-II54.

45. Bekkering GE, Hendriks HJ, van Tulder MW et al. Prognostic factors for low back pain in patients referred for physiotherapy: comparing outcomes and varying modeling techniques. Spine. 2005;30:1881-1886.

46. Jansen MJ, Hendriks HJM, de Bie RA, Dekker J, Oostendorp RAB. Handelen volgens de KNGFrichtlijn 'Artrose heup-knie': een prospectieve cohortstudie. Ned Tijdschr Fysiother. 2005;115:6873.

47. Barnsley J, Berta W, Cockerill R, MacPhail J, Vayda E. Identifying performance indicators for family practice: assessing levels of consensus. Can Fam Physician. 2005;51:700-701.

48. Campbell SM, Braspenning J, Hutchinson A, Marshall M. Research methods used in developing and applying quality indicators in primary care. Qual Saf Health Care. 2002;11:358-364.

49. Hermens RP, Ouwens MM, Vonk-Okhuijsen SY et al. Development of quality indicators for diagnosis and treatment of patients with non-small cell lung cancer: A first step toward implementing a multidisciplinary, evidence-based guideline. Lung Cancer. 2006;54:117-124.

50. Eddy DM. Clinical decision making: from theory to practice. Guidelines for policy statements: the explicit approach. JAMA. 1990;263:2239-40, 2243.

51. Grimshaw J, Eccles M, Russell I. Developing clinically valid practice guidelines. J Eval Clin Pract. 1995;1:37-48.

52. Guidelines International Network (G-I-N). www.g-i-n.net. 2008.

53. National Guideline Clearinghouse (NGC). www.guideline.gov. 2008.

54. Fervers B, Burgers JS, Haugh MC et al. Adaptation of clinical guidelines: literature review and proposition for a framework and procedure. Int J Qual Health Care. 2006;18:167-176.

55. Arah OA, Westert GP, Hurst J, Klazinga NS. A conceptual framework for the OECD Health Care Quality Indicators Project. Int J Qual Health Care. 2006;18 Suppl 1:5-13.

56. Bekkering GE, Engers AJ, Wensing $M$ et al. Development of an implementation strategy for physiotherapy guidelines on low back pain. Aust J Physiother. 2003;49:208-214.

57. Fleuren, $\mathrm{M}$ and Jans, M. Basisvoorwaarden voor implementatie en borging van de KNGFRichtlijnen. Leiden: TNO Kwaliteit van Leven; 2008

58. Bartholomew LK, Parcel GS, Kok G, Gottlieb NH. Planning health promotion programs: an intervention mapping approach. San Fransisco: Jossey-Bass; 2006.

59. Rutten G, Kremers S, Rutten S, Harting J. A Dutch theory-based cross-sectional survey demonstrated the important role of awareness in guideline implementation. J Clin Epidemiol. 2008;62:167-176.

60. van der Wees PJ, Jamtvedt G, Rebbeck T, de Bie RA, Dekker J, Hendriks EJ. Multifaceted strategies may increase implementation of physiotherapy clinical guidelines: a systematic review. Aust J Physiother. 2008;54:233-241.

61. Bouter LM, van Dongen MCIM. Interventie. Epidemiologisch onderzoek. Opzet en interpretatie. Houten/Diegem: Bohn Stafleu Van Loghum; 2000:329-60.

62. Rutten GM, Harting J, Rutten ST, Bekkering GE, Kremers SP. Measuring physiotherapists' guideline adherence by means of clinical vignettes: a validation study. J Eval Clin Pract. 2006;12:491-500.

63. Mead J, Van der Wees PJ. Clinical guidelines: An introduction. WCPT Keynotes. EBP ed. London: World Confederation for Physical Therapy (WCPT); 2006.

64. Van der Wees PJ, Mead J. Clinical guidelines 2: Developing the guidelines. WCPT Keynotes. EBP ed. London: World Confederation for Physical Therapy (WCPT); 2006.

65. Van der Wees PJ, Mead J. Framework for clinical guideline development. Brussels: European Region of World Confederation for Physical Therapy; 2004. 

Summary 
Development and implementation of evidence-based clinical guidelines is a major focus of healthcare policy in many countries. Clinical guidelines are 'systematically developed statements designed to help practitioners and patients to make decisions about appropriate healthcare for specific circumstances'. Development of clinical guidelines in health services is generally considered an important instrument to improve and manage the care process.

Important goals in guideline development are higher quality and improved costeffectiveness, ideally resulting in improved health outcomes. Moreover, the process of guideline development addresses the need to decrease variability in clinical practice, and practitioners' desire to legitimize their profession in the eyes of external stakeholders. The concept of evidence-based practice, supported by clinical guidelines, is a common aspect of healthcare today.

New developments in the field of guideline research have resulted in the need to evaluate and update the procedure of the Royal Dutch Society for Physical Therapy (KNGF) for guideline development in physical therapy. One of the recent developments was the foundation of the AGREE collaboration (Appraisal of Guidelines, Research and Evaluation), which has published an instrument to appraise the quality of clinical practice guidelines. The AGREE Instrument provides a framework, including 23 criteria, to assess the quality of clinical practice guidelines. The instrument is based on international consensus about methods to develop evidencebased clinical guidelines, and also helps guideline developers to structure and improve the process of guideline development.

Another reason to undertake the present research project was that the international field of physical therapy lacked a body of knowledge about guideline development and implementation: it was unclear whether clinical guidelines can be used in physical therapy and what implementation strategies would be effective. Knowledge about applicability is essential for the process of updating the guidelines, and implementation strategies should be based on current knowledge. The World Confederation for Physical Therapy (WCPT) recognized the necessity of creating a body of knowledge and prioritized the development and implementation of clinical guidelines in its policy, in order to facilitate evidence-based practice.

These objectives and questions are reflected in this thesis, and fit the cyclic process of developing, implementing, evaluating, and updating clinical guidelines. Ankle sprain was the first guideline in KNGF's guideline program, and is the case example used in this thesis to describe the development cycle.

\section{Developing and updating clinical guidelines}

One of the optional steps in the KNGF procedure for guideline development is to perform a prospective cohort study to investigate the applicability of guidelines 
based on data collected from patient records. Outcomes of the cohort study can then be used to update the guidelines. In our assessment of the first published guideline, on ankle sprain, we used a preliminary paper version to collect data. Information from the cohort study was used to update this clinical guideline. The results of this study (Chapter 2) showed that the guideline is applicable in daily practice, and the results were promising for further implementation (9). Adherence to individual recommendations ranged from $71 \%$ to $100 \%$. Several patient characteristics (recurrent sprain, co-morbidity, female sex) were associated with the necessity for physical therapists to exceed the expected number of treatment sessions. It was not clear why female patients needed more sessions.

The procedure to update the clinical guideline on ankle sprain started with a systematic review of the literature to collect evidence for the effectiveness of exercise therapy and manual mobilization in acute ankle sprain and functional instability (Chapter 3). The review showed that exercise therapy was effective in reducing the risk of recurrent injuries after acute ankle sprain, and with functional instability. This was an important result for the formulation of recommendations in the updated ankle sprain guideline. Manual mobilization has an initial effect on dorsiflexion range of motion. The studies on manual mobilization may have limited value for physical therapy treatment, since the mobilization techniques studied in them are not commonly used by physical therapists or manual therapists. Our conclusions were reflected in the recommendations in the updated KNGF ankle sprain guideline, which was published separately from this thesis.

In our effort to review and update the KNGF procedure for guideline development we compared various guideline programs (Chapter 4). Comparison of six guideline programs from various countries showed that most of them adhered to the AGREE criteria for development procedures. The AGREE instrument closely reflects the international consensus about methods for developing evidence-based clinical guidelines, and the various programs met this standard. The KNGF program however, met only 13 of the 23 criteria. Compliance was mainly lacking as regards specific and systematic formulation of recommendations, based on evidence and other considerations. Nor did the KNGF program provide a procedure for updating guidelines. Based on the outcome of our study, a project was started to improve the KNGF procedure, which resulted in an updated procedure, published separately from this thesis. The updated guideline development procedure complied with 22 of the AGREE criteria.

\section{Implementing and evaluating clinical guidelines}

We examined the implementation of clinical guidelines in physical therapy by performing a systematic review of the literature (Chapter 5 ) to study the effectiveness 
of strategies to increase this implementation. Five papers, reporting on three cluster-randomized trials, evaluated whether multifaceted strategies based on educational meetings increased the implementation of low back pain guidelines ( 2 trials) or whiplash guidelines ( 1 trial). Educational meetings were effective in increasing adherence to the following recommendations in low back pain guidelines: limiting the number of sessions, using active intervention, giving adequate information, increasing activity level, and changing attitudes/beliefs about pain. Such meetings were also effective in increasing adherence to the following recommendations of whiplash guidelines: reassuring the patient, advising the patient to continue their usual activities, and using functional outcome measures. There was no evidence that patient health was improved or that cost of care changed. Our conclusion was that multifaceted strategies, based on educational meetings, did indeed increase adherence to a number of recommendations in low back pain and whiplash guidelines. Our findings were comparable with results among other healthcare professions.

Following the first study on adherence to the ankle sprain guideline, we performed a second cohort study based on the updated guideline. The data were used to study specific measurement instruments recommended in the ankle sprain guideline. One of these measurement instruments is the Ankle Function Score (AFS). The AFS was developed by De Bie et al, and their study showed that the AFS, as a prognostic instrument, is well able to distinguish between mild and severe sprains. After this initial publication, however, no further studies were published to validate the AFS in terms of its properties as a prognostic tool. We further validated the AFS by studying its construct validity, prognostic validity, and responsiveness (Chapter 6). The results showed a moderate prognostic validity of the instrument: sensitivity and specificity for the prognosis of recovery two weeks after injury were $88 \%$ and $57 \%$ respectively. The instrument showed mixed results as regards construct validity and responsiveness. Our conclusion was that the AFS can be used in addition to subjective clinical judgment, as a prognostic tool for recovery after acute ankle sprain and to evaluate progress in patient functioning.

The Ottawa Ankle Rules (OAR) are an excellent instrument to exclude fractures after acute ankle sprain in an emergency department setting, and the ankle sprain guideline recommends the use of this instrument as a clinical decision rule for physical therapists. It was unknown, however, whether the OAR could be usefully applied in a primary care setting. Our study assessed whether the OAR can be used in primary care by physical therapists, and if physical therapists' characteristics influence the interpretation of the test results (Chapter 7). The OAR were positive in 17 patients who had consulted a physical therapist without being referred, while no fractures were identified for these patients during or after the course of treat- 
ment. The study showed that the use of the OAR by physical therapists in primary care results in very high numbers of false-positives, and suggests that the OAR cannot be generalized for use in a primary care setting. The specific setting and patient mix in primary care may require more subtle clinical decision making when using the OAR.

The general discussion (Chapter 8) presents the main results and methodological reflections. It describes and discusses implementation strategies, and uses a 6-step model of implementation by Grol, Wensing, and Eccles as a basis for recommendations to KNGF for the further development and implementation of clinical guidelines:

- KNGF should continue its attempts to simplify the guideline development procedure and to present practical and interactive guidelines.

- $\quad$ KNGF should integrate valid and reliable quality indicators in physical therapy guidelines, to assess the structure, process, and outcome of care.

- KNGF should identify barriers that hamper implementation, in order to develop implementation strategies aimed at individual physical therapists, and at parties involved at the social, organizational, economic and political levels.

- KNGF should include diagnostic analysis as a prominent step in the development and selection of strategies for guideline implementation in physical therapy.

- KNGF should base the actual implementation on a plan for each guideline, in which objectives are described, activities are planned, and conditions are arranged.

- KNGF should establish collaboration with researchers, in order to link implementation strategies to research for the evaluation of these strategies.

To further promote the development of clinical guidelines in the international field of physical therapy, we recommend that WCPT strengthen its policy in a number of respects: by promoting the adaptation of existing guidelines using the ADAPTE framework; by continuing participation in the Guidelines International Network (G$\mathrm{I}-\mathrm{N}$ ); and by increasing the participation of physical therapists in multidisciplinary guideline development. 



\section{Samenvatting}


De ontwikkeling en implementatie van evidence-based richtlijnen zijn in veel landen speerpunt van beleid in de gezondheidszorg. Richtlijnen zijn 'systematisch ontwikkelde aanbevelingen die zorgverleners en patiënten ondersteunen bij het nemen van beslissingen voor het leveren van goede zorg in specifieke omstandigheden'. Richtlijnen worden in de gezondheidszorg gezien als belangrijke instrumenten om de kwaliteit van zorg inzichtelijk te maken en te verbeteren. De voornaamste doelen van richtlijnen zijn verhoging van de kwaliteit, vergroten van kosteneffectiviteit, en betere uitkomsten van de zorg. Daarnaast kunnen richtlijnen bijdragen aan het verminderen van de variatie in de behandeling tussen zorgverleners, en aan het legitimeren van het vakgebied aan externe partijen. Het concept van evidencebased practice, ondersteund door richtlijnen, is een vanzelfsprekend onderdeel van de huidige gezondheidszorg.

Aanleiding voor dit onderzoek was het ontstaan van nieuwe wetenschappelijke inzichten binnen het internationale veld van richtlijnontwikkeling, die resulteerden in de noodzaak om de methode voor richtlijnontwikkeling van het Koninklijk Nederlands Genootschap voor Fysiotherapie (KNGF) te herzien. Een van de recente ontwikkelingen betrof de oprichting van de AGREE collaboration (Appraisal of Guidelines, Research and Evaluation). Binnen de AGREE collaboration is het AGREE instrument ontwikkeld dat bestaat uit een raamwerk van 23 criteria om de kwaliteit van richtlijnen te beoordelen. Het instrument is gebaseerd op internationale consensus over de beste methodiek voor richtlijnontwikkeling, en biedt een belangrijk houvast voor ontwikkelaars van richtlijnen om het proces van richtlijnontwikkeling te structureren en te verbeteren.

Een tweede reden voor de uitvoering van dit onderzoeksproject was het ontbreken van een body of knowledge voor de ontwikkeling en implementatie van richtlijnen in het internationale veld van de fysiotherapie: het was onduidelijk of en hoe richtlijnen gebruikt kunnen worden in de fysiotherapie en wat effectieve strategieën voor implementatie zijn. Kennis over toepasbaarheid is essentieel voor de herziening van richtlijnen, en strategieën voor implementatie dienen gebaseerd te zijn op huidige wetenschappelijke inzichten. De World Confederation for Physical Therapy (WCPT) onderschreef de noodzaak voor het opbouwen van een body of knowledge en heeft prioriteit gegeven in het beleid aan de ontwikkeling en implementatie van richtlijnen, om zodoende evidence-based practice te bevorderen.

Bovenstaande doelstellingen en vragen vormen de basis voor dit proefschrift en passen bij het cyclische proces van ontwikkelen, implementeren, evalueren en herzien van richtlijnen. De richtlijn Enkelletsel was de eerste richtlijn in het programma van het KNGF en vormt de specifieke casus van dit proefschrift voor het beschrijven van het cyclische proces. 


\section{Ontwikkelen en bijstellen van richtlijnen}

Een van de (optionele) stappen in de KNGF-methode voor richtlijnontwikkeling is de uitvoering van een prospectieve cohort studie om de toepasbaarheid van richtlijnen te onderzoeken op basis van verzamelde data uit patiëntendossiers. Uitkomsten van de cohort studie kunnen dan gebruikt worden om richtlijnen te herzien. Om de toepasbaarheid van de eerste KNGF-richtlijn Enkelletsel te onderzoeken gebruikten we een papieren versie van het patiëntendossier om data te verzamelen. Informatie uit de cohort studie is gebruikt om de KNGF-richtlijn Enkelletsel te herzien. De resultaten van deze studie (Hoofdstuk 2) laten zien dat de richtlijn toepasbaar is in de dagelijkse praktijk en de resultaten vormen een goede basis voor verdere implementatie. In $71 \%$ tot $100 \%$ van de gevallen werden de verschillende aanbevelingen van de richtlijn opgevolgd. Meerdere kenmerken van de patiënt (recidiefletsel, comorbiditeit, vrouwelijk geslacht) waren geassocieerd met de noodzaak voor fysiotherapeuten om het verwachte aantal behandelzittingen te overschrijden. Het was onduidelijk waarom vrouwelijke patiënten meer zittingen nodig hadden.

De procedure voor herziening van de KNGF-richtlijn Enkelletsel begon met de uitvoering van een systematisch literatuuronderzoek om evidentie te verzamelen voor de effectiviteit van oefentherapie en manuele verrichtingen (mobilisatie) bij acuut enkelletsel en bij functionele instabiliteit (Hoofdstuk 3). Het literatuuronderzoek toonde aan dat oefentherapie effectief was voor het verminderen van het risico op recidieven na acuut enkelletsel en bij functionele instabiliteit. Dit was een belangrijk resultaat voor het formuleren van aanbevelingen in de herziene KNGF-richtlijn Enkelletsel. Manuele verrichtingen hebben een initieel effect op de verbetering van de dorsaalflexie van de enkel. De gevonden studies over manuele verrichtingen hebben mogelijk beperkte waarde voor de fysiotherapie omdat de onderzochte mobilisatietechnieken niet gebruikelijk zijn in de fysiotherapie. De conclusies van ons onderzoek zijn verwerkt in de aanbevelingen van de herziene KNGF-richtlijn Enkelletsel. De richtlijn is apart van dit proefschrift gepubliceerd (www.fysionet.nl). Om de KNGF-methode voor richtlijnontwikkeling uit 1996 te herzien hebben we een aantal richtlijnprogramma's met elkaar vergeleken (Hoofdstuk 4). Vergelijking van zes richtlijnprogramma's uit verschillende landen liet zien dat de programma's over het algemeen voldeden aan de AGREE criteria voor de ontwikkeling van richtlijnen. Het AGREE instrument is gebaseerd op internationale consensus en de meeste programma's voldeden aan deze internationale standaard. De KNGFmethode voldeed slechts aan 13 van de 23 criteria, hoewel veel nieuwe inzichten al wel in het ontwikkelproces waren geïncorporeerd. Het grootste hiaat betrof de specifieke en systematische formulering van aanbevelingen. Daarnaast voorzag de KNGF-methode niet in een expliciete procedure voor herziening van richtlijnen. Op 
basis van de uitkomsten van onze studie is een project uitgevoerd om de KNGFmethode voor richtlijnontwikkeling te herzien, en resulteerde in een nieuwe methode die apart van dit proefschrift is gepubliceerd (www.fysionet.nl). De herziene methode voldeed aan 22 AGREE criteria.

\section{Implementeren en evalueren van richtlijnen}

De effecten van strategieën voor de implementatie van richtlijnen in de fysiotherapie zijn onderzocht in een systematisch literatuuronderzoek (Hoofdstuk 5). Het literatuuronderzoek leverde vijf artikelen op, waarin de resultaten van drie clustergerandomiseerde studies over effectiviteit van implementatiestrategieën waren gepubliceerd. In deze studies werden gecombineerde interventies toegepast op basis van educatieve strategieën, om de implementatie van richtlijnen over lage rugpijn ( 2 studies) en whiplash ( 1 studie) te bevorderen. Educatieve strategieën waren effectief voor toename in het opvolgen (adherence) van de volgende aanbevelingen bij richtlijnen voor lage rugpijn: beperken van het aantal behandelsessies, uitvoeren van een actieve interventie, geven van adequate informatie, verhogen van het activiteitenniveau, en veranderen van attitude/vooronderstellingen over pijn. Educatieve strategieën waren ook effectief voor toename in het opvolgen van aanbevelingen bij richtlijnen over whiplash: geruststellen van de patiënt, adviseren van de patiënt om normale activiteiten te continueren, en het gebruiken van functionele uitkomstmaten. Er was geen bewijs voor het verbeteren van de gezondheidstoestand van de patiënt of voor het verminderen van de kosten van de zorg. Onze conclusie was dat gecombineerde interventies, gebaseerd op educatieve strategieën, een verhoging lieten zien van het opvolgen (adherence) van een aantal aanbevelingen bij richtlijnen voor lage rugpijn en whiplash. Onze bevindingen waren vergelijkbaar met resultaten van studies naar de effectiviteit van implementatie van richtlijnen bij andere beroepsgroepen in de gezondheidszorg.

In navolging van onze eerste studie naar het gebruik van de KNGF-richtlijn Enkelletsel, hebben we een tweede cohort studie uitgevoerd op basis van de herziene richtlijn. De met een elektronisch patiëntendossier verzamelde data uit de cohort studie zijn gebruikt om de toepassing van specifieke meetinstrumenten uit de richtlijn Enkelletsel te onderzoeken. Een van deze meetinstrumenten betreft de Ankle Function Score (AFS). De AFS is ontwikkeld door De Bie et al, en hun studie liet zien dat de AFS als prognostisch instrument goed in staat is om lichte enkelletsels van zware enkelletsels te onderscheiden. Na initiële publicatie waren er geen vervolgstudies gepubliceerd waarin de validiteit van de AFS is onderzocht. In onze studie hebben we de AFS verder gevalideerd door de constructvaliditeit, prognostische validiteit en responsiviteit te onderzoeken (Hoofdstuk 6). De resultaten laten een matige prognostische validiteit van de AFS zien: sensitiviteit en specificiteit voor de 
prognose van herstel binnen twee weken na acuut enkelletsel waren respectievelijk $88 \%$ and $57 \%$. De resultaten varieerden ten aanzien van de constructvaliditeit en responsiviteit van de AFS. Onze conclusie was dat de AFS in aanvulling op de klinische beoordeling gebruikt kan worden om de prognose voor herstel van acuut enkelletsel te bepalen, en om voortgang van het herstel in functioneren te evalueren.

De Ottawa Ankle Rules (OAR) zijn een uitstekend instrument om fracturen uit te sluiten na acuut enkelletsel op een eerste hulppost van het ziekenhuis, en in de KNGF-richtlijn Enkelletsel wordt het gebruik van de OAR aanbevolen als beslissingsondersteunend instrument. Het is echter niet bekend wat de toepasbaarheid van de OAR is in de eerstelijns gezondheidszorg. In onze studie onderzochten we of de OAR toepasbaar zijn door fysiotherapeuten in een eerstelijns praktijksetting, en of kenmerken van fysiotherapeuten van invloed zijn op de interpretatie van de testresultaten van de OAR (Hoofdstuk 7). De OAR waren positief bij 17 patiënten die een fysiotherapeut hadden geconsulteerd zonder verwijzing van een (huis)arts, terwijl bij geen van deze patiënten een fractuur werd geïdentificeerd tijdens of na de behandelepisode. Onze studie liet zien dat de toepassing van de OAR door fysiotherapeuten in een eerstelijns praktijk een zeer hoog aantal vals-positieve uitkomsten van de OAR liet zien, en de resultaten suggereren dat toepassing van de OAR niet generaliseerbaar is voor gebruik in de eerstelijns praktijk. De specifieke praktijksetting en patiëntenmix in de eerstelijns praktijk vragen mogelijk om meer genuanceerde besluitvorming bij toepassing van de OAR.

In de algemene discussie (Hoofdstuk 8 ) worden de belangrijkste resultaten van ons onderzoek gepresenteerd en worden methodologische kanttekeningen besproken. Strategieën voor de implementatie van richtlijnen worden beschreven, waarbij een 6-stappen model van Grol, Wensing en Eccles wordt gebruikt om aanbevelingen te doen aan het KNGF voor de verdere ontwikkeling en implementatie van richtlijnen:

- Het KNGF dient door te gaan met activiteiten om het proces van richtlijnontwikkeling verder te vereenvoudigen en richtlijnen op praktische en interactieve wijze te publiceren.

- Het KNGF dient de ontwikkeling van betrouwbare en valide indicatoren te integreren in het proces van richtlijnontwikkeling, zodat structuur, proces en uitkomst van de fysiotherapeutische zorg geëvalueerd kan worden.

- Het KNGF dient onderzoek te initiëren en te ondersteunen naar belemmerende factoren voor implementatie, zodat effectieve implementatiestrategieën ontwikkeld kunnen worden die gericht zijn op de individuele fysiotherapeut, en op de sociale, organisatorische, economische en politieke context. 
- Het KNGF dient een diagnostische analyse in te bouwen als prominente stap in de ontwikkeling en selectie van implementatiestrategieën voor richtlijnen in de fysiotherapie.

- Het KNGF dient de feitelijke implementatie te baseren op een plan voor elke richtlijn waarin doelstellingen zijn beschreven, activiteiten worden gepland en randvoorwaarden worden gecreëerd.

- Het KNGF dient samenwerking met wetenschappelijk onderzoekers te realiseren, zodat implementatiestrategieën van richtlijnen gekoppeld kunnen worden aan de evaluatie van deze strategieën.

Om de ontwikkeling van richtlijnen in het internationale veld van de fysiotherapie te bevorderen, dient de WCPT het beleid op een aantal punten verder te versterken: door gebruik en aanpassing van bestaande richtlijnen te bevorderen met behulp van het ADAPTE raamwerk, door deelname aan het Guidelines International Network (G-I-N) te continueren, en door de participatie van fysiotherapeuten aan de ontwikkeling van multidisciplinaire richtlijnen te bevorderen. 
Dankwoord 
Dit proefschrift is begonnen met de opmerking van Paul Helders dat het tijd werd dat ik 'eens wat ging doen met al die data die langskwamen in mijn werk bij het KNGF'. Toen ik mijn eerste voorstel op papier had gezet bevestigde ook mijn toenmalige directeur Ad Borstlap dat het goed was dat ik een keuze had gemaakt, en hij heeft het mogelijk gemaakt om het onderzoek in te passen binnen mijn werk. Mijn huidige directeur Micky Adriaansens heeft de steun vanuit het KNGF onvoorwaardelijk overgenomen en er tot op de dag van vandaag voor gezorgd dat ik me heb kunnen ontwikkelen als wetenschapper. Beste Paul, Ad en Micky, ik wil jullie graag bedanken voor jullie steun bij het initiëren, uitvoeren en afronden van dit proefschrift.

Uiteraard had dit proefschrift er niet gelegen zonder de begeleiding van mijn promotoren: Rob de Bie, Joost Dekker en Erik Hendriks. Rob, ik wil jou graag bedanken voor je innoverende visie op de (toekomstige) ontwikkeling en implementatie van richtlijnen en voor het bewaken van de samenhang van het onderzoek. Ik kijk uit naar onze verdere samenwerking in mijn nieuwe functie aan de universiteit! Joost, jij bent van grote waarde voor mij geweest voor het bewaken en sturen van de methodologie van het onderzoek en voor het helder en systematisch presenteren van de resultaten. En niet te vergeten het houden van focus. Ik wil je daar graag voor bedanken. Erik, ik wil jou graag bedanken voor je dagelijkse begeleiding als copromotor. Jouw creativiteit heeft me gestimuleerd in het benaderen van de vraagstellingen van verschillende kanten en het zoeken naar alternatieve oplossingen. Tegelijkertijd heb je als fysiotherapeut een scherp oog voor het slaan van de brug met de praktijk.

Voor de uitvoering van de cohort studies wil ik graag alle fysiotherapeuten bedanken die de data voor het onderzoek hebben verzameld met behulp van het (elektronisch) patiëntendossier. Zonder jullie inzet was dit onderzoek niet mogelijk geweest. Daarnaast wil ik alle patiënten bedanken die bereid waren om hun gegevens ter beschikking te stellen voor het onderzoek.

Tijdens mijn onderzoek heb ik de essentiële ondersteuning mogen ervaren van Hans van Beers die als student een jaar lang heeft gewerkt aan het opzetten en vullen van de database. Hans, ik wil je bedanken voor je inzet en ik ben blij je als coauteur te hebben in een van de gepubliceerde artikelen, en hopelijk volgen er meer. Daarnaast wil ik graag Vivian Bruls bedanken die de ondersteuning van Hans heeft overgenomen. Vivian, ik wens je veel succes toe met je eigen promotieonderzoek! 
De leden van de beoordelingscommissie, prof.dr. Geert Walenkamp, prof.dr. Harm Kuipers, prof.dr. Martin Prins, prof.dr. Ria Nijhuis-van der Sanden, dr. Trudy Van der Weijden wil ik bedanken voor het lezen en beoordelen van mijn proefschrift.

Hoewel ik maar beperkt op de universiteit aanwezig was, heb ik de collegialiteit op de vakgroep Epidemiologie als zeer plezierig ervaren. Ik wil vooral mijn kamergenoten Carolien Bastiaenen en Bart Staal bedanken voor hun collegiale steun. Jullie stonden altijd klaar voor het beantwoorden van mijn vragen. En ik kijk erg uit naar de verdere samenwerking! Als externe promovendus is het van groot belang dat je een vast ankerpunt hebt waar je terecht kunt. Dat ankerpunt was Conny de Zwart. Conny, ik wil je graag bedanken voor je onverminderde bereidheid om me wegwijs te maken binnen de universiteit.

Ook mijn collega's van het KNGF hebben een belangrijke rol gepeeld bij de totstandkoming van dit proefschrift. Mijn directe collega's van de afdeling Beleid \& Ontwikkeling hebben altijd gerespecteerd dat ik een dag per week op de universiteit aanwezig was. Ik wil jullie hierbij allemaal bedanken! Jan Custers en Martin Schrama hebben een belangrijke rol gespeeld bij de ontwikkeling en implementatie van KNGF-richtlijnen, en ik verwacht veel van onze verdere samenwerking.

Ik wil graag twee mensen speciaal noemen: Joan Lor en Simone Paulusma. Joan, ik ben je enorm dankbaar voor je jarenlange onschatbare steun. Simone, jij zorgt er elke dag weer voor dat er nog iets van orde in mijn dagelijkse chaos komt. Dank je wel. Van mijn collega's in het management team heb ik altijd steun ervaren en jullie hielden rekening met mijn onderzoeksactiviteiten. Bedankt! Daarbij wil ik graag specifiek Rian Veldhuizen noemen. Rian, dank je wel voor je 'mental support' die je me jarenlang hebt gegeven, eerst als collega in de afdeling en later als collega manager.

Ik wil graag het Algemeen Bestuur van het KNGF bedanken voor het mogelijk maken van mijn onderzoek.

The themes of my research were subject of debate in the working group Professional Issues of the European Region of WCPT. I really enjoyed the discussions and your collegiality during our meetings. Thank you for that! I would like to thank the Executive Committee of the European Region of WCPT for their interest in my research and prioritizing the development and implementation of clinical guidelines. I especially would like to thank the general secretary of ER-WCPT David Gorria as 'spider in the web'. I also want to thank my colleagues from the headquarters of WCPT in London for their support in getting clinical guidelines on the agenda. 
Tijdens de laatste fase van mijn onderzoek kwam de vraag naar boven wat de volgende stap in mijn carrière zou kunnen zijn. Richard Grol heeft daarbij voor mij een belangrijke rol gespeeld. Richard, ik wil je hierbij graag bedanken voor je coaching en inspiratie. Ik ben erg verheugd met het resultaat, waarbij ik ga werken aan de implementatie en evaluatie van richtlijnen in een samenwerkingsverband tussen KNGF, IQ healthcare en Maastricht University. Onder leiding van Micky Adriaansens, Ria Nijhuis en Rob de Bie, kijk ik uit naar een uitdagende nieuwe fase.

Tot slot de belangrijkste in mijn leven. Marjon, je bent mijn onvoorwaardelijke steun en toeverlaat en we zijn samen over pieken en door dalen gegaan. De start van dit onderzoek viel samen met een belangrijke fase in ons leven, en je hebt me alle ruimte gegeven om mijn onderzoek te kunnen doen en geaccepteerd dat het onderzoek vaak ten koste ging van onze gezamenlijke vrije tijd. Ik hou van je! Daarnaast heb je ook een belangrijke inhoudelijke bijdrage geleverd, onder meer als voorbeeld van de doelgroep van de veertigjarige vrouw die haar enkel verstuikt door met een glas wijn te veel op van de fiets te vallen. 
About the author 

Philip J van der Wees was born on August 25, 1966 in Benthuizen, the Netherlands. He completed his secondary school at the Oranje Nassau College in Zoetermeer, and studied Physical Therapy at the University of Applied Sciences in Den Haag. After his graduation in 1987 he worked as physical therapist in a primary care practice and started to study Human Movement Sciences at the Vrije Universiteit in Amsterdam. During his study he started to work at Leiden University of Applied Sciences as lecturer at the school for physical therapy. He graduated as human movement scientist in 1994, and moved to the United States to work as a lecturer at the school for physical therapy of Old Dominion University in Norfolk, Virginia.

After his return from the United States he started working for the Royal Dutch Society for Physical Therapy (KNGF) in 1996 as staff member. He became Head of Quality, Research \& Education in 2000 and Manager Strategy \& Development in 2006. Since 2004 he worked on his thesis at the Centre for Evidence Based Physiotherapy (CEBP) of Maastricht University.

In June 2009 he started in a new position as Program manager and Researcher in the project 'Quality \& Implementation' of KNGF, Maastricht University, and IQ healthcare, UMC St Radboud. Main objective of the project is to systematically stimulate and evaluate the implementation of clinical guidelines. 



\section{List of publications}


Van Rijn RM, Van Heest JAC, Van der Wees PJ, Koes BW, Bierma-Zeinstra SMA. Some benefit from physiotherapy intervention in the subgroup of patients with severe ankle sprain as determined by the ankle function score: a randomised trial. Australian Journal of Physiotherapy 2009; 55:107-113

Van der Wees PJ, Jamtvedt G, Rebbeck T, De Bie RA, Dekker J, Hendriks HJM. Multifaceted strategies may increase implementation of physiotherapy clinical guidelines: a systematic review. Australian Journal of Physiotherapy 2008; 54:233-241

Van der Wees PJ, Hendriks EJ, Custers JW, Burgers JS, Dekker J, de Bie RA. Comparison of international guideline programs to evaluate and update the Dutch program for clinical guideline development in physical therapy. BMC Health Serv Res 2007;7:191

Swinkels IC, van den Ende CH, de BD, Van der Wees PJ, Hart DL, Deutscher D, et al. Clinical databases in physical therapy. Physiother Theory Pract 2007 May;23(3):153-67.

Van der Wees PJ, Hendriks EJ, Jansen MJ, van Beers H, de Bie RA, Dekker J. Adherence to physiotherapy clinical guideline acute ankle injury and determinants of adherence: a cohort study. BMC Musculoskelet Disord 2007;8:45

Van der Wees PhJ, Lenssen AF, Hendriks HJM, Stomp DJ, Dekker J, De Bie RA. Effectiveness of exercise therapy and manual mobilisation in acute ankle sprain and functional instability: a systematic review. Australian Journal of Physiotherapy 2006; 52:27-37

Van der Wees PhJ, Lenssen AF, Feijts YAEJ, Bloo $H$, van Moorsel SR, Ouderland R, Opraus KWF; Rondhuis G; Simons A; Swinkels RAHM; Vaes P; Verhagen E; Hendriks HJM; De Bie RA. KNGF richtlijn Enkelletsel. Ned Tijdschr Fysioth 2006;116:5S

Van der Wees PhJ, Hendriks HJM, Jansen MJ, Laurant MGH, Dekker J, De Bie RA. Het gebruik van de richtlijn Acuut Enkelletsel in de praktijk. Ned Tijdschr Fysiother 2005; 115 (3):74-79

Stomp DJ, Hendriks HJM, Heemskerk MAMB, Van der Wees PhJ, De Bie RA. Effectiviteit van fysiotherapie bij patiënten met chronische functionele instabiliteit van de enkel: een systematisch literatuuroverzicht. Ned Tijdschr Fysiother 2005; 115(2):2631

Van Peppen RPS, Kwakkel G, Wood-Dauphinee S, Hendriks HJM, Van der Wees PhJ, Dekker J. The impact of Physical Therapy on functional outcomes after stroke: what's the evidence? Clinical Rehabilitation 2004;18:833-862 
Van der Wees PJ, Hendriks EJM, Veldhuizen RJ. Quality assurance in the Netherlands: from development to implementation and evaluation. Dutch Journal of Physical Therapy 2003;113(S):3-6

Hendriks, HJM, Bekkering GE, Van Ettekoven, H, Brandsma, JW, Van der Wees, PJ and De Bie, RA. Development and Implementation of National Practice Guidelines: a prospect for Continuous Quality Improvement in Physiotherapy. Physiotherapy 2000, 86(10): 535-547

Zuurbier CJ, Everard AJ, Van der Wees PJ, Huijing PA. Length-force characteristics of the aponeurosis in the passive and active muscle condition and in the isolated condition. Journal of Biomechanics 1994; 27(4): 445-453

Van der Wees Ph.J., Bobbert M.F., Harlaar J. Ontwikkeling van een standaardprotocol voor isokinetische metingen aan de knie. Geneeskunde en Sport 1993b; 26(6):203-212

Van der Wees Ph.J., Bobbert M.F., Harlaar J. Gebruik van isokinetische apparatuur in Nederland: een inventarisatie. Geneeskunde en Sport 1993a; 26(6):197-202

\section{CONTRIBUTIONS TO BOOKS}

Van der Wees PhJ, GMMJ Kerkhoffs, CN van Dijk, HCPM van Weert. Restklachten na enkelletsel (hoofdstuk 4). In: Het Medisch jaar 2008/2009. Editors: JN Keeman, JA Mazel, FG Zitman. Houten: Bohn Stafleu van Lochum; 2009

Van der Wees PhJ, P Offerhaus P, Leytens J. Evaluatie van richtlijnen in de fysiotherapie, verloskunde, en verpleging en verzorging. In: Evidence-based richtlijnontwikkeling (chapter 17). Een leidraad voor de praktijk. Editors: Van Everdingen,JJE; Burgers,JS; Assendelft,WJJ; Swinkels,JA; Van Barneveld,TA; Van de Kundert,JLM. Houten: Bohn Stafleu Van Lochum; 2004

\section{SUBMITTED}

Van der Wees PJ, Hendriks HJM, Bruls V, Dekker J, De Bie RA. Applicability of the Ottawa ankle rules in primary care: results from a pilot study.

Van der Wees PJ, Hendriks HJM, van Beers H, van Rijn RM, Dekker J, de Bie RA. Validity and responsiveness of the Ankle Function Score after acute ankle injury. 
